\title{
Binary and Ternary Vanadium Oxides: General Overview, Physical Properties, and Photochemical Processes for Environmental Applications
}

\author{
Olivier Monfort ${ }^{1, *(1)}$ and Patrícia Petrisková ${ }^{2}$ \\ 1 Department of Inorganic Chemistry, Faculty of Natural Sciences, Comenius University in Bratislava, \\ Ilkovicova 6, Mlynska Dolina, 84215 Bratislava, Slovakia \\ 2 Institute of Inorganic Chemistry, Slovak Academy of Sciences, Dubravska Cesta 9, 84536 Bratislava, Slovakia; \\ patricia.petriskova@savba.sk \\ * Correspondence: monfort1@uniba.sk; Tel.: +421-290142141
}

check for updates

Citation: Monfort, O.; Petrisková, P. Binary and Ternary Vanadium

Oxides: General Overview, Physical Properties, and Photochemical

Processes for Environmental

Applications. Processes 2021, 9, 214.

https://doi.org/10.3390/pr9020214

Academic Editor:

Monika Wawrzkiewicz

Received: 30 December 2020

Accepted: 21 January 2021

Published: 24 January 2021

Publisher's Note: MDPI stays neutral with regard to jurisdictional claims in published maps and institutional affiliations.

Copyright: (c) 2021 by the authors. Licensee MDPI, Basel, Switzerland. This article is an open access article distributed under the terms and conditions of the Creative Commons Attribution (CC BY) license (https:/ / creativecommons.org/licenses/by/ $4.0 /)$.

\begin{abstract}
This review article is a comprehensive report on vanadium oxides which are interesting materials for environmental applications. Therefore, a general overview of vanadium and its related oxides are presented in the first two parts. Afterwards, the physical properties of binary and ternary vanadium oxides in single and mixed valence states are described such as their structural, optical, and electronic properties. Finally, the use of these vanadium oxides in photochemical processes for environmental applications is detailed, especially for the production of hydrogen by water splitting and the degradation of organic pollutants in water using photocatalytic and photo-Fenton processes. The scientific aim of such a review is to bring a comprehensive tool to understand the photochemical processes triggered by vanadium oxide based materials where the photo-induced properties are thoroughly discussed based on the detailed description of their intrinsic properties.
\end{abstract}

Keywords: vanadium oxide; photochemistry; environment; materials; pollutant; hydrogen

\section{Introduction}

Vanadium (V) is a chemical element discovered by Andres Manuel Del Rio in 1801 in the form of an ore, called today vanadinite $\left(\mathrm{Pb}_{5}\left(\mathrm{VO}_{4}\right)_{3} \mathrm{Cl}\right)$ [1,2]. At that time, vanadium was named "panchromium" since its different salts exhibit a wide variety of colors. In 1831, Nils Gabriel Sefstrom (re)discovered this chemical element in the form of oxide [3]. He called this chemical element "vanadium" after Vanadis, a goddess in the Norse mythology. Vanadium is an early first-row transition metal (Group 5; $Z=23$ ), with the electronic configuration of [Ar] $3 \mathrm{~d}^{3} 4 \mathrm{~s}^{2}$ [4]. In the earth's crust, vanadium is 5 th $(0.019 \%)$ among all transitional metals and 22nd among all discovered elements $[5,6]$, that corresponds to an average amount of $159 \mathrm{~g}$ per ton [7]. In the soil, the average abundance of vanadium is $>100 \mathrm{mg} \cdot \mathrm{kg}^{-1}$, but this value depends strongly on the geology and the human activity $[2,7]$. Vanadium can be found in various minerals in the form of either vanadate, silicate, sulfide, sulfate, phosphate, or oxide, such as vanadinite, carnotite, roscoelite, patronite, bravoite and davidite [2,8]. Concerning the physico-chemical properties of this transition metal, vanadium has a melting point at $1910{ }^{\circ} \mathrm{C}$ and forms oxide with different oxidation states $($ from $+\mathrm{II}$ to $+\mathrm{V})$ and with various crystalline structures [9].

Vanadium is a transition metal of high environmental and biological importance. Indeed, vanadium is ubiquitously distributed in soil, water, air and living organisms. For instance, in sea water, vanadium (mainly in the form of $\mathrm{H}_{2} \mathrm{VO}_{4}^{-}$) is the second most abundant transition metal element with a mean concentration of $2 \mu \mathrm{g} \cdot \mathrm{L}^{-1}[2,10]$ while in rivers, lakes and groundwater, the maximum concentration of vanadium is up to $30 \mu \mathrm{g} \cdot \mathrm{L}^{-1}[2,11]$. The presence of vanadium in the environment is due to both natural and human activities. The main natural sources for vanadium are marine aerosols, dust 
from soils and rocks weathering, and volcanic emissions [12-15]. From anthropogenic activity, vanadium loads are mainly from mining and burning of crude oil, thus resulting in atmospheric pollution. Vanadium from human contamination is also observed in water resources (rivers, lakes and seas). The quantity of vanadium released into the atmosphere is estimated at more than 60,000 tons each year, and mostly from combustion of fossil fuels [16]. In addition, $\mathrm{V}$ has the ability to stay in the air, water and soil for long period of time [17].

In biochemistry, vanadium is an essential trace element for several mammals. Indeed, $\mathrm{V}$ has a key role in some enzymes such as nitrogenase and haloperoxidase [2]. Vanadium enters in the blood through gastro-intestinal and respiratory systems and then is transported into the other parts of the body in the form of citrates, lactates, or phosphates [18]. Most of V accumulates in vital organs such as kidneys, spleen and liver [19]. In the human body, about $100 \mu \mathrm{g}$ of vanadium is present. It is important to notice that vanadium in the form of vanadate $\left(\mathrm{VO}_{4}{ }^{3-}\right)$ is isostructural to phosphate. It is therefore a competitive element with $\mathrm{PO}_{4}{ }^{3-}$ and can inhibit and/or motivate several phosphate-metabolizing enzymes [20]. Therefore, at high levels, vanadates can be fatal for human [2]. For plants, it is known that $\mathrm{V}$ can affect the metabolism including mineral uptake, enzymatic activities, photosynthetic activity, and the biological yield of plants.

This review article starts with an overview of the applications of various vanadium compounds (Section 2). Afterwards binary and ternary vanadium oxides are introduced (Section 3) with an emphasis on their structure and physical properties before a discussion on their use in photochemical processes for environmental applications (Section 4). Usually, transition metal oxides (TMOs) and especially vanadium oxides have unique physical, chemical, optical, electronic, thermal, and magnetic properties. Therefore, vanadium oxides can find promising applications in various fields such as energy conversion and storage [21]. The particularity of vanadium oxide based materials is that most of them exhibit an insulator-to-metal transition (IMT). Indeed, below a critical temperature $\left(T_{c}\right)$, the properties of the material are insulating or semiconducting while at temperature above they have a metallic behavior. There are different vanadium oxides, therefore the IMT are observed over a wide range of temperatures depending on the oxide, i.e., O/V ratio [22,23]. Due tof this IMT, vanadium oxides are known to be chromogenic materials: they can change their optical properties by applying some external stimuli in the form of photon radiation, temperature change and voltage pulse, thus defining vanadium oxides as photochromic, thermochromic, and electrochromic materials, respectively [22].

In addition to the potential use of vanadium oxides in new technologies, the challenge of environmental remediation is one of the most crucial issues for the present and future generations. The deterioration and contamination of the environment combined to the threat of energy shortage have led the society to explore alternatives to fossil fuels and to pay more attention to our actual way of life. One of the main goals of national governments is to reduce their energy consumption and greenhouse gas emission and to save the natural environment [24]. Indeed, international agreements, such as Kyoto protocol (1995), Stockholm convention (2001), and Paris agreements (2015) have been signed, thus limiting our impact on the planet. Although these attempts are unprecedented, the development of green and efficient remediation treatments is necessary. Our natural environment has been considerably damaged, especially from the last industrial revolution, and is still being deteriorated due to the human activity, in particular factories in the field of textile, chemistry, agriculture, and pharmacy [25-27]. For instance, the quality of water which is a rare and precious resource (around $0.5 \%$ of water on the Earth is drinkable and accessible) is alarming because the different types of industry release many organic and inorganic pollutants such as pesticides and fertilizers, sulfur derivatives, active pharmaceutical ingredients, etc. [25-28]. Among them, many pollutants are persistent and of emerging concern, i.e., they are known compounds which are detected by accumulation effect and whose chemistry and interaction with the environment are unknown. Such pollutants may have harmful effects because they include endocrine disruptor compounds, pharmaceutical 
and personal care products, etc. [29-32]. These contaminants are potentially toxic for humans, animals and plants, thus pushing the national environmental agencies to impose strict measures to limit the pollution [26]. However, limiting the pollution does not remediate the damages already caused to the planet [33]. In addition, the water resources are subjected to an imbalance between availability and demand in water which is caused by its overuse for domestic, industrial, and agricultural purposes, but also by the climate disorder (longer, more intense and more frequent droughts).

Regarding these issues, vanadium oxides are promising materials. As semiconductors, vanadium oxides can be employed in photocatalysis which is a viable alternative to conventional biological, chemical, and physical technologies for the removal of pollutants, especially in water $[25,26]$. In addition, these photocatalytic (and other photo-induced processes) can be triggered by solar energy for environmental applications. In addition to decontamination treatments (Section 4.2), another task is the supply of sustainable and clean energy (Section 4.1). Indeed, vanadium oxide based materials are also able to convert solar energy for the production of hydrogen. To resume, binary and ternary vanadium oxides are attractive for a wide range of environmental applications [9]. Despite the numerous scientific contributions on vanadium oxides, the novelty of this review article is to (i) introduce this versatile element in a global overview, followed by (ii) a strong emphasis on the physical properties of vanadium oxides based materials and their use in (iii) photochemical processes for environmental applications which are one of the biggest issues in the modern time.

\section{Vanadium: A Versatile Element for Various Applications}

\subsection{Vanadium Compounds in Homogeneous Systems}

The common oxidation states of vanadium are from $+\mathrm{II}$ to $+\mathrm{V}$. The chemistry of this transition element in aqueous solution is a key point to understand its versatile properties. In water, vanadium with oxidation states from $+\mathrm{II}$ to $+\mathrm{V}$ form either aqua-complexes or oxo-cations with typical colors. The hexa-aqua-complexes $\left[\mathrm{V}^{\mathrm{II}}\left(\mathrm{H}_{2} \mathrm{O}\right)_{6}\right]^{2+}$ and $\left[\mathrm{V}^{\mathrm{III}}\left(\mathrm{H}_{2} \mathrm{O}\right)_{6}\right]^{3+}$ are violet and green, while vanadyl $\left(\mathrm{V}^{\mathrm{IV}} \mathrm{O}^{2+}\right)$ and pervanadyl $\left(\mathrm{V}^{\mathrm{V}} \mathrm{O}_{2}^{+}\right)$cations are blue and yellow, respectively. Regarding the aqueous redox reactions (Equations (1)-(3)), vanadium (II) is a reducing agent while vanadium (V) is an oxidant [34,35]. In the environment, $\mathrm{V}$ (IV) and V (V) are in the form of vanadyl and vanadate, respectively, while V (II) is thermodynamically unstable and V (III) is stable only under strongly anoxic conditions [2].

$$
\begin{gathered}
\mathrm{VO}_{2}{ }^{+}+2 \mathrm{H}^{+}+e^{-}=\mathrm{VO}^{2+}+\mathrm{H}_{2} \mathrm{O} ; E^{0}=1.0 \mathrm{~V} \\
\mathrm{VO}^{2+}+5 \mathrm{H}_{2} \mathrm{O}+2 \mathrm{H}^{+}+e^{-}=\left[\mathrm{V}\left(\mathrm{H}_{2} \mathrm{O}\right)_{6}\right]^{3+} ; E^{0}=0.24 \mathrm{~V} \\
{\left[\mathrm{~V}\left(\mathrm{H}_{2} \mathrm{O}\right)_{6}\right]^{3+}+e^{-}=\left[\mathrm{V}\left(\mathrm{H}_{2} \mathrm{O}\right)_{6}\right]^{2+} ; E^{0}=-0.26 \mathrm{~V}}
\end{gathered}
$$

In this section, the chemistry of vanadium (V) in aqueous solution is briefly discussed since many molecular species have been discovered [36]. The speciation of these V (V) compounds depends mainly on vanadium concentration, temperature, and solution $\mathrm{pH}$. There are basically two main types of reaction which control the formation of vanadium (V) species: hydrolysis and condensation [37]. At room temperature, dissolved V (V) salts are solvated in aqueous solution by water molecules, thus giving rise to hydrated species $\left[\mathrm{V}\left(\mathrm{H}_{2} \mathrm{O}\right)_{n}\right]^{5+}$ [37]. However, the water molecule ligands are partially deprotonated (Equation (4)) due to the strong polarizing power of highly charged vanadium (V). This hydrolysis process results in a decrease in $\mathrm{pH}$.

$$
\left[\mathrm{V}\left(\mathrm{H}_{2} \mathrm{O}\right)_{6}\right]^{5+}+h \mathrm{H}_{2} \mathrm{O} \rightarrow\left[\mathrm{V}\left(\mathrm{H}_{2} \mathrm{O}\right)_{6-h}(\mathrm{OH})_{h}\right]^{(5-h)+}+h \mathrm{H}_{3} \mathrm{O}^{+}
$$

The term " $h$ " is the hydrolysis ratio and it increases with increasing $\mathrm{pH}$, thus leading to the formation of aqua, hydroxo, and oxo species. Therefore, at low $\mathrm{pH}(\mathrm{pH}<2)$, the hydrolysis ration $h=4$ and $\left[\mathrm{V}(\mathrm{OH})_{4}\left(\mathrm{H}_{2} \mathrm{O}\right)_{2}\right]^{+}$is formed. Since V (V) is highly charged, internal proton transfer occurs to decrease this high positive charge and it leads to the 
formation of pervanadyl species $\left[\mathrm{VO}_{2}\left(\mathrm{H}_{2} \mathrm{O}\right)_{4}\right]^{+}$or $\left[\mathrm{VO}_{2}\right]^{+}$with $\mathrm{V}=\mathrm{O}$ double bonds (vanadyl groups) in cis position [38]. At $\mathrm{pH} \approx 6$, the coordination number of $\mathrm{V}(\mathrm{V})$ decreases from 6 to 4 since $\mathrm{V}-\mathrm{O}$ bonds are more covalent, thus leading to the formation of four-fold coordinated vanadate $\left[\mathrm{H}_{n} \mathrm{VO}_{4}\right]^{(3-n)-}$. Above $\mathrm{pH}=12$, vanadate species are fully deprotonated. It is worth noting that monomeric species are observed only in dilute solutions. At higher vanadium concentration, condensation process dominates and occurs through olation and oxolation (Equations (5) and (6)) [37]:

$$
\begin{gathered}
\text { Olation: }>\mathrm{V}-\mathrm{OH}+>\mathrm{V}-\mathrm{OH}_{2} \rightarrow>\mathrm{V}-\mathrm{O}(\mathrm{H})-\mathrm{V}<+\mathrm{H}_{2} \mathrm{O} \\
\text { Oxolation: }>\mathrm{V}-\mathrm{OH}+>\mathrm{V}-\mathrm{OH} \rightarrow>\mathrm{V}-\mathrm{O}-\mathrm{V}<+\mathrm{H}_{2} \mathrm{O}
\end{gathered}
$$

The temperature has also strong effect on the molecular structure of vanadium species [37]. Once vanadium precursors have been condensed to decavanadate species, they can transform upon heating into cyclic metavanadates (Equation (7)) [39]. This dissociation process is a reversible reaction:

$$
2\left[\mathrm{H}_{2} \mathrm{~V}_{10} \mathrm{O}_{28}\right]^{6-}+4 \mathrm{H}_{2} \mathrm{O}=5\left[\mathrm{~V}_{4} \mathrm{O}_{12}\right]^{4-}+12 \mathrm{H}^{+}
$$

In addition to the chemistry of aqueous vanadium species, their biological relevance (Figure 1) is also a point which needs to be briefly developed. Only higher oxidation states of vanadium are considered in the physiological $\mathrm{pH}(2<\mathrm{pH}<8)$, i.e., $\mathrm{V}$ (IV) and $\mathrm{V}$ (V) in cationic and anionic forms. On the other hand, V (III) is mainly present in primitive organisms such as ascidians and worms and it is not present in complex organisms [40,41]. Vanadium at higher oxidation states is present in most of mammal tissues (around $20 \mathrm{nM}$ ). In the human body, the average vanadium concentration is approximately $0.3 \mu \mathrm{M}$ [42-48]. Vanadium in the form of vanadate $\left(\mathrm{H}_{2} \mathrm{VO}_{4}{ }^{-}\right)$, which can be present in drinking water, is partially reduced in the stomach before being precipitated in the intestines in the form of $\mathrm{VO}(\mathrm{OH})_{2}$ [10]. Vanadium can also enter directly in the blood stream by intravenously injection [49]. Once in the blood, vanadium undergoes redox conversion between $\mathrm{V}(\mathrm{V})$ and $\mathrm{V}$ (IV) according to the level of oxygen and the presence of reductants/oxidants. Thus, vanadium could form either anionic $\mathrm{VO}_{4}{ }^{3-}$, cationic $\mathrm{VO}^{2+}$ or neutral/charged vanadium complex. Concerning the toxicity of vanadium, the limit values to observe harmful effect on human health during one-time exposure is around $7 \mathrm{mg}$ by intravenous application and $35 \mathrm{mg}$ by inhalation [10,50]. Vanadium contents (in the blood) can decrease to about $30 \%$ within $24 \mathrm{~h}[49,50]$ since it is eliminated via urine or distributed in tissues. In bones, the residence time is of about one month since vanadium can replace phosphorus in hydroxyapatite [51]. The vanadium path in the body is summarized in Figure 1.

On the other hand, vanadium has high potential as metallodrugs, especially for the treatment of diabetes which was the first use of vanadium in pharmacology. Indeed, in the form of salts including sodium metavanadate, sodium orthovanadate, and vanadyl sulphate, the effect on patient whom needed insulin is positive. This is due to the ability of these vanadium species to activate insulin receptor [42]. Vanadium derivatives can also inhibit/activate several ATPases and phosphatases enzymes since vanadate is a phosphate mimic anion [34,42]. Vanadium is also used for the treatment of several pathologies such as hyper-lipidemia, obesity, and hyper-tension [42]. It is worth mentioning that $\mathrm{V}$ has anti-cancer properties. Indeed, vanadium compounds can be used to prevent wear and tear of essential biomolecules such as DNA, thus protecting the genomic stability $[52,53]$. Vanadium derivatives can be also used in anti-bacterial and anti-viral applications [34,42]. 


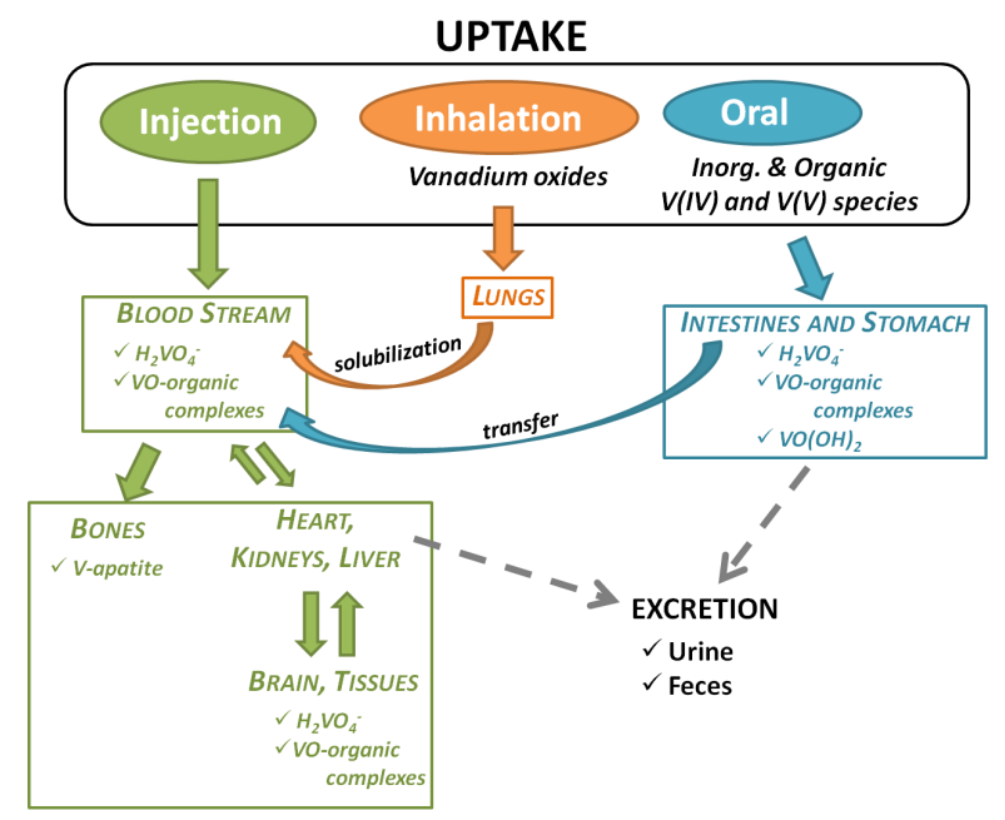

Figure 1. The pathway of vanadium in the human metabolism.

In addition to medicinal applications, vanadium can be used in the field of energy production as, for instance, the redox flow battery. A redox flow battery is similar to an electrochemical cell composed of two compartments and two electrolyte reservoirs (Figure 2). The electrolytes circulate through the cell by a pump while the compartments are separated by an ion exchange membrane to allow the diffusion of ions (Figure 2) [54]. The main disadvantage in typical redox flow batteries such as iron/chromium or iron/titanium is the cross contamination of the electrolytes due to different redox couple species in each half-cell compartment $[55,56]$. In vanadium redox flow batteries, this problem is overcome by employing the same electrolyte in both compartments, thus eliminating the cross-contamination as well as the problems from the maintenance of electrolyte solution. Indeed, a vanadium electrolyte is used in both half-cells where the $\mathrm{V}^{2+} / \mathrm{V}^{3+}$ redox couple operates in the negative one while the $\mathrm{VO}^{2+} / \mathrm{VO}_{2}{ }^{+}$redox couple operates in the positive half-cell [54]. Therefore, such pioneered vanadium-based batteries are considered as the 1st generation of such a type of battery.

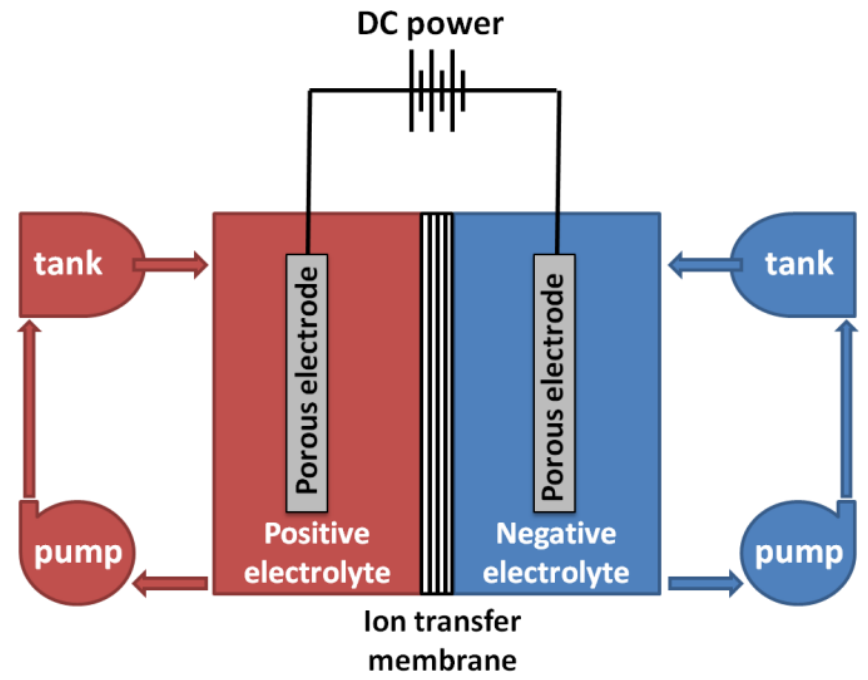

Figure 2. Scheme of a redox flow battery. 
All the above applications of vanadium in homogeneous systems are very different from each other due to the chemical versatility of vanadium. Depending on its oxidation states, this element promotes a wide variety of chemistries, especially in catalysis (Figure 3). Concerning the chemistry of coordination compounds, vanadium is very flexible, especially V $(\mathrm{V})$. Vanadium $(\mathrm{V})$ has not rigid stereochemical requirements and, thus, can form a variety of complexes, including tetrahedral and octahedral geometries, as well as trigonal and pentagonal bipyramids [57]. On the other hand, vanadium (IV) is less flexible and forms mainly square pyramidal complexes or distorted octahedral geometries [57]. Vanadium complexes like peroxido-vanadium complexes can be involved in biological and catalytic applications $[34,58]$. Indeed, catalytic properties of peroxido-vanadium complexes are focused on the oxidation of organic compounds. In these oxidative reactions, the complex is formed in-situ from either ammonium vanadate or $\mathrm{V}_{2} \mathrm{O}_{5}$ by reaction with hydrogen peroxide and the resulting complex can oxidize aliphatic and aromatic hydrocarbon structures [58]. Other catalytic applications involving vanadium complexes exist, such as polymerization, C-C bond cleavage and activation, hydrogenation, etc. (Figure 3) [59-61].

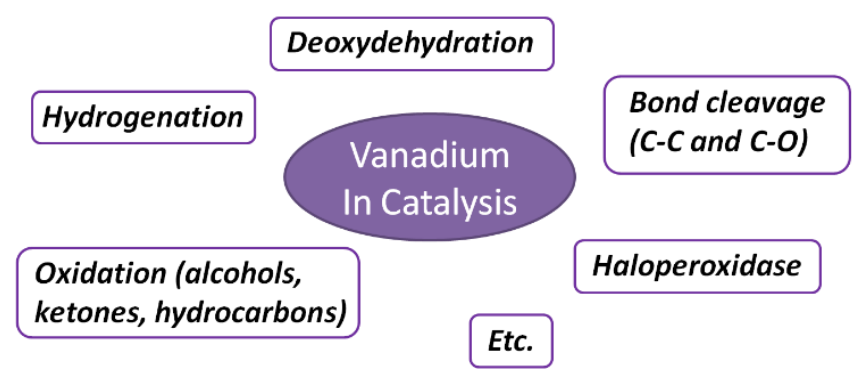

Figure 3. Some of the possible uses of vanadium in catalytic processes.

\subsection{Vanadium Materials in Heterogeneous Systems}

In this section, other applications than environmental ones (Section 4) are discussed. In the form of solid materials, vanadium is mainly used in metallurgy for the formation of ferrovanadium alloy $(\mathrm{FeV})$ or as steel additive [34]. Mixed with aluminum in titanium alloys, vanadium is also used in jet engines, high-speed airframes, and dental implants [34]. The metallurgy accounts for $85 \%$ of the vanadium use. Moreover, vanadium is also used for the storage of hydrogen [62]. Hydrogen is considered as the alternative source of energy to fossil fuels. Even if it is an eco-friendly energy which is relatively easy to produce, its storage and transportation are crucial for the development of hydrogen-based energy system since hydrogen is an explosive compound [62,63]. Usually, the storage and transportation of hydrogen is based on high-pressure gaseous $\mathrm{H}_{2}$ and cryogenicallycooled liquid hydrogen. In such conditions, the storage and transportation is associated with safety issues and unpractical heavy tanks [64]. Therefore, to avoid these problems, hydrogen can be stored in the form of metal hydrides like those of vanadium which are considered as a viable method [63]. In addition to the high hydrogen storage capacity of vanadium hydrides including vanadium based alloys also exhibit good hydrogenationdehydrogenation kinetics at room temperature [62].

On the other hand, vanadium can be used in the form of chalcogenides (oxides, sulfides, etc.), nitrides, carbides, and a number of halides which are stable materials [35]. Vanadium sulfide $\left(\mathrm{VS}_{2}\right)$ which belongs to the group of transition metal dichalcogenide (TMD) has a structure composed of V layers sandwiched between two layers of S [65]. These layers are stacked together by Van der Walls interactions. Vanadium sulfide has interesting electrical properties, especially high 2D metallic behavior. This 2D conducting material is of high interest for the design of planar supercapacitors [66,67]. Indeed, $\mathrm{VS}_{2}$ in the form of nanosheets can be used in next-generation energy storage devices [68]. However, the most important vanadium chalcogenide are the oxides which are the most commercially available. Among vanadium oxides, $\mathrm{V}_{2} \mathrm{O}_{5}$ is the most used. This yellow- 
brown oxide can be obtained easily either by calcination of vanadium metal powder in an excess of oxygen or by thermal decomposition of ammonium metavanadate (Equation (8)):

$$
2 \mathrm{NH}_{4} \mathrm{VO}_{3} \rightarrow \mathrm{V}_{2} \mathrm{O}_{5}+2 \mathrm{NH}_{3}+\mathrm{H}_{2} \mathrm{O}
$$

Nowadays, vanadium pentoxide is a key component in the production of sulfuric acid since it catalyzes the oxidation of sulfur dioxide to sulfur trioxide. In addition, $\mathrm{V}_{2} \mathrm{O}_{5}$ and materials containing vanadium pentoxide are used in many other catalytic reactions [34,69]. Due to its catalytic activity and selectivity, $\mathrm{V}_{2} \mathrm{O}_{5}$ is a known catalyst for the selective oxidation of various organic compounds, mainly hydrocarbons and alcohols, e.g., butane to maleic anhydride, propene to acrolein and methanol to formaldehyde [34,70]. These latter cases are examples of commercial products synthesized using vanadium pentoxide. $\mathrm{V}_{2} \mathrm{O}_{5}$ is also used in other oxidative processes such as the oxidative dehydrogenation of alkanes [34,71]. However, $\mathrm{V}_{2} \mathrm{O}_{5}$ and generally vanadium oxide based materials are also important catalysts for environmental applications which are developed in Section 4. Besides the catalytic properties, the layered structure of vanadium pentoxide is promising for the design of electrodes in lithium ion batteries (LIB) [72]. Indeed, $\mathrm{V}_{2} \mathrm{O}_{5}$ has high ionic storage capacity and as a cathode material, vanadium pentoxide has a theoretical energy density of about $1.1 \mathrm{~kW} \cdot \mathrm{h} \cdot \mathrm{Kg}^{-1}$ which corresponds to $440 \mathrm{~mA} \cdot \mathrm{h} \cdot \mathrm{g}^{-1}$ for fully-lithiated $\mathrm{V}_{2} \mathrm{O}_{5}\left(\mathrm{Li}_{3} \mathrm{~V}_{2} \mathrm{O}_{5}\right)$ [73]. It is far more than classical cathode material like coarse-grained $\mathrm{LiCoO} 2$ which has a practical energy density $<0.5 \mathrm{~kW} \cdot \mathrm{h} \cdot \mathrm{Kg}^{-1}\left(274 \mathrm{~mA} \cdot \mathrm{h} \cdot \mathrm{g}^{-1}\right)$. However, charging more than one $\mathrm{Li}$ ion per $\mathrm{V}_{2} \mathrm{O}_{5}$ unit cell leads to irreversible structural changes [74]. When one lithium is stored $\left(\mathrm{LiV}_{2} \mathrm{O}_{5}\right)$, the lattice structure is extremely reversible with over 1000 cycles without capacity loss and the energy density is still higher than classical $\mathrm{CoO}_{2}$ cathode $\left(294 \mathrm{~mA} \cdot \mathrm{h} \cdot \mathrm{g}^{-1}\right)$ [75]. It is worth noting that Panasonic has commercialized vanadium pentoxide as cathode material in rechargeable Li-ion batteries. Such a cathode can be used for low-energy application only because of kinetic problems, thus other layered vanadium oxides should be designed to improve the LIB performance [76]. That is the case of $\mathrm{V}_{6} \mathrm{O}_{13}$ which is obtained from $\mathrm{V}_{2} \mathrm{O}_{5}$ (Equation (9)). Indeed, the theoretical specific

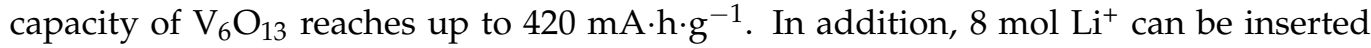
in the layered structure of $1 \mathrm{~mol} \mathrm{~V}_{6} \mathrm{O}_{13}$. However, the poor cycling performance of this vanadium oxide is one of the most serious drawbacks for a use as cathode materials in LIBs [77]. Therefore, another strategy is to substitute $\mathrm{V}$ cations or vanadium vacancies with other cations such as $\mathrm{Ag}^{+}, \mathrm{Mn}^{2+}$, and $\mathrm{Ti}^{4+}$, thus improving the electrochemical properties of $\mathrm{V}_{6} \mathrm{O}_{13}$ cathode.

$$
9 \mathrm{~V}_{2} \mathrm{O}_{5}+4 \mathrm{NH}_{3} \rightarrow 3 \mathrm{~V}_{6} \mathrm{O}_{13}+2 \mathrm{~N}_{2}+6 \mathrm{H}_{2} \mathrm{O}
$$

Vanadium dioxide is also an intensively studied vanadium oxide phase, especially for its thermochromic properties. Indeed, in the form of coating, $\mathrm{VO}_{2}$ can change its appearance from transmissive to opaque due to a reversible insulator-to-metal transition (IMT) [78]. At a critical temperature $\left(T_{C}=68^{\circ} \mathrm{C}\right)$ and without any additional external stimuli, phase transition between IR-transparent $\mathrm{VO}_{2}(\mathrm{M})$ and IR-translucent $\mathrm{VO}_{2}(\mathrm{R})$ occurs (Figure 4). The insulator-to-metal transition is not only accompanied by optical changes, but also by changes in electrical properties. For instance, the electrical resistivity of $\mathrm{VO}_{2}$ varies at the critical temperature from $20 \Omega \cdot \mathrm{cm}$ in the insulating phase to about $0.1 \Omega \cdot \mathrm{cm}$ in the metallic phase, which is accounts to a factor 200 [79]. This reversible change in electrical properties occurs within $100 \mathrm{fs}$ [80]. Regarding the ultrafast switching time and the sharp change in resistivity, $\mathrm{VO}_{2}$ is an excellent temperature sensor. Regarding all these properties, the $\mathrm{VO}_{2} \mathrm{IMT}$ is an excellent feature for the design of smart windows since energy consumption can be saved and greenhouse gas emission reduced [9]. This is an actual issue since, according to a survey, buildings are one of the main problems in this field with an energy consumption of $40 \%$ along with $30 \%$ of anthropogenic greenhouse gas emission [81]. These negative statistics are due to the excessive use of lighting, airconditioning and heating [81]. In addition, the heat exchange between building indoor and 
the outdoor environment are occurring through the windows and, thus, amplifying the energy consumption.
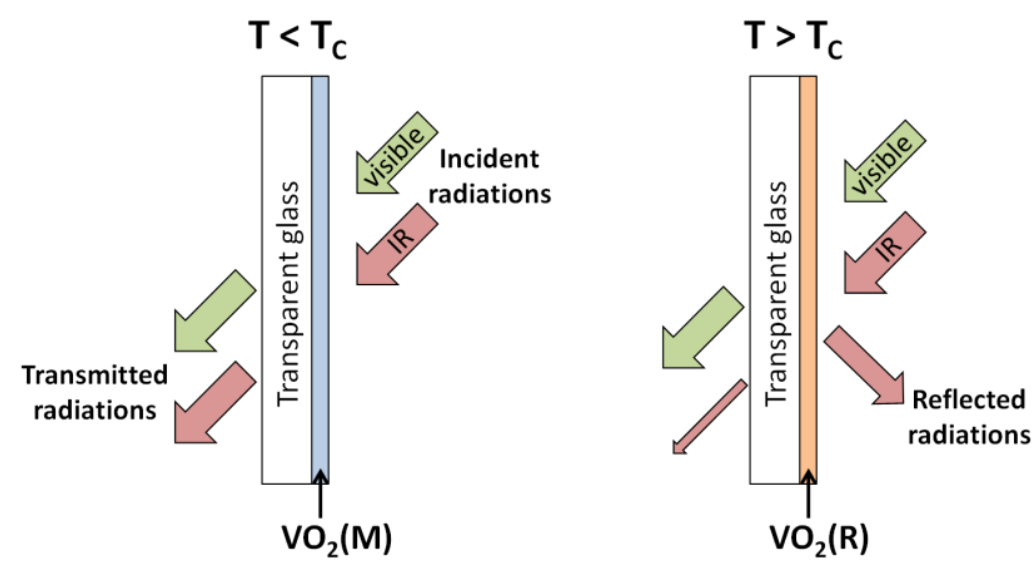

Figure 4. Principle of $\mathrm{VO}_{2}$ thermochromic coating deposited on transparent support.

The vanadium oxides are also widely used in recent technologies such as memory devices and sensors [82]. Vanadium oxide based materials are attractive due to their easy way of fabrication which is inexpensive, non-toxic, and using scalable wet chemical techniques [83]. It is important to remind that vanadium can form a large number of oxides but only few of them provide stability needed in microelectronic devices. That is the case of $\mathrm{VO}_{2}, \mathrm{~V}_{2} \mathrm{O}_{3}$, and $\mathrm{V}_{2} \mathrm{O}_{5}$ which are oxides containing vanadium in a single oxidation state. Because of their reversible changes of physical properties, these thermoand electro-chromic vanadium oxides exhibit hysteresis loop. The width of this loop is a crucial parameter for applications in microelectronics. Indeed, the memory aspect of vanadium oxides materials lies in the hysteresis of the insulator-to-metal transition. One of the most known applications involving vanadium oxides, such as $\mathrm{V}_{2} \mathrm{O}_{3}, \mathrm{VO}_{2}$, and $\mathrm{V}_{2} \mathrm{O}_{5}$ are bolometers. A bolometer is a thermal infrared detector. Therefore, bolometers are used in infrared imaging applications such as thermal camera, night vision camera, mine detection, early fire detection, medical imaging and gas leakage detection [84]. Materials which are used in bolometers require high temperature coefficient of resistance (TCR) and a small noise constant (1/f) [84]. Vanadium oxides belong to this category. Although pure and stoichiometric binary oxides such as $\mathrm{VO}_{2}, \mathrm{~V}_{2} \mathrm{O}_{3}$, and $\mathrm{V}_{2} \mathrm{O}_{5}$ have high TCR, they are difficult to synthesize as single crystals. $\mathrm{V}_{2} \mathrm{O}_{3}$ is an excellent candidate due to the critical temperature of its IMT transition which is far below the room temperature and, thus, the level of noise is low. However, the actual strategy is to use systems mixing different single-valence vanadium oxides in order to design stable microbolometric materials with high TCR and resistivity [85]. The use of vanadium oxides for such bolometric applications appeared after 1992 since, fprior to this date, it was classified by the US government.

\section{Structures and Physical Properties of Binary and Ternary Vanadium Oxides \\ 3.1. Case of Binary Vanadium Oxides}

As most of the d-transition metals, vanadium has different oxidation states which are present in oxides as either single or mixed valence states. The vanadium oxides existing in a single valence state are typically $\mathrm{V}^{\mathrm{II}} \mathrm{O}, \mathrm{V}^{\mathrm{III}}{ }_{2} \mathrm{O}_{3}, \mathrm{~V}^{\mathrm{IV}} \mathrm{O}_{2}$, and $\mathrm{V}_{2}{ }_{2} \mathrm{O}_{5}$ while couples of mixed valence oxides exist such as $\mathrm{V}_{3} \mathrm{O}_{5}, \mathrm{~V}_{4} \mathrm{O}_{7}, \mathrm{~V}_{5} \mathrm{O}_{9}, \mathrm{~V}_{6} \mathrm{O}_{11}, \mathrm{~V}_{6} \mathrm{O}_{13}, \mathrm{~V}_{7} \mathrm{O}_{13}$, and $\mathrm{V}_{8} \mathrm{O}_{15}$. These latter oxides mix mainly two valence states of vanadium [22]. The formation of vanadium oxide of particular oxidation state(s) is highly dependent on the preparation method, i.e., the experimental parameters such as the temperature, the partial pressure of the oxidant/reducer [73]. For instance, the following phases are formed and transformed subsequently in an oxidative atmosphere in the order: $\mathrm{VO}_{2}, \mathrm{~V}_{6} \mathrm{O}_{13}, \mathrm{~V}_{4} \mathrm{O}_{9}, \mathrm{~V}_{3} \mathrm{O}_{7}$, and $\mathrm{V}_{2} \mathrm{O}_{5}$. This order of appearance during the synthesis is closely related to the increasing oxidation 
state. For these oxides, the oxidation states for the vanadium is 4.0,4.3, 4.5, 4.7, and 5.0 , respectively $[86,87]$. Such vanadium oxides ranging from $\mathrm{V}_{2} \mathrm{O}_{5}$ to $\mathrm{VO}_{2}$ belong to the Wadsley series, i.e., oxides of general formula $\mathrm{V}_{n} \mathrm{O}_{2 n+1}$ [72]. Another important category of vanadium oxides is the so-called Magnéli phases with a general formula $\mathrm{V}_{n} \mathrm{O}_{2 n-1}$ [72] .

The structure of the most important vanadium oxides are described below along with their properties. The rich coordination-style configurations for the vanadium ions, which is also one reason why vanadium has various valence states, leads to the formation of numerous and varied frameworks [88]. The control of vanadium oxide structures is not an easy task. Usually in transition metal oxides, the electronic properties are related to the sband associated with the transition metal ion and the p-band associated with the oxygen ion. As a consequence, these orbitals are pushed away from the Fermi level while the remaining $\mathrm{d}$-orbitals are close to this level [89]. Thus, the d-orbitals of the metal are of significant importance in the explanation of electronic properties using either crystal field theory or conventional band theory. In the crystal field theory, the splitting energy for $3 \mathrm{~d}$-series ions in oxides has a value of $1-2 \mathrm{eV}$ and this value increases as cation oxidation state increases. In conventional band theory, which treats the electrons as extended plane wave, the metal d-orbitals form the conduction band. According to this theory, the semiconductors are defined as materials having completely filled valence band and an empty conduction band separated by a short energy band gap $\left(E_{g}\right)$. The structure and the morphology of solid state materials are mainly responsible of the observed properties [37]. In other words, the physical properties of a material depend strongly on its structure. The various atom-stacking style form the numerous crystal structures of vanadium oxides [90,91], thus providing the foundation to understand the interplay between the properties and the structures. In this section, binary vanadium oxides with both single and mixed valence states are discussed.

\subsubsection{Structure of $\mathrm{VO}_{2}, \mathrm{~V}_{2} \mathrm{O}_{5}$, and $\mathrm{V}_{2} \mathrm{O}_{3}$}

The oxides of formula $\mathrm{VO}_{2}, \mathrm{~V}_{2} \mathrm{O}_{5}$, and $\mathrm{V}_{2} \mathrm{O}_{3}$ are formed of vanadium in one valence state. Their melting points are 1967,690 , and $1970{ }^{\circ} \mathrm{C}$, respectively, while metallic vanadium melts at $1910{ }^{\circ} \mathrm{C}$. The two ends of the Wadsley series, that are $\mathrm{VO}_{2}$ and $\mathrm{V}_{2} \mathrm{O}_{5}$, are known layered vanadium oxides [73]. For the highest valence state of vanadium $\left(\mathrm{V}^{5+}\right)$, there is only one $\mathrm{V}_{2} \mathrm{O}_{5}$ phase which is the orthorhombic crystal system (space group of $P_{m m n}$ ) [92]. Indeed, as long as the reaction temperature is high enough and the oxygen is sufficiently provided, orthorhombic $\mathrm{V}_{2} \mathrm{O}_{5}$ would be exclusively formed [93]. The orthorhombic lattice of vanadium pentoxide is composed of $\left[\mathrm{VO}_{5}\right]$ pyramids which form alternating double chains (pyramids-up/pyramids-down) along the $b$-axis. These double chains are connected laterally by bridging oxygens to form a sheet or a ribbon in the $a-b$ plane. The planes themselves are connected by Van der Waals bonds [83]. The Van der Waals bonds are weak and create easy cleavage along these planes [83]. Since $\mathrm{V}_{2} \mathrm{O}_{5}$ has a layered structure it is, therefore, possible to extract few layers (of nanometer thickness) or even a monolayer of vanadium pentoxide [22]. Although the sheets/ribbons along the $b$-axis direction are very robust, the $\mathrm{V}_{2} \mathrm{O}_{5}$ lattice is fairly open and permeable to smaller intercalating cations. In addition, the surface of the Van der Waals planes is polar, thus allowing hydration phenomenon [94]. Theoretically, in the crystal structure of $\mathrm{V}_{2} \mathrm{O}_{5}$, the nominal valence state of vanadium atoms is $+\mathrm{V}$, but thermal agitation and crystal defects create a small concentration of V (IV) in the solid. Therefore, electronic conduction occurs by means of electron hopping. This is equivalent to the motion of the $+\mathrm{IV}$ valent vanadium states. The presence of $\mathrm{V}(\mathrm{IV})$ in $\mathrm{V}_{2} \mathrm{O}_{5}$ also creates local lattice distortion [83].

For $\mathrm{VO}_{2}$, more than 10 types of $\mathrm{V}$ (IV) oxide phases have been reported and the preparation of the desired structure is hard since the structures are very similar. Among these vanadium dioxides, $\mathrm{VO}_{2}(\mathrm{M}), \mathrm{VO}_{2}(\mathrm{R})$ and $\mathrm{VO}_{2}(\mathrm{~B})$ are the three main phases, from which $\mathrm{VO}_{2}(\mathrm{~B})$ is metastable. The other vanadium dioxide polymorphs are metastable phases including $\mathrm{VO}_{2}(\mathrm{~A}), \mathrm{VO}_{2}(\mathrm{~B}), \mathrm{VO}_{2}(\mathrm{C})$, and $\mathrm{VO}_{2}(\mathrm{D})$, but also mineral phases such as paramontroseite and nsutite-type structures $[95,96]$. Compared to $\mathrm{VO}_{2}(\mathrm{M})$ and $\mathrm{VO}_{2}(\mathrm{R})$, 
the synthesis of metastable phases usually requires a lower temperature. The $\mathrm{VO}_{2}(\mathrm{M} / \mathrm{R})$ exhibits an IMT where $\mathrm{VO}_{2}(\mathrm{M})$ and $\mathrm{VO}_{2}(\mathrm{R})$ are the insulating and the metallic phases, respectively. Below the phase transition temperature $\left(T_{C}\right)$, vanadium dioxide has a monoclinic structure $\left(\mathrm{VO}_{2}(\mathrm{M})\right)$ [97] while above $T_{\mathrm{C}}, \mathrm{VO}_{2}$ is in rutile form $\left(\mathrm{VO}_{2}(\mathrm{R})\right)$ [22]. In rutile phase, each vanadium is coordinated to six nearest oxygens, thus forming $\left[\mathrm{VO}_{6}\right]$ octahedra [83]. These $\left[V_{6} \mathrm{O}_{6}\right]$ octahedra are symmetrical and form edge-sharing chains along the $c$-axis of the crystal lattice. This tetragonal lattice has a space group $P 4_{2} / \mathrm{mnm}$ while the monoclinic phase, $\mathrm{VO}_{2}(\mathrm{M})$, has a space group $P 2_{1} / c$. At room temperature, the metastable phases also exist and $\mathrm{VO}_{2}(\mathrm{~B})$ is the most investigated one. Eventually, $\mathrm{VO}_{2}(\mathrm{~B})$ can be converted to metastable $\mathrm{VO}_{2}(\mathrm{~A})$ or $\mathrm{VO}_{2}(\mathrm{M})$ by heat treatment [98]. $\mathrm{VO}_{2}(\mathrm{~B})$ is sometimes named as $\mathrm{VO}_{2}(\mathrm{M} 2)$ since it has a monoclinic structure. The main difference between the $\mathrm{VO}_{2}(\mathrm{M})$ and $\mathrm{VO}_{2}(\mathrm{~B})$ monoclinic structures is based on the $\beta$ angle of the lattice structure which is $122.62^{\circ}$ in $\mathrm{VO}_{2}(\mathrm{M})$ and $92.88^{\circ}$ in $\mathrm{VO}_{2}(\mathrm{~B})$. In addition, $\mathrm{VO}_{2}(\mathrm{~B})$ does not exhibit an insulating-to-metal transition, neither the tetragonal $\mathrm{VO}_{2}(\mathrm{~A})$ phase. The IMT in $\mathrm{VO}_{2}(\mathrm{M} / \mathrm{R})$ is induced by temperature gradient leading to a huge change in resistivity. The structural changes involve small distortions of the infinitely linear $\mathrm{V}-\mathrm{V}$ chains (with a $\mathrm{V}-\mathrm{V}$ distance of $0.288 \mathrm{~nm}$ along the $c$-axis) in $\mathrm{VO}_{2}(\mathrm{R})$, thus giving rise to the dimerization of $\mathrm{V}-\mathrm{V}$ pairs (with two values of $0.262 \mathrm{~nm}$ and $0.316 \mathrm{~nm}$ between $\mathrm{V}-\mathrm{V}$ ) in $\mathrm{VO}_{2}(\mathrm{M})$ [72]. In the rutile phase, the electrons from d-orbitals are shared by all of the vanadium atoms along the $c$-direction of the lattice, thus leading to the metallic behavior. In the monoclinic phase, the vanadium atoms form dimers, thus resulting in the insulating behavior (i.e., semiconducting $\left.\mathrm{VO}_{2}(\mathrm{M})\right)$ [99]. Furthermore, during the phase transition to $\mathrm{VO}_{2}(\mathrm{R})$, the $\mathrm{V}-\mathrm{V}$ pairs in the chains in $\mathrm{VO}_{2}(\mathrm{M})$ do not only undergo dimerization, but also a twist from linear to zigzag-type chains [72] (Figure 5). The local structural rearrangement around the $\mathrm{V}$ atoms during the insulator-to-metal transition provides a key factor to modify the band-gap value [72]. It is important to note that monoclinic and rutile $\mathrm{VO}_{2}$ phases have different crystal systems, but their crystal lattices are of great similarity. The only difference between these two structures is the displacement of the vanadium atoms in the chains. Therefore, this structural similarities between the metallic and insulating phases makes the understanding of the IMT more difficult.
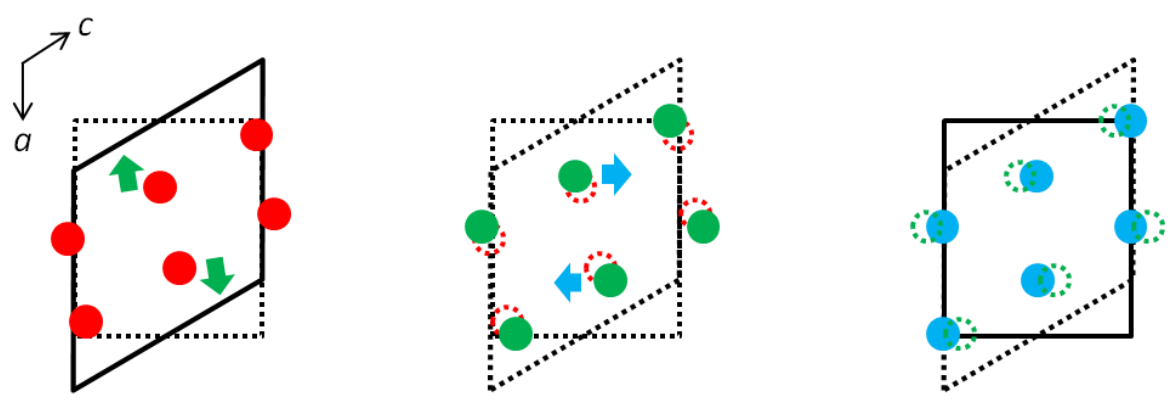

time

Figure 5. Changes in the crystalline structure during $\mathrm{VO}_{2}$ phase transition. The schematized sequence occurs in the picoseconds scale.

Concerning $\mathrm{V}_{2} \mathrm{O}_{3}$, there are very limited numbers of phases. This is mainly related to the chemical instability of the low valence state vanadium ions, here $\mathrm{V}$ (III). However, there is still intense research in searching for new $\mathrm{V}_{2} \mathrm{O}_{3}$ crystal polymorphs. Similar to iron(III) oxides $\left(\mathrm{Fe}_{2} \mathrm{O}_{3}\right)$ which is known as either hematite $\left(\alpha-\mathrm{Fe}_{2} \mathrm{O}_{3}\right)$, beta phase $\left(\beta-\mathrm{Fe}_{2} \mathrm{O}_{3}\right)$, gamma phase $\left(\gamma-\mathrm{Fe}_{2} \mathrm{O}_{3}\right)$, maghemite $\left(\delta-\mathrm{Fe}_{2} \mathrm{O}_{3}\right)$, or epsilon phase $\left(\varepsilon-\mathrm{Fe}_{2} \mathrm{O}_{3}\right)$ [100], only $\delta-\mathrm{V}_{2} \mathrm{O}_{3}$ and $\varepsilon-\mathrm{V}_{2} \mathrm{O}_{3}$ have not been discovered up to now. Vanadium sesquioxide $\left(\mathrm{V}_{2} \mathrm{O}_{3}\right)$ also exhibits an IMT where $\mathrm{V}_{2} \mathrm{O}_{3}$ has a monoclinic/rhombohedral structure below $T_{C}$, and a corundum structure above $T_{C}$ [22]. In its insulating phase (below $T_{C}$ ), $\mathrm{V}_{2} \mathrm{O}_{3}$ has body 
centered monoclinic structure with space group I2/a. The metallic phase of $\mathrm{V}_{2} \mathrm{O}_{3}$ (above $T_{C}$ ) has a trigonal corundum structure with space group $R \overline{3} c$.

\subsubsection{Properties of $\mathrm{VO}_{2}, \mathrm{~V}_{2} \mathrm{O}_{5}$, and $\mathrm{V}_{2} \mathrm{O}_{3}$}

The control of the synthesis of binary vanadium oxides of particular structure is a key parameter to tailor the desired electronic properties [72]. It is well known that the charge carrier concentration in the prepared materials is crucial to understand and explain the performance of different vanadium oxides in various applications such as energy conversion, in particular photocatalysis and water photosplitting (Section 4). Indeed, the electronic properties are usually discussed using the band structure of the semiconductor materials, which is the plot of electron energies against the wave vector. Prior to further process in this section on the properties (especially electronic ones) of binary vanadium oxides with single vanadium valence, it is important to introduce some notions of the band structure theory. The number of bands (in a band structure diagram) is equal to the number of atomic orbitals in the unit cell of the compound. The overlap integral, which is the overlap between the interacting orbitals, determines the bandwidth (or the band dispersion), i.e., it is the difference in energy between the lowest and highest levels in a band. The greater is the overlap between neighboring orbitals, the greater is the bandwidth (and vice versa). Therefore, the behavior of electrons in a solid can be studied microscopically from its electronic band structure (Figure 6) [101]. From these electronic properties, and more particularly from the band structure diagram, it is possible to extract additional important information about the material such as optical properties. Indeed, in a material, optical properties originate from the response of electrons to a stimulus which is the transition between energy levels under an incident radiation. The energy band gap calculation and the absorption edge estimation are of high interest in many research fields due to potential applications in optical, electronic, and optoelectronic devices. The electronic band structure of a material is dependent on the crystal structure of the material.

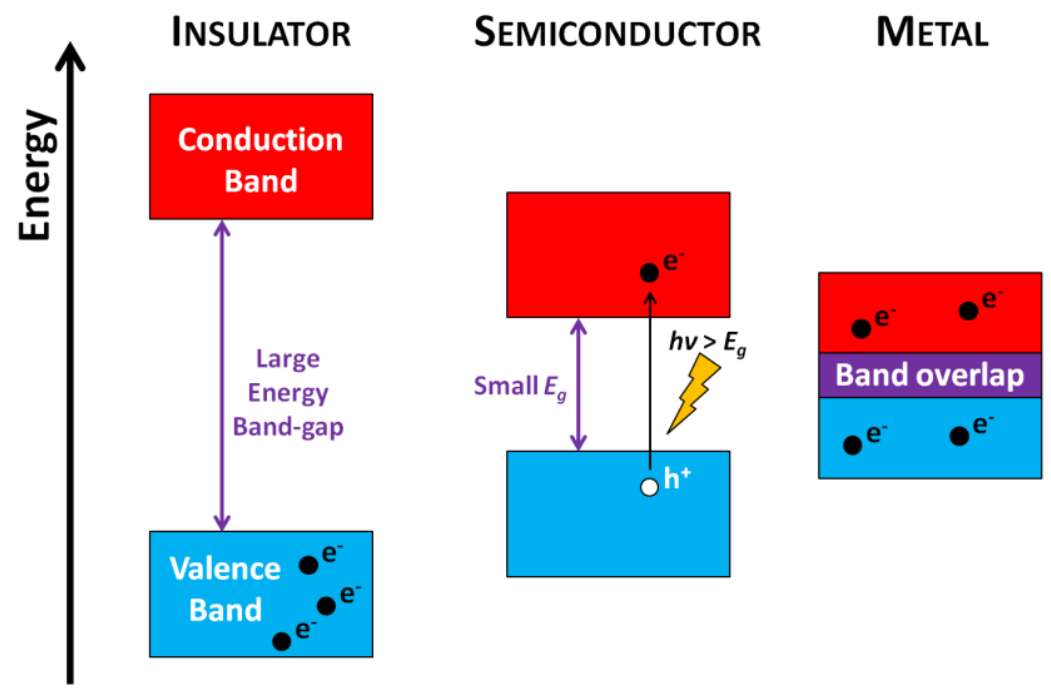

Figure 6. The band structures of insulator, semiconductor and metal.

Concerning the main single valence state of binary vanadium oxides $\left(\mathrm{VO}_{2}, \mathrm{~V}_{2} \mathrm{O}_{5}\right.$, and $\mathrm{V}_{2} \mathrm{O}_{3}$ ), their electronic structure are all characterized by a strong hybridization between the $2 \mathrm{p}$ oxygen and $3 \mathrm{~d}$ vanadium bands, which are the valence orbitals. Their optical properties can be explained using their electronic properties. Since most of the binary vanadium oxides exhibit an insulator-to-metal transition which leads to electrochromic and thermochromic properties, such oxides are very interesting for the design of advanced materials. Indeed, the IMT can be triggered using different stimuli including voltage and heat. Since the vanadium-oxygen bonds are highly ionic in vanadium oxides, the value of 
transition temperature of the IMT strongly depends on the oxidation state of the vanadium ion, i.e., $T_{C}$ increases with oxidation states of the vanadium atom [22]. The resulting phase transitions in vanadium oxides are reversible and are accompanied by changes in structural, magnetic, optical and electrical properties. The structural change is a key factor since it leads to a displacement of the atoms in the crystal lattice and to a redistribution of electronic charges and, hence, the observed physico-chemical properties change [102].

In $\mathrm{V}_{2} \mathrm{O}_{5}$, the Fermi energy, which corresponds to the highest occupied electronic band, is calculated at $1.62 \mathrm{eV}$. This Fermi level is separated from higher conduction band by about $0.6 \mathrm{eV}$ [103] while the valence band is at about $2.7 \mathrm{eV}$. Vanadium pentoxide has an indirect bandgap of $1.7 \mathrm{eV}$ calculated by DFT (Density Functional Theory) but this value is smaller than the experimental one $(2.3 \mathrm{eV})$. This underestimation of the bandgap is a common problem using the DFT. Concerning the indirect $E_{g}$, it is the result of the split-off of oxygen $2 \mathrm{p}$ band up to the vanadium $3 \mathrm{~d}$ band [83]. In addition, there are two discrete intermediate bands (situated within the bandgap) with narrow bandwidth of about $0.7 \mathrm{eV}$ [103], and they can make significant contribution to charge transport phenomena or mediate optical transitions from valence to conduction bands. Concerning the optical and electrical properties, $\mathrm{V}_{2} \mathrm{O}_{5}$ exhibits significant optical anisotropy in the visible region [22]. This anisotropy is due to the bands which are dispersive to various extents, and this is a clear indication of the crystal structure anisotropies. For instance, the electronic conduction within the $a-b$ planes of $\mathrm{V}_{2} \mathrm{O}_{5}$ crystal lattice is considerably higher than that perpendicular to these planes [83]. The electron hopping (resulting from small concentration of $\mathrm{V}^{4+}$ in $\mathrm{V}_{2} \mathrm{O}_{5}$ ) is much easier within the $a-b$ planes due to the shorter distances between vanadium atoms compared to the perpendicular direction to these planes. This leads to in-plane/out-of-plane conduction anisotropy [83]. In the form of films, the electrical conductivity of $\mathrm{V}_{2} \mathrm{O}_{5}$ remains low (from $10^{-2}$ to $10^{-3} \mathrm{~S} \cdot \mathrm{cm}^{-1}$ ) [104]. Apart from the anisotropic behavior observed in vanadium pentoxide, the presence of dispersive bands is also an indication of strong hybridization, since the more bands are dispersive, the stronger is the hybridization, and vice versa. In addition, in the semiconducting state, vanadium pentoxide exhibits high transmittance in near-UV and blue part of the visible spectrum, and low transmittance in near-IR and red part of the visible spectrum. The most known/popular property associated with $\mathrm{V}_{2} \mathrm{O}_{5}$ is its electrochromic effect, which can produce series of different colours of the material. Concerning the electrochemical properties of $\mathrm{V}_{2} \mathrm{O}_{5}$, the voltammograms of $\mathrm{V}_{2} \mathrm{O}_{5}$ films exhibit only one couple of redox peaks at around $0.70 \mathrm{~V}$ and $-0.4 \mathrm{~V}$, and these peaks are ascribed to the $\mathrm{V}^{5+} / \mathrm{V}^{4+}$ pair (the voltammograms were obtained at a scan rate of $0.030 \mathrm{~V} \cdot \mathrm{s}^{-1}$ over a potential range of $\pm 1 \mathrm{~V}$ ). As the number of deposited layers increases, the produced current linearly increases as well as the optical modulation. Indeed, a voltage of $-1 \mathrm{~V}$ is required to color the films while the color is subsequently bleached under a voltage of $1 \mathrm{~V}$. The electrochromic transitions in $\mathrm{V}_{2} \mathrm{O}_{5}$ films have an excellent reversibility [105]. However, it is difficult to classify $\mathrm{V}_{2} \mathrm{O}_{5}$ in the cathodic or anodic electrochromism category. The cathodic electrochromism refers to a decrease in transmittance caused by charge injection (the case of Ti and W oxides), while anodic electrochromism refers to an increase in the transmittance (for instance $\mathrm{Cr}, \mathrm{Mn}$, and Fe oxides). Vanadium pentoxide is unique since it exhibits a transmittance increase in the near-UV and blue part of the visible spectrum and, simultaneously, a transmittance decrease in the near-IR and red part of the visible by charge injection [106]. The charge injection in $\mathrm{V}_{2} \mathrm{O}_{5}$ can be performed by intercalation into the van der Waals planes of small cation such as $\mathrm{H}^{+}, \mathrm{Li}^{+}$, and $\mathrm{Na}^{+}$, which cause electrochemical charge transfer reactions. The electrochromic properties of $\mathrm{V}_{2} \mathrm{O}_{5}$ have been developed for the design smart windows. On the other hand, vanadium pentoxide is also a thermochromic material with a transition at $530 \mathrm{~K}$ [107]. The resulting IMT is only observed when $\mathrm{V}_{2} \mathrm{O}_{5}$ is deposited in the form of thin films (nanostructure effect). However, the observed transition does not involve structural change. In the bulk phase, there is not IMT since vanadium pentoxide remains semiconducting at all temperatures [108]. 
In $\mathrm{VO}_{2}$, the metallic rutile and the monoclinic insulating phases have a Fermi level at almost the same energy level, i.e., $7.47 \mathrm{eV}$, and $7.44 \mathrm{eV}$, respectively [22]. Vanadium dioxide is transparent in the IR region above $T c$ and the optical transmittance changes by about two orders of magnitude during the transition [109]. The IR transmittance of $\mathrm{VO}_{2}$ exhibits hysteresis loops around the transition temperature: upon heating the optical switching occurs around $80^{\circ} \mathrm{C}$ while upon cooling, it is at about $60^{\circ} \mathrm{C}$. Both phases of $\mathrm{VO}_{2}$ (metallic and insulating) absorb in the visible. Indeed, the material in insulating phase has a brown-yellow color, which turns into reddish-brown when deposited in the form of thin films, while the metallic state exhibits a greenish blue color [110]. The optical and electronic properties of $\mathrm{VO}_{2}$ can be explained by the band theory, where the number of band groups in the insulating phase is exactly the same as in the metallic phase, but in the latter, each band group is doubled. Therefore, in the rutile metallic structure, there is a finite overlapping of valence and conduction bands, which is a characteristic of metallic behavior [22]. In the monoclinic insulating structure, there is a gap of energy between the bands resulting from the oxygen $2 \mathrm{p}$ orbitals and the vanadium $3 \mathrm{~d}$ orbitals. As a consequence, the observed energy band gap $\left(E_{g}\right)$ in the rutile structure is $0.6 \mathrm{eV}$ [111], while for the monoclinic structure, $E_{g}$ is $2.5 \mathrm{eV}$. These properties of $\mathrm{VO}_{2}(\mathrm{M} / \mathrm{R})$ can be also described (and, thus, better understood) using the crystal field theory [22]. In the metallic rutile phase $\left(T>T_{C}\right)$, vanadium (IV) is at the center of an oxygen octahedron. Therefore, in a symmetry point of view, the $3 \mathrm{~d}$ orbitals are split into doubly-degenerated $e_{g}$ and triply-degenerated $t_{2 g}$ levels. The $e_{g}$ orbitals are directed towards the $2 \mathrm{p}$ orbitals of the oxygen ligand and they form the $e_{g}{ }^{\sigma}$ bands in Figure 7. Regarding the monoclinic and rutile symmetries, the $t_{2 g}$ orbitals, which are not directed toward the $2 p$ orbitals of oxygens but between them, form the $e_{g}{ }^{\pi}$ and $a_{1 g}$ bands (Figure 7). The $t_{2 g}$ orbitals are also responsible for pairing between vanadium (IV) creating dimer resulting in the splitting of $a_{1 g}$ into two bands. However, this dimerization effect in the metallic rutile phase is weak and pairing of vanadium (IV) does not happen. That is why the overlapping between $a_{1 g}$ and $e_{g}{ }^{\pi}$ bands occurs at the Fermi level and it results in the metallic properties of rutile $\mathrm{VO}_{2}$ (Figure 7). In the insulating monoclinic phase, the distortion of the lattice results in stronger dimerization effect between vanadium (IV) pairs, thus splitting the $a_{1 g}$ into two bands without overlap between $a_{1 g}$ and $e_{g}{ }^{\pi}$ at Fermi level (Figure 7). In addition, in the monoclinic phase, the $e_{g}{ }^{\pi}$ band is destabilized by V-O overlapping and thus pushes this band upwards from the Fermi level [112,113].

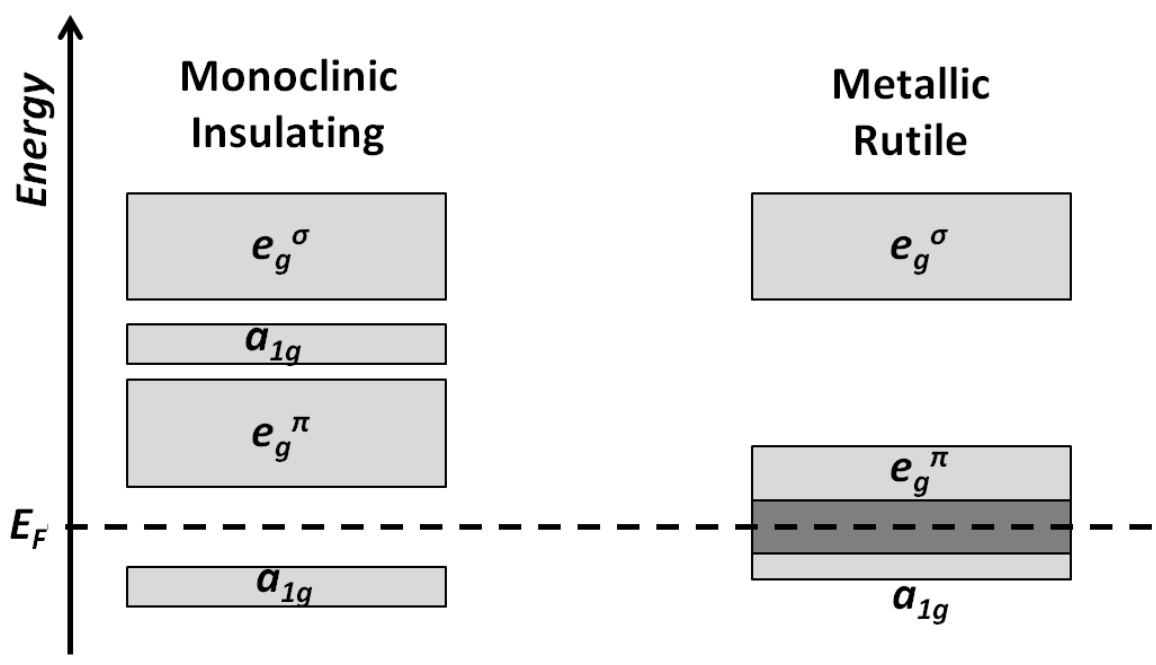

Figure 7. Energy diagrams of monoclinic insulating and metallic rutile phases of $\mathrm{VO}_{2}$.

Concerning the optical properties, $\mathrm{VO}_{2}$ shows significant anisotropy in the infrared region [22]. Similar to $\mathrm{V}_{2} \mathrm{O}_{5}, \mathrm{VO}_{2}$ can also change its optical properties in a persistent and reversible way in response to a voltage [114]. Although $\mathrm{VO}_{2}$ is electrochromic, it is 
rather used as thermochormic materials with an IMT at $340 \mathrm{~K}$ [115], since $\mathrm{V}_{2} \mathrm{O}_{5}$ exhibits better electrochromic performance. In addition, the optical excitation through laser pulses is also an effective method (compared to excitation using heat gradient, i.e., by change of temperature) to control the phase transition in $\mathrm{VO}_{2}(\mathrm{M} / \mathrm{R})$ [116]. Indeed, laser pulses of sufficiently high energy could trigger a non-thermal sub-picosecond structural phase transition [117]. During this optical excitation, electrons are promoted from the VB to the $\mathrm{CB}$ of $\mathrm{VO}_{2}$. Subsequently, the collapse of the band gap occurs, thus leading to the transition into metallic phase. After depopulation of the $e_{g}{ }^{\sigma}$ bonding orbitals, the reversible transition occurs.

On the other hand, the strains present in $\mathrm{VO}_{2}$ is also a way to regulate the physical and chemical properties of the $\mathrm{VO}_{2}(\mathrm{M} / \mathrm{R})$ material. Indeed, deposited in the form of films, the source of strain is from the lattice and elastic mismatches between the $\mathrm{VO}_{2}$ material and the substrate. According to the relative size of the mismatch, the strain can be divided into tensile stress and compressive stress. For $\mathrm{VO}_{2}$ thin films, the induced strain can effectively adjust the IMT due to the presence of lattice mismatch between the sample and the substrate, thus causing a change of the transition point of $\mathrm{VO}_{2}$ IMT [118]. In addition to the different physical excitation detailed just above, the doping is also an effective method to affect the IMT in $\mathrm{VO}_{2}(\mathrm{M} / \mathrm{R})$ by either decreasing or increasing $T_{C}$ [117]. Doping is a typical chemical method to control the carrier concentration in semiconducting materials by insertion of discrete energy levels within the energy band gap. Depending on the nature of the doped elements (i.e., p- or n-type dopants), electrons injection (in the conduction band) or holes injection (in the valence band) in the host material is performed. In the case of W (VI) doping which has a much larger size than vanadium, injection of electrons in the parent materials occurs as well as an additional effect: the induction of lattice strain. This structural change plays an important role in the decrease of the phase-transition temperature [119]. Indeed, the insertion of $W$ atoms not only breaks the lattice symmetry but also increases the spacing between the metal cations [120]. On the other hand, lowvalence metal ions such as $\mathrm{Cr}^{3+}, \mathrm{Ga}^{3+}$, and $\mathrm{Al}^{3+}$ are used to increase the temperature of the $\mathrm{VO}_{2}$ phase transition $[121,122]$.

Another possibility to induce IMT transition is the use of an electric field through the Joule heating effect (from leakage/loss of current) [117]. However, it is important to rule out the electric and thermal effects from other processes. By applying an electric field transverse to the material's interface with a gate electrode, i.e., metal oxide semiconductor field effect transistor (MOSFET) (Figure 8), it is observed that the IMT is suppressed at high bias [73].

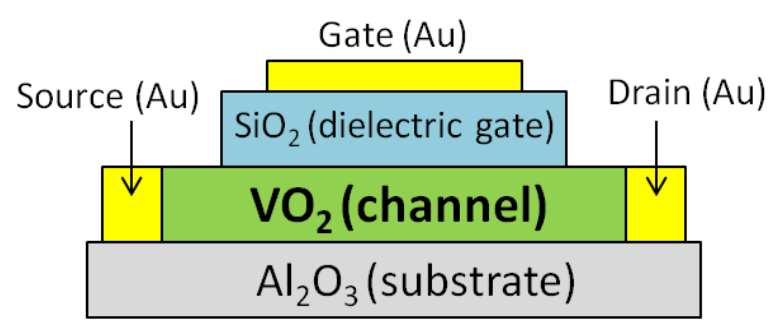

Figure 8. Scheme of a MOSFET using thermochromic $\mathrm{VO}_{2}$.

In $\mathrm{V}_{2} \mathrm{O}_{3}$, a striking IMT occurs at $150 \mathrm{~K}$ which is marked by a jump in the resistivity by seven orders of magnitude and an antiferromagnetic ordering of spins. $\mathrm{V}_{2} \mathrm{O}_{3}$ also shows electrochromism with a transition at about $160 \mathrm{~K}$. The Fermi level of $\mathrm{V}_{2} \mathrm{O}_{3}$ is at $9.2 \mathrm{eV}$ while the observed energy gap is about $0.66 \mathrm{eV}$. At temperature below $150 \mathrm{~K}$, vanadium trioxide exists in its insulating phase with a monoclinic structure [72]. At a temperature above $150 \mathrm{~K}$, the high-temperature paramagnetic $\mathrm{V}_{2} \mathrm{O}_{3}$ phase exists with a corundum crystal structure that exhibits metallic behavior. Therefore, at room temperature, there is a finite overlapping of valence and conduction bands, thus giving its metallic behavior of the corundum structure. Similar to $\mathrm{VO}_{2}$, the crystal field, which is generated by the 
oxygen on vanadium in the octahedra $\left[\mathrm{VO}_{6}\right]$, leads to the splitting of the d-orbitals into two sets of bands: $t_{2 g}$ (lower band) and $e_{g}{ }^{\sigma}$ (upper band). In $\mathrm{V}_{2} \mathrm{O}_{3}$, the upper band is doubly degenerated and it consists in fact of $d_{x z}$ and $d_{y z}$ bands. Concerning the lower band, the noncubic arrangement of vanadium ions in the lattice combined with the trigonal distortion leads to the degeneration of $t_{2 g}$ orbitals into $a_{1 g}$ singlet $\left(d_{3 z 2-r 2}\right)$ and doubly-degenerated $e_{g}{ }^{\pi}$ bands $\left(d_{x y}\right.$ and $\left.d_{x 2-y 2}\right)$ as shown in Figure 9 [123]. In the insulating monoclinic phase, the symmetry of the crystal field is lower than in corundum phase. Therefore, the $a_{1 g}$ and $e_{g}{ }^{\pi}$ bands are split, thus creating an energy gap between $a_{1 g}$ and $e_{g}{ }^{\pi}$ bands while, in the metallic corundum phase, the $a_{1 g}$ and $e_{g}{ }^{\pi}$ bands overlap at the Fermi level (Figure 9) [124].

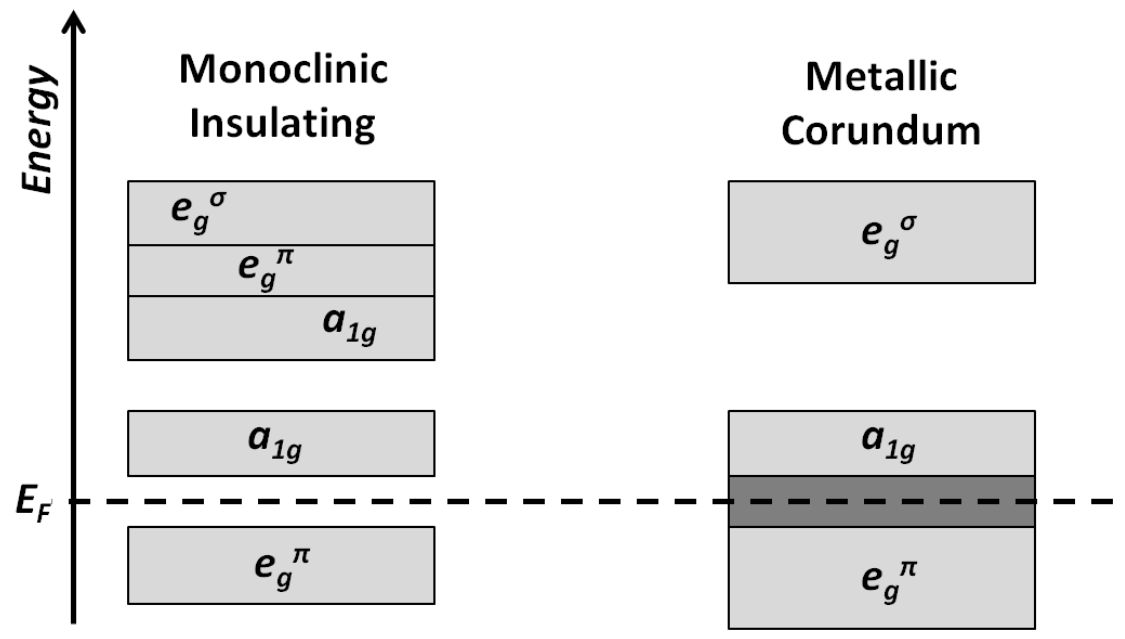

Figure 9. Energy diagrams of monoclinic insulating and metallic corundum phases of $\mathrm{V}_{2} \mathrm{O}_{3}$.

It is worth noting that the degree of anisotropy in binary vanadium oxides of single vanadium valence increases in the following order: $\mathrm{V}_{2} \mathrm{O}_{3}<\mathrm{VO}_{2}<\mathrm{V}_{2} \mathrm{O}_{5}$. Finally, vanadium monoxide (VO) also exists but it is usually a non-stoichiometric oxide. Vanadium monoxide crystallizes in cubic rock salt structure $(\mathrm{NaCl})$ where all the $\left[\mathrm{VO}_{6}\right]$ distorted octahedra are connected by the edges [125].

\subsubsection{Binary Vanadium Oxides with Mixed Valence States}

The oxides of the general formula $\mathrm{V}_{n} \mathrm{O}_{(2 n+1)}$, i.e., the Wadsley phases, exist between $\mathrm{V}_{2} \mathrm{O}_{5}$ and $\mathrm{VO}_{2}$. This means that these phases have a mixture of vanadium (IV) and (V) because of oxygen vacancies. On the other hand, the Magnéli phases, i.e., oxides of the general formula $\mathrm{V}_{n} \mathrm{O}_{(2 n-1)}$, point out the vanadium oxides which exist between $\mathrm{VO}_{2}$ and $\mathrm{V}_{2} \mathrm{O}_{3}$. This means that these phases have a mixture of vanadium (IV) and (III). The compounds of Magnéli and Wadsley series are intermediate oxides with vanadium in a mixed valence state formed from slabs of rutile-like structure sharing faces [126]. This is also known as the "shear structure" concept. These binary vanadium oxides have interesting electromagnetic properties due to strong electron correlation. It includes the insulator-to-metal transition (IMT), which is one of the most important parameters in strongly correlated electron systems [126]. In the Magnéli phases, i.e., oxides between $\mathrm{V}_{2} \mathrm{O}_{3}$ and $\mathrm{VO}_{2}$, the arrangement of atomic planes in the rutile $\mathrm{VO}_{2}$ structure is $[A B A B \ldots]$, where $A=\mathrm{O}$ and $B=\mathrm{VO}$. By applying the shear operations which are (i) to periodically eliminate one $A$-plane every $n B$-planes, and (ii) to close the resulting gaps by operating a shear vector, the formula $n \mathrm{VO}+(n-1) \mathrm{O}=\mathrm{V}_{n} \mathrm{O}_{(2 n+1)}$ is obtained [126]. The structure of Magnéli phases includes $n \mathrm{VO}_{2}$ units between shear planes. Until now, six compounds ( $n=$ from 3 to 8 ) have been isolated. Almost all $\mathrm{V}_{n} \mathrm{O}_{(2 n+1)}$ compounds $(n=4,5,6,8)$ show an IMT accompanied by sharp reduction of the magnetic susceptibility due to the formation of spin-singlet $\mathrm{V}^{4+}-\mathrm{V}^{4+}$ pairs in the low temperature insulating phase [126]. For $n=3$ and 7, the insulating compound $\mathrm{V}_{3} \mathrm{O}_{5}$ has an antiferromagnetic state below $T_{N}=75 \mathrm{~K}$, 
while the metallic compound $\mathrm{V}_{7} \mathrm{O}_{13}$ has a rare antiferromagnetic groundstate [126]. On the other hand, in the Wadsley series which contain oxides between $\mathrm{VO}_{2}$ and $\mathrm{V}_{2} \mathrm{O}_{5}$, only two compounds, $\mathrm{V}_{3} \mathrm{O}_{7}$ and $\mathrm{V}_{6} \mathrm{O}_{13}$, have been obtained in both powder and single crystal [126]. In addition, the $\mathrm{V}_{n} \mathrm{O}_{(2 n+1)}$ compounds exhibit interesting electronic properties like $\mathrm{V}_{2} \mathrm{O}_{5}$, i.e., electron hopping [126].

The structure of $\mathrm{V}_{6} \mathrm{O}_{13}$ can be explained by the shear structure concept and this vanadium oxide undergoes insulator-to-metal transition at $-123{ }^{\circ} \mathrm{C} . \mathrm{V}_{6} \mathrm{O}_{13}$ contains a mixture of vanadium at a valence of $+\mathrm{IV}$ and $+\mathrm{V}$, which is beneficial to the electronic conductivity. At room temperature, i.e., high temperature phase, $\mathrm{V}_{6} \mathrm{O}_{13}$ is in its metallic state with a layered structure belonging to space group $\mathrm{C} 2 / \mathrm{m}$. In the low temperature insulating state, the structure of $\mathrm{V}_{6} \mathrm{O}_{13}$ belongs to space group $P 2_{1} / a$. In addition to its IMT, $\mathrm{V}_{6} \mathrm{O}_{13}$ also exhibits an antiferromagnetic transition [126]. As mentioned above, the IMT in $\mathrm{V}_{6} \mathrm{O}_{13}$ is accompanied by a sharp reduction of magnetic susceptibility, which highlights the formation of spin-singlet $\mathrm{V}^{4+}-\mathrm{V}^{4+}$ pairs in the insulating phase. $\mathrm{V}_{6} \mathrm{O}_{13}$, as most of the Wadsley compounds (including $\mathrm{V}_{2} \mathrm{O}_{5}, \mathrm{~V}_{6} \mathrm{O}_{13}, \mathrm{~V}_{3} \mathrm{O}_{7}$, and $\mathrm{VO}_{2}(\mathrm{~B})$ ), are promising materials for cathodes in rechargeable Li-ion batteries (LIBs) mainly due to their stable layered structure but also to their high specific capacity [126,127]. Furthermore, $\mathrm{V}_{6} \mathrm{O}_{13}$ has additional advantages such as higher rate capability, better reversible capacity, smaller volume expansion and safer lithiation potential. Indeed, at room temperature, $\mathrm{V}_{6} \mathrm{O}_{13}$ could manage high rate of charge and discharge because of the metallic character of this oxide at ambient temperatures. In term of molar ratio of inserted lithium ions into the layered material, the theoretical specific capacity of the cathode material is $8 \mathrm{~mol} \mathrm{Li}^{+}$in $1 \mathrm{~mol} \mathrm{~V}_{6} \mathrm{O}_{13}$. However, the preparation of $\mathrm{V}_{6} \mathrm{O}_{13}$ is complicated to achieve owing to the valence fluctuation of vanadium atoms, i.e., it is hard to control the ratio between +IV and $+\mathrm{V}$ valence states [77].

Concerning $\mathrm{V}_{3} \mathrm{O}_{7}$, it is also an intermediate phase between $\mathrm{VO}_{2}$ and $\mathrm{V}_{2} \mathrm{O}_{5}$ which is often reported in the literature as hydrate compound $\left(\mathrm{V}_{3} \mathrm{O}_{7} \cdot \mathrm{H}_{2} \mathrm{O}\right)$ at room temperature, i.e., in its insulating phase [128]. $\mathrm{V}_{3} \mathrm{O}_{7}$ is a mixed valence oxide with a ratio of $\mathrm{V}^{4+} / \mathrm{V}^{5+}=0.5$. This vanadium oxide has a bandgap of $2.5 \mathrm{eV}$ at room temperature, and it is rather considered as a semiconductor as most of the vanadium oxides in their insulating phase [129]. The structure of crystalline $\mathrm{V}_{3} \mathrm{O}_{7} \cdot \mathrm{H}_{2} \mathrm{O}$ is orthorhombic with a space group Pnam $[127,128]$. This phase has a layered structure similar to orthorhombic $\mathrm{V}_{2} \mathrm{O}_{5}$ since $\mathrm{V}_{3} \mathrm{O}_{7} \cdot \mathrm{H}_{2} \mathrm{O}$ is mostly prepared from vanadium $(\mathrm{V})$ oxide [127]. $\mathrm{V}_{3} \mathrm{O}_{7} \cdot \mathrm{H}_{2} \mathrm{O}$ is composed of layers of $\left[\mathrm{VO}_{6}\right.$ ] octahedra and $\left[\mathrm{VO}_{5}\right]$ trigonal bipyramids sharing corners $[126,128,129]$. In the structure of $\mathrm{V}_{3} \mathrm{O}_{7} \cdot \mathrm{H}_{2} \mathrm{O}$, the water molecule is bound to vanadium by replacing one of the oxygen atoms in the $\left[\mathrm{VO}_{6}\right]$ octahedron, thus forming hydrogen bonds with the octahedron in the next layer which gives a $3 \mathrm{D}$ structure [128]. Like $\mathrm{V}_{6} \mathrm{O}_{13}, \mathrm{~V}_{3} \mathrm{O}_{7} \cdot \mathrm{H}_{2} \mathrm{O}$ is also a promising cathode material in LIBs since these materials have high initial capacity which is closely related to their layered structure together with the presence of mixed valence states of vanadium ions [127]. In addition, $\mathrm{V}_{3} \mathrm{O}_{7} \cdot \mathrm{H}_{2} \mathrm{O}$ exhibits excellent electrochromic performance because of optical modulation in both anodic and cathodic reactions, thus making $\mathrm{V}_{3} \mathrm{O}_{7} \cdot \mathrm{H}_{2} \mathrm{O}$ an excellent candidation cathode material for electrochromic applications [129]. For instance, in the form of films, $\mathrm{V}_{3} \mathrm{O}_{7} \cdot \mathrm{H}_{2} \mathrm{O}$ can switch reversibly between a reduced blue state (at $-1.2 \mathrm{~V}$ ) and an oxidized orange state (at $+1.9 \mathrm{~V})$ [130]. These reversible changes are accompanied by changes of reflectance, especially at $590 \mathrm{~nm}$. Therefore, similar to $\mathrm{V}_{2} \mathrm{O}_{5}, \mathrm{~V}_{3} \mathrm{O}_{7} \cdot \mathrm{H}_{2} \mathrm{O}$ is characterized by a typical muli-electrochromism but with faster kinetics. The fast kinetics observed in the $\mathrm{V}_{3} \mathrm{O}_{7} \cdot \mathrm{H}_{2} \mathrm{O}$ film can be explained by its unique structure combined with mixed valence states of $\mathrm{V}(\mathrm{V})$ and $\mathrm{V}(\mathrm{IV})$. That contributes to higher electronic conductivity and more active redox sites during the reduction and oxidation processes [130]. On the other hand, non-hydrated $\mathrm{V}_{3} \mathrm{O}_{7}$ has received less attention than its hydrate form. This fact is mainly due to its metastable behavior. Indeed, the non-hydrated phase can be formed by heat treatment of $\mathrm{V}_{3} \mathrm{O}_{7} \cdot \mathrm{H}_{2} \mathrm{O}$ which leads to removal of the water molecule starting at $75^{\circ} \mathrm{C}$ and finishing at about $305^{\circ} \mathrm{C}$. However, the formed $\mathrm{V}_{3} \mathrm{O}_{7}$ is metastable and plays the role of growing seeds for the formation of $\mathrm{V}_{2} \mathrm{O}_{5}$. In orther words, although $\mathrm{V}_{3} \mathrm{O}_{7} \cdot \mathrm{H}_{2} \mathrm{O}$ 
can be prepared from $\mathrm{V}_{2} \mathrm{O}_{5}$, its heating in air gives rise to both dehydration and oxidation into $\mathrm{V}_{2} \mathrm{O}_{5}$. It is possible to synthesize directly $\mathrm{V}_{3} \mathrm{O}_{7}$ (with a stable structure) by using spray pyrolysis technique on substrate heated at $400{ }^{\circ} \mathrm{C}$ [129]. The crystalline phase of $\mathrm{V}_{3} \mathrm{O}_{7}$ has a monoclinic structure belonging to space group Pmmn [129]. In addition, $\mathrm{V}_{3} \mathrm{O}_{7}$ exhibits higher intercalation capability, fast switching intercalation/extraction rate and better reversibility than $\mathrm{V}_{2} \mathrm{O}_{5}$ [129].

Another interesting phase in the Wadsley series is $\mathrm{V}_{4} \mathrm{O}_{9}$. The synthesis of this $\mathrm{V}_{n} \mathrm{O}_{(2 n+1)}$ with $n=4$ is a real challenge since it has a formal valence ratio $\mathrm{V}^{4+} / \mathrm{V}^{5+}=1$. In addition, $\mathrm{V}_{4} \mathrm{O}_{9}$ is a special compound in the Wadsley series in the sense that its structure and properties are still not clear (although its existence has been recognized), thus, this phase is often called "the missing link" in binary vanadium oxides [126]. Usually, $\mathrm{V}_{4} \mathrm{O}_{9}$ is synthesized by a solid state reaction in a reducing atmosphere of an appropriate mixture of binary vanadium oxides with single valence state: $\mathrm{V}_{2} \mathrm{O}_{5}$ and $\mathrm{V}_{2} \mathrm{O}_{3}$ (or $\mathrm{VO}_{2}$ ). As reducing agents, carbon and $\mathrm{SO}_{2}$ are the most used and the synthesis is carried out under ultra-high vacuum. However, the best method to prepare single phase $\mathrm{V}_{4} \mathrm{O}_{9}$ is by using sulfur (S) as a reducing agent (Equation (10)), but an excess of $\mathrm{S}$ leads to the formation of $\mathrm{VO}_{2}(\mathrm{~B})$ phase [126]. The structure of $\mathrm{V}_{4} \mathrm{O}_{9}$ is not a plane fault type but a tunnel defect type. The crystal system of $\mathrm{V}_{4} \mathrm{O}_{9}$ is orthorhombic and belongs to the space group Cmcm. Since $\mathrm{V}_{4} \mathrm{O}_{9}$ is prepared from $\mathrm{V}_{2} \mathrm{O}_{5}$ reduction where an excess of reductant gives $\mathrm{VO}_{2}(\mathrm{~B})$, this suggests that $\mathrm{V}_{4} \mathrm{O}_{9}$ has a layered structure similar to those from $\mathrm{V}_{2} \mathrm{O}_{5}$ and $\mathrm{VO}_{2}(\mathrm{~B})$.

$$
4 \mathrm{~V}_{2} \mathrm{O}_{5}+\mathrm{S} \rightarrow 2 \mathrm{~V}_{4} \mathrm{O}_{9}+\mathrm{SO}_{2}
$$

To better explain the structure of $\mathrm{V}_{4} \mathrm{O}_{9}$, the shear structure concept can be used. The lattice of $\mathrm{V}_{2} \mathrm{O}_{5}$ is formed of layers of $\left[\mathrm{V}_{2} \mathrm{O}_{3}\right]$ (called " $a$ ") which are stacked and sharing $\left[\mathrm{O}_{2}\right]$ units in the $c$-direction (layers called " $b$ "), thus $\mathrm{V}_{2} \mathrm{O}_{5}$ has a layered structure of $\left[\mathrm{VO}_{5}\right]$ pyramids-up/pyramids-down along the $a b$-plane (Section 3.1.1). Hence, the structure of $\mathrm{V}_{2} \mathrm{O}_{5}$ has the stacking of layers as [ababa ... ] in the c-direction (or parallel to the $a b$ plane). On the other hand, the crystal structure of $\mathrm{VO}_{2}(\mathrm{~B})$ has a [abaaba ... I stacking which can be regarded as a daughter structure of $\mathrm{V}_{2} \mathrm{O}_{5}$. Indeed, this stacking manner of $[a b a a b a \ldots$. $]$ is obtained from $\mathrm{V}_{2} \mathrm{O}_{5}$ stacking by using the following shear operation: to periodically eliminate one $b$-layer every two $a$-layers, so the arrangement is [abaxabaxa ... ] ( $x=$ gap) where the gaps are closed by connecting each [aba]-block, thus giving the stacking manner of [abaabaa ... ]. For $\mathrm{V}_{4} \mathrm{O}_{9}$, it is supposed that its stacking structure has a cleavage plane. This suggests that the $a b$-plane of $\mathrm{V}_{4} \mathrm{O}_{9}$ is a cleavage plane with a lattice similar to that of $\mathrm{V}_{2} \mathrm{O}_{5}$ or $\mathrm{VO}_{2}(\mathrm{~B})$. If the structure of $\mathrm{V}_{4} \mathrm{O}_{9}$ were a shear structure derived from $\mathrm{V}_{2} \mathrm{O}_{5}$, it would have a stacking manner of [abababaabababaab ... ]. This stacking manner is derived by two operations: the periodic elimination of one $b$-layer every four $a$-layers, so the arrangement is [abababaxabababaxab ... ] with closing the gaps and thus obtaining the composition of $8 \mathrm{~V}_{2} \mathrm{O}_{3}+6 \mathrm{O}_{2}=4 \mathrm{~V}_{4} \mathrm{O}_{9}$. However, the observed $c$-parameter is much shorter than the calculated value for the stacking periodicity of [abababaabababaab ... ]. To obtain the composition of $\mathrm{V}_{4} \mathrm{O}_{9}$, half of oxygen atoms should be removed from half of $b$-layers in

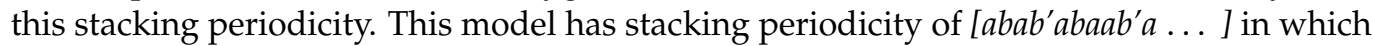
half of oxygen atoms in $b^{\prime}$-layers are deficient in an ordered manner to form tunnel defects. Hence, the composition is $4 \mathrm{~V}_{2} \mathrm{O}_{3}$ (a-layers) $+2 \mathrm{O}_{2}$ (b-layers) $+2 \mathrm{O}$ (b'-layers) $=2 \mathrm{~V}_{4} \mathrm{O}_{9}$ [126] In other words, the obtained structure is composed of $\left[\mathrm{VO}_{5}\right]$ pyramids, $\left[\mathrm{VO}_{6}\right]$ distorted octahedra and $\left[\mathrm{VO}_{4}\right]$ tetrahedra that is very similar to the structure of vanadyl pyrophosphate $(\mathrm{VO})_{2} \mathrm{P}_{2} \mathrm{O}_{7}$ (by replacing $\left[\mathrm{PO}_{4}\right]$ tetrahedra by $\left[\mathrm{VO}_{4}\right]$ tetrahedra). The similarities of $\mathrm{V}_{4} \mathrm{O}_{9}$ to $(\mathrm{VO})_{2} \mathrm{P}_{2} \mathrm{O}_{7}$ are even lager, especially in magnetic properties. Indeed, the excitation gap between the singlet groundstate and the excited triplet state is approximately $73 \mathrm{~K}$. Therefore, the resemblance of magnetic properties between $\mathrm{V}_{4} \mathrm{O}_{9}$ and $(\mathrm{VO})_{2} \mathrm{P}_{2} \mathrm{O}_{7}$ strongly supports the reliability of the structure [126]. 


\subsection{Case of Ternary Vanadium Oxides}

Ternary vanadium oxides are interesting materials since their properties can be tuned according to the third element composing them. In terms of modifying the photoinduced properties of materials, it was observed that metal impurities in homometallic oxide can modify the energy bandgap by the overlapping of outer s- and d-orbitals of the $\mathrm{p}$ - and d-block metals ions, respectively, thus giving rise to smaller energy band gap $\left(E_{g}\right)$ [131]. Therefore, it was assumed that $\mathrm{p}$ - and d-block metals could be used to design single phase heterometallic and nowadays, many visible light-responsive photoactive materials are heterometallic oxides, e.g., ternary and quaternary oxides [131]. Concerning the oxides based on vanadium, one promising class of material is the metal orthovanadates which are composed of $\mathrm{VO}_{4}{ }^{3-}$ tetrahedral. Several orthovanadates including $\mathrm{BiVO}_{4}, \mathrm{FeVO}_{4}$, $\mathrm{Mn}_{3}\left(\mathrm{VO}_{4}\right)_{2}, \mathrm{CeVO}_{4}, \mathrm{NdVO}_{4}$, and $\mathrm{GdVO}_{4}$ have been widely studied during the last decades due to their promising properties and ease of preparation. Other metal vanadates such as, for instance, $\mathrm{Cu}_{2} \mathrm{~V}_{2} \mathrm{O}_{7}, \mathrm{Cu}_{3} \mathrm{~V}_{2} \mathrm{O}_{8}, \mathrm{Co}_{3} \mathrm{~V}_{2} \mathrm{O}_{8}, \mathrm{FeV}_{3} \mathrm{O}_{8}, \mathrm{Ag}_{4} \mathrm{~V}_{2} \mathrm{O}_{7}$ have received also a strong interest from the scientific community. Indeed, these vanadium based oxides can be used in (photo)catalysis, lithium-ion batteries, solar cells, gas sensors, water splitting technologies, optoelectronics, etc. [132-134]. Such an interest for transition metal vanadates is due to their interesting optical, electric and magnetic properties, thus being useful in the above mentioned applications [135]. Although most of the ternary vanadium oxides are not thermochromic and/or electrochromic as the binary vanadium oxides, these transition metal vanadates have attracted considerable attention for environmental applications since they are semiconductors which can be activated under UV or visible light radiations. Therefore, ternary vanadium oxide based materials can trigger photoinduced chemical reactions such as photocatalysis and photo-Fenton process for contaminant removal or photosplitting of water (for $\mathrm{O}_{2}$ and/or $\mathrm{H}_{2}$ production) as discussed in Section 4 [135].

\subsubsection{Bismuth Vanadates}

Bismuth vanadates are ternary oxides which exhibit a wide variety of structures [136]. The most promising one is $\mathrm{BiVO}_{4}$. This oxide is a n-type semiconductor that exists in three polymorphs: monoclinic scheelite-like, tetragonal scheelite-like, and tetragonal zircon-like structures with an energy band gap $\left(E_{g}\right)$ of $2.40,2.34$, and $2.90 \mathrm{eV}$, respectively [137-139]. All these crystal structures are built up with $\left[\mathrm{VO}_{4}\right]$ tetrahedra and $\left[\mathrm{BiO}_{8}\right]$ polyhedra where $\mathrm{V}(\mathrm{V})$ and $\mathrm{Bi}(\mathrm{III})$ are in the center of these units. In both scheelite phases, each $\left[\mathrm{BiO}_{8}\right]$ is surrounded by eight vanadium units, whereas in zircon structure, Bi units are surrounded by only six $\left[\mathrm{VO}_{4}\right][139]$. Comparing the scheelite structures, the difference between monoclinic and tetragonal phases is based on the local environment, where vanadium and bismuth units are more distorted in the monoclinic structure [139]. In addition, a reversible phase transition between monoclinic scheelite-like (low temperature phase) and tetragonal scheelite-like (high temperature phase) structures occurs at $255^{\circ} \mathrm{C}[138,139]$. However, between tetragonal zircon-like and tetragonal scheelite-like structure, an irreversible phase transition is observed at about $400-500{ }^{\circ} \mathrm{C}[138,139]$. Therefore, at room temperature, there are two $\mathrm{BiVO}_{4}$ polymorphs which are stable. Among them, the monoclinic scheelite-like structure exhibits the best photoactivity under solar light, e.g., longer lifetime of photogenerated charge carriers and higher photocurrent. This is due to better photon absorption and charge carrier transport resulting from smaller $E_{g}$ and distorted $\left[\mathrm{VO}_{4}\right]$ and $\left[\mathrm{BiO}_{8}\right]$ units, respectively $[138,139]$.

The crystalline structure and the energy band gap of $\mathrm{BiVO}_{4}$ have an influence on the efficiency of photo-induced processes triggered by this semiconductor, e.g., photocatalytic reactions. However, the exposed crystal facets are maybe more important since they can affect the thermodynamic and the kinetic of a chemical reaction [137]. By designing a particular crystal, the crucial parameters of photo-induced chemical reactions in heterogeneous phase can be tuned such as the preferential adsorption of a reactant, the surface transfer of photo-generated charge carriers and the desorption of products $[137,140]$. In the case of bismuth vanadate where the monoclinic structure is the most photoactive one, the $\{010\}$ 
and $\{110\}$ crystal facets has redox functions since they provide reduction and oxidation sites, respectively, in which photogenerated electrons and holes are available [141,142]. The effect of these crystal facets on the efficiency of $\mathrm{BiVO}_{4}$ in photo-induced processes is often investigated by photoelectrochemical (PEC) and transient absorption spectroscopy (TAS) analyses [143]. PEC measurements could explain the charge carriers' behavior at the surface of $\mathrm{BiVO}_{4}$, especially the surface recombination which could be evaluated by amperometry, i.e., by analyzing the shape of photogenerated current curve at potential near the onset of steady state photocurrent (larger is the current "spike", higher is the recombination). TAS is another powerful tool (which is detailed hereafter) to understand the charge carriers' dynamics including relaxation rate, recombination rate, and mechanism of recombination $[143,144]$. The operation of this fast spectroscopy is based on the excitation of the sample by a pulse followed by the optical measurement (using a spectrophotometer) and the analysis of spectral differences between excited and the ground state levels of the sample as a function of time [144]. Since the delay between excitation and measurement sets the time scales that can be studied, TAS is considered as a fast spectroscopic technique [144]. The advantage of TAS studies resolved in time (compared to PEC studies) is the possibility to investigate the dynamics of photogenerated holes. Indeed, TAS allows the observation of these dynamics where $h^{+}$is responsible, for instance, to water oxidation or generation of hydroxyl radicals while in PEC analysis, the hole dynamics is indirectly deduced from the current signal which is monitored via external circuit. In the future, studies based on transient absorption spectroscopy will surely developed since currently, TAS studies of transition metal oxides are limited $[143,144]$. To date, the dynamics of photogenerated holes in $\mathrm{BiVO}_{4}$ was studied using transient absorption spectroscopy coupled to photoelectrochemical measurement. In such a study (in aqueous medium), the constant of decay time of spectroscopic signal of $h^{+}$is dependent to the applied bias due to kinetic competition between water oxidation and charge carrier recombination. In addition, the time constant for charge carriers' recombination (measured with transient absorption spectroscopy) is different to the time constant of back electron transfer (measured with transient photocurrent measurements using chopped light), thus indicating two distinct recombination processes which limit the photocurrent generation in $\mathrm{BiVO}_{4}$ photoanodes. One recombination process is fast (occurring within microseconds) and assigned to direct bulk electron/hole recombination, while the other one is slow (occurring within milliseconds) and identified as recombination of surface-accumulated holes with bulk electrons. The latter process, also called back electron transfer, can be avoided at strong anodic bias which provides a large energetic barrier to prevent this recombination process [143]. With regard to TAS and PEC analyses of $\mathrm{BiVO}_{4}$ photoanaode, a model of carrier dynamics can be schematized (Figure 10). After the electron/hole separation under simulated solar light, hole trapping process in energy levels closed to VB occurs at 5 picoseconds. At 40 ps and $2.5 \mathrm{~ns}$, electron relaxation and trapping, respectively, are in competition with direct recombination with trapped holes. The relaxation and trapping processes are expected to be dominant over recombination. After $10 \mathrm{~ns}$ to $10 \mu \mathrm{s}$, recombination of trapped charge carriers can occur (Figure 10). In addition, at such time scales, no spectral or kinetic differences are observed between systems under a bias voltage or not, thus indicating that the effects of bias voltage occur on longer time scales [144]. 

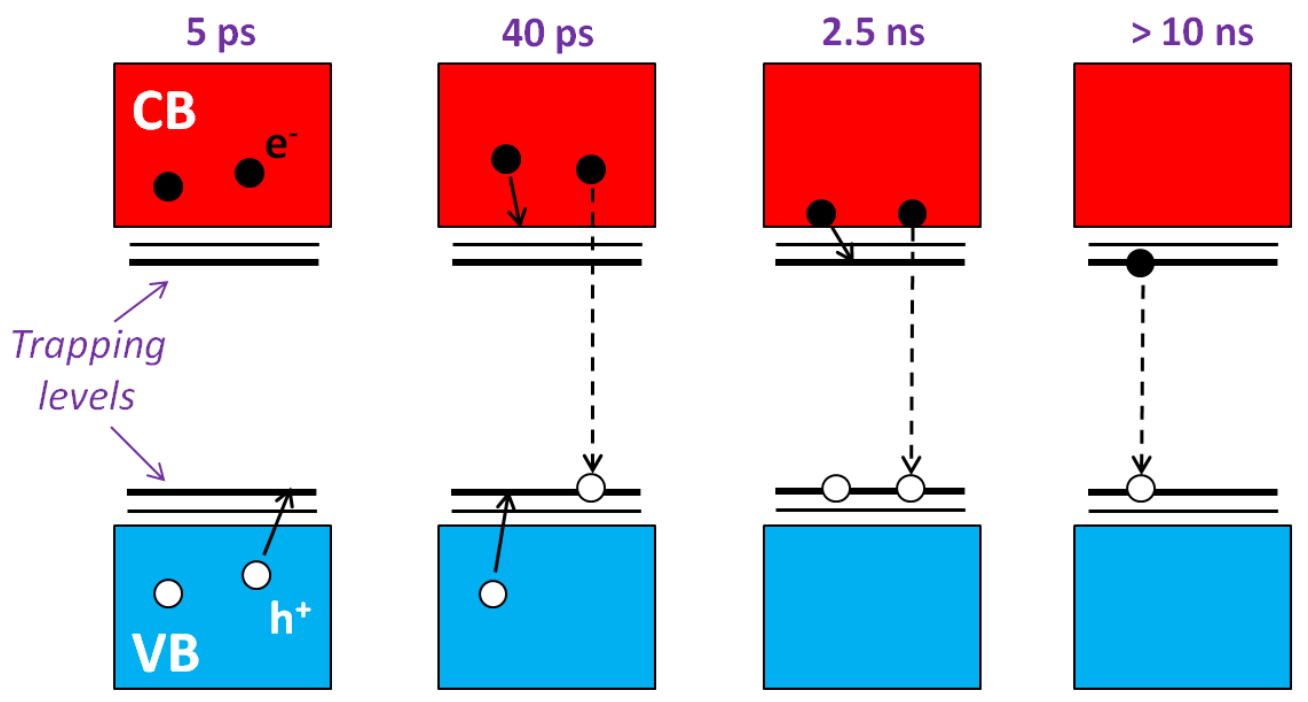

Figure 10. Scheme of charge carriers dynamics within the first stages of $\mathrm{BiVO}_{4}$ photoactivation.

The main advantages of $\mathrm{BiVO}_{4}$ are its non-toxicity and its energy band gap located in the visible region. However, several drawbacks are responsible of the low efficiency of bismuth vanadate in photo-induced chemical reactions such as its poor electron mobility and high $e^{-} / h^{+}$recombination rate $[137,138]$. In addition, $\mathrm{BiVO}_{4}$ has a short hole diffusion length $(70-100 \mathrm{~nm})$ that compromises the optimization of film thickness and light harvesting according to the optical penetration depth principle [138]. All these disadvantages are mainly due to the structure of $\mathrm{BiVO}_{4}$ and the vanadium $3 \mathrm{~d}$ orbitals which constitute the conduction band, since $\left[\mathrm{VO}_{4}\right]$ tetrahedra are not connected to each other and the $\mathrm{V} 3 \mathrm{~d}$ orbitals are strongly localized, respectively [138].

On the other hand, there are many other bismuth vanadates in the ternary system $\mathrm{Bi}-\mathrm{V}-\mathrm{O}$. These bismuth vanadates exhibit different crystalline structures, from which the most known are the Aurivillius-type $\mathrm{Bi}_{4} \mathrm{~V}_{2} \mathrm{O}_{11}$ phase (and also, its reduced form: $\mathrm{Bi}_{4} \mathrm{~V}_{2} \mathrm{O}_{10}$ ) [145-149]. Beside $\mathrm{Bi}_{4} \mathrm{~V}_{2} \mathrm{O}_{11}$, there are also hollandite-type $\mathrm{Bi}_{8} \mathrm{~V}_{2} \mathrm{O}_{17}$ structure, $\mathrm{Bi}_{3.33}\left(\mathrm{VO}_{4}\right)_{2} \mathrm{O}_{2}, \mathrm{Bi}_{2} \mathrm{VO}_{5.5}$, etc. [136]. However, $\mathrm{Bi}_{4} \mathrm{~V}_{2} \mathrm{O}_{11}$ and $\mathrm{Bi}_{3.33}\left(\mathrm{VO}_{4}\right)_{2} \mathrm{O}_{2}$ compounds are the most studied materials in photo-induced processes.

Concerning $\mathrm{Bi}_{3.33}\left(\mathrm{VO}_{4}\right)_{2} \mathrm{O}_{2}$, it crystallizes in the triclinic system (space group $P \overline{1}$ ) with the following lattice parameters: $\mathrm{a}=7.114 \AA \mathrm{A}, \mathrm{b}=7.844 \AA$, $\mathrm{c}=9.372 \AA, \alpha=106.090^{\circ}$, $\beta=94.468^{\circ}$, and $\gamma=112.506^{\circ}$ [136]. This crystal structure could be described by the alternative stacking along the b-axis of two types of layer (layers I and II). The layer I has four distinct Bi sites and $\left[\mathrm{VO}_{4}\right]$ tetrahedra while the layer II has three distinct Bi sites and $\left[\mathrm{VO}_{4}\right]$ tetrahedra. It is worth noting the deformation of coordination environments for all $\mathrm{Bi}$ atoms (due to lone pair of $\mathrm{Bi}^{3+}$ ), but the $\left[\mathrm{VO}_{4}\right]$ tetrahedra remain regular. In the two types of tetrahedral (in $\left.\mathrm{Bi}_{3.33}\left(\mathrm{VO}_{4}\right)_{2} \mathrm{O}_{2}\right)$, the mean $\mathrm{V}-\mathrm{O}$ distance is $1.715 \AA$ which is slightly shorter than $1.74 \AA$ for tetrahedra in $\mathrm{BiVO}_{4}$. About the four Bi atoms in layer I, the coordination number is 8 while for the three Bi atoms in layer II, it is 6 . Therefore, the mean interatomic distances $\mathrm{Bi}-\mathrm{O}$ is between $2.39 \AA$ and $2.61 \AA$ and it is consistent to those in $\mathrm{BiVO}_{4}(2.48 \AA) . \mathrm{Bi}_{3.33}\left(\mathrm{VO}_{4}\right)_{2} \mathrm{O}_{2}$ has a yellow color and its optical band gap is estimated at $2.36 \mathrm{eV}$, which is similar to the monoclinic scheelite $\mathrm{BiVO}_{4}$ [136].

Concerning $\mathrm{Bi}_{4} \mathrm{~V}_{2} \mathrm{O}_{11}$, it is a material which was discovered in the 1980s. It is defined as an intermediate compound in the system $\mathrm{Bi}_{2} \mathrm{O}_{3}-\mathrm{V}_{2} \mathrm{O}_{5}$. This bismuth vanadate material is particularly interesting due to its physical properties, e.g., dielectric properties, ferroelectricity and pyroelectricity at room temperature. The crystalline structure of $\mathrm{Bi}_{4} \mathrm{~V}_{2} \mathrm{O}_{11}$ is the parent structure of the BIMEVOX family materials $(B I=$ bismuth, $M E=$ metal subtitution, $V O X=$ vanadates) which have attractive conduction properties at moderate temperature [146]. $\mathrm{Bi}_{4} \mathrm{~V}_{2} \mathrm{O}_{11}$ has also attracted interest due to its photo-induced properties for organic pollutants removal in water (Section Bismuth Vanadates in Section 4.2.3) [148]. 
$\mathrm{Bi}_{4} \mathrm{~V}_{2} \mathrm{O}_{11}$ exhibits two reversible phase transitions at $430{ }^{\circ} \mathrm{C}$ and at $570{ }^{\circ} \mathrm{C}$ while the melting temperature is $870{ }^{\circ} \mathrm{C}[145,146,148]$. Therefore, there are three phases of $\mathrm{Bi}_{4} \mathrm{~V}_{2} \mathrm{O}_{11}$ which are the low-temperature $\alpha$-form, the intermediate $\beta$-form, and the high-temperature $\gamma$-form which crystallize in the monoclinic, orthorhombic and tetragonal system, respectively [147]. The tetragonal gamma phase belongs to the $I 4 / \mathrm{mmm}$ space group while the orthorhombic beta polymorph has Amam space group [146]. For the alpha $\mathrm{Bi}_{4} \mathrm{~V}_{2} \mathrm{O}_{11}$, it is more complicated to assign a space group since its monoclinic structure is a three-fold supercell [147]. However, the sructure was refined recently in the $A 2$ space group [147]. All these three modifications can be described from a mean orthorhombic subcell having $\mathrm{a}_{\mathrm{m}} \approx 5.53 \AA, \mathrm{b}_{\mathrm{m}} \approx 5.61 \AA$ and $\mathrm{c}_{\mathrm{m}} \approx 15.29 \AA$ (c being the stacking direction). The relationships between the unit cell parameters of the three phases and those of the subcell are: $\mathrm{a}_{\gamma}=$ $b_{\gamma}=a_{m} /(2)^{1 / 2}, c_{\gamma}=c_{m} ; a_{\beta}=2 a_{m}, b_{\beta}=b_{m}, c_{\beta}=c_{m} ; a_{\alpha}=6 a_{m}, b_{\alpha}=b_{m}$ and $c_{\alpha}=c_{m}$ [146]. From a structural point of view, the structure of the three $\mathrm{Bi}_{4} \mathrm{~V}_{2} \mathrm{O}_{11}$ phases is built from $\left[\mathrm{Bi}_{2} \mathrm{O}_{2}\right]^{2+}$ layers separated by vanadium-oxygen deficient perovskite slabs $\left[\mathrm{VO}_{3.5}\right]$ [145]. Therefore, $\mathrm{Bi}_{4} \mathrm{~V}_{2} \mathrm{O}_{11}$ has the general formula $\left[\mathrm{Bi}_{2} \mathrm{O}_{2}\right]\left[A_{m-1} B_{m} \mathrm{O}_{3 m+1}\right]$ consisting of an intergrowth between $\left[\mathrm{Bi}_{2} \mathrm{O}_{2}\right]^{2+}$ sheets and $\left[A_{m-1} B_{m} \mathrm{O}_{3 m+1}\right]^{2-}$ perovskite-like slabs with $m$ as the number of $\left[\mathrm{BO}_{6}\right]$ octahedra stacked along the direction perpendicular to the sheets. Therefore, $\mathrm{Bi}_{4} \mathrm{~V}_{2} \mathrm{O}_{11}$ (or $\mathrm{Bi}_{2} \mathrm{VO}_{5.5}$ ) is the corresponding oxygen deficient structure with $m=1$ i.e., $\left[\mathrm{Bi}_{2} \mathrm{O}_{2}\right]\left[\mathrm{VO}_{3.5} \square_{0.5}\right]$ (“口" symbolizes the oxygen deficiency) [146]. A deepened comparison between the polymorphs, based on their structure and their conductivity, can be also discussed. Structurally, the alpha structure mainly differs from the two high temperature polymorphs by a specific vanadium-oxygen surroundings. Indeed, the vanadium-oxygen slabs exhibit vanadium with three different oxygen environments [147]. About conductive properties, the gamma polymorph has the highest conductivity compared to the two other phases, i.e., $0.2 \mathrm{~S} \cdot \mathrm{cm}^{-1}$ is observed at $600{ }^{\circ} \mathrm{C}$ with a strong drop during the phase transition from gamma to beta and beta to alpha [145]. The conductivity of beta and alpha phases is $0.01 \mathrm{~S} \cdot \mathrm{cm}^{-1}$ at $500{ }^{\circ} \mathrm{C}$ and $10-5 \mathrm{~S} \cdot \mathrm{cm}^{-1}$ at $300{ }^{\circ} \mathrm{C}$, respectively. The observed drop in electrical performance is obviously due to the crystal structure, and particularly to the ordering of the oxygen vacancies in the V-O slabs [145]. These slabs are the components that mainly differ (strucrurally and electrically) from one phase to another [145]. For example, in the gamma phase, there is a large disorder of the oxygen atoms in $\mathrm{V}-\mathrm{O}$ slabs which leads to fast diffusion properties. In addition to the electrical conductivity, $\mathrm{Bi}_{4} \mathrm{~V}_{2} \mathrm{O}_{11}$ has interesting optical properties with an energy band gap of $2.15 \mathrm{eV}$. This low $E_{g}$ makes $\mathrm{Bi}_{4} \mathrm{~V}_{2} \mathrm{O}_{11}$ a promising visible-light-active material in photocatalysis. In addition, since $\mathrm{Bi}_{4} \mathrm{~V}_{2} \mathrm{O}_{11}$ has a layered structure (Aurivillius-related phase), the separation of photogenerated carriers is favored in the stacking direction, thus improving its photocatalytic efficiency. However, within the layers, the photogenerated electrons and holes are easily recombined because of the short band gap (2.15 eV) [149]. Another characteristic of $\mathrm{Bi}_{4} \mathrm{~V}_{2} \mathrm{O}_{11}$ is its ability to be easily reduced and re-oxidized as, for example, through $\mathrm{Bi}_{4} \mathrm{~V}_{2} \mathrm{O}_{10}$. In this reduced phase, there are also high and low temperature polymorphs where the structure of the low temperature one $\left(\alpha-\mathrm{Bi}_{4} \mathrm{~V}_{2} \mathrm{O}_{10}\right)$ is similar to $\alpha-\mathrm{Bi}_{4} \mathrm{~V}_{2} \mathrm{O}_{11}:\left[\mathrm{Bi}_{2} \mathrm{O}_{2}\right]$ and $\left[V \mathrm{O}_{3}\right]$ layers are identified but the latter one, $\left[\mathrm{VO}_{3}\right]$, is built up by $\left[\mathrm{VO}_{5}\right]$ square pyramids sharing basal corners.

\subsubsection{Iron Vanadates}

In the last decade, many scientists have focused on iron vanadates due to their versatile properties (photocatalysis, Fenton-based process, etc.). Among these ternary oxides, $\mathrm{FeVO}_{4}, \mathrm{FeV}_{3} \mathrm{O}_{8}, \mathrm{Fe}_{2} \mathrm{VO}_{4}, \mathrm{FeV}_{2} \mathrm{O}_{4}, \mathrm{Fe}_{2} \mathrm{~V}_{4} \mathrm{O}_{13}, \mathrm{Fe}_{4}\left(\mathrm{VO}_{4}\right)_{4}$ have been successfully synthesized using different routes [134]. Usually, vanadates exhibit higher melting point and lower decomposition rate (at high temperatures) than $\mathrm{V}_{2} \mathrm{O}_{5}$. This is particularly the case of iron vanadates where the incorporation of Fe leads to stabilization of the material, thus decreasing the volatility of $\mathrm{V}$. The most studied iron vanadate is $\mathrm{FeVO}_{4}$ (also called iron orthovanadate) which has a stoichiometric ratio $\mathrm{V}: \mathrm{Fe}=1 . \mathrm{FeVO}_{4}$ is also paramagnetic at room temperature with a saturation magnetization of $0.15 \mathrm{emu} \cdot \mathrm{g}^{-1}$ [132]. This stoichiometric iron vanadate exhibits four different phases usually labeled as $\mathrm{FeVO}_{4}-\mathrm{I}, \mathrm{FeVO}_{4}$-II, 
$\mathrm{FeVO}_{4}$-III, and $\mathrm{FeVO}_{4}$-IV. The $\mathrm{FeVO}_{4}$-I polymorph is the only stable phase formed at room temperature while other ones are all metastable phases formed at high pressures and/or high temperatures. Pure $\mathrm{FeVO}_{4}$-I crystallizes in triclinic system with space group P $\overline{1}$ [133]. Structurally, this polymorph is built from distorted $\left[\mathrm{FeO}_{6}\right]$ octahedra and distorted $\left[\mathrm{FeO}_{5}\right]$ trigonal bipyramids linked together according the following sequence: two octahedra and one trigonal bypiramid. These Fe-O polyhedra are arranged in doubly-bent chains which are joined together by $\left[\mathrm{VO}_{4}\right]$ tetrahedral in order to form a 3D framework. The other forms of iron orthovanadates, i.e., $\mathrm{FeVO}_{4}$-II, -III, and -IV, crystallize in the orthorhombic $\mathrm{CrVO}_{4}$, orthorhombic $\alpha-\mathrm{PbO}_{2}$ and monoclinic wolframite $\mathrm{NiWO}_{4}$ structures, respectively $[150,151]$. It is worth noting that hydrated $\mathrm{FeVO}_{4}$ is amorphous, but after prolonged reaction time at normal pressure and low temperature, crystalline monoclinic $\mathrm{FeVO}_{4} \cdot x \mathrm{H}_{2} \mathrm{O}$ can be obtained. Concerning the physico-chemical properties of crystalline $\mathrm{FeVO}_{4}$-I, it is a stable n-type semiconductor with a narrow energy band gap $\left(E_{g}\right)$. The $E_{g}$ has been estimated between 2.70 (direct) and 2.05 (indirect) $\mathrm{eV}$ depending on the synthesis parameters and the size and morphology of the prepared material [150-154]. The energetic position of the conduction band is above zero and more precisely at $-0.4 \mathrm{eV}$ [155]. This means that $\mathrm{FeVO}_{4}$ semiconductor can theoretically produce hydrogen $\left(E^{0}\left(H^{+} / H_{2}\right)=0 \mathrm{~V}\right)$ under appropriate irradiation $\left(h \nu>E_{g}\right)$, and the theoretical STH (solar-to-hydrogen) efficiency is relatively high (16\%). Concerning the photophysical properties, the photocurrent density in undoped $\mathrm{FeVO}_{4}$ is low (less than $0.1 \mathrm{~mA} \cdot \mathrm{cm}^{-2}$ ) at $1.23 \mathrm{~V}$ vs. RHE (reversible hydrogen electrode) [154]. However, to improve the photophysical properties of $\mathrm{FeVO}_{4}$, synthesis of nanostructured materials and their modification using dopants can increase the specific surface area and improve the electronic properties (by modifying the band structure of $\mathrm{FeVO}_{4}$ ), respectively [156]. In the case of Mo-doped $\mathrm{FeVO}_{4}$, the photocurrent under simulated solar irradiation increases with increasing the dopant concentration with a maximum value of $0.2 \mathrm{~mA} \cdot \mathrm{cm}^{-2}$ for $2 \%$ of Mo at $1.6 \mathrm{~V}$ vs. RHE [154]. The produced photocurrent is improved of about $90 \%$ compared to undoped $\mathrm{FeVO}_{4}$. At higher percentage of Mo, the photocurrent decreases since the presence of high amount of intrinsic defects act as recombination centers. Regarding the IPCE, 2\% Mo-doped $\mathrm{FeVO}_{4}$ exhibits an efficiency of $7 \%$ at $400 \mathrm{~nm}$, while it is only $1 \%$ for undoped $\mathrm{FeVO}_{4}$ at the same experimental conditions. Since the IPCE remains low at longer wavelength, the direct band gap appears to contribute more to the photocurrent than the indirect $E_{g}$ [154]. In order to enhance the electronic properties without the use of dopants, quaternary oxides can be designed. Indeed, bismuth-substituted iron vanadate $\left(\mathrm{Fe}_{1-x} \mathrm{Bi}_{x} \mathrm{VO}_{4}\right)$ has improved charge carrier mobility and exhibits a shift of $E_{g}$ towards higher energies with an increase of Bi content [154]. However, during the synthesis of either pristine or modified iron vanadates, particular attention is required to limit the formation of secondary phases like $\mathrm{Fe}_{2} \mathrm{~V}_{4} \mathrm{O}_{13}$ [154]. Concerning metastable $\mathrm{FeVO}_{4}$ phases, few works are reported but $\mathrm{FeVO}_{4}$-II has shown better properties than stable $\mathrm{FeVO}_{4}$-I in gas sensing and photocatalytic activity. Indeed, metastable phases usually exhibit unique properties which are better than the pure phase. Such a fact is also observed in the case of vanadium oxides with metasable $\mathrm{VO}_{2}(\mathrm{~B})$ which has better photo-induced properties than stable $\mathrm{VO}_{2}(\mathrm{M})$, especially in the degradation of organic pollutants. Finally, although there are numerous PEC studies of $\mathrm{FeVO}_{4}$, TAS has not been performed yet, in contrary to one of the most popular vanadate, $\mathrm{BiVO}_{4}$ (Section 3.2.1).

Another widely studied iron vanadate is $\mathrm{Fe}_{2} \mathrm{~V}_{4} \mathrm{O}_{13}$. This compound has a monoclinic structure which consists of tetrahedrally coordinated $\left[\mathrm{VO}_{4}\right]$ and octahedrally coordinated $\left[\mathrm{Fe}_{2} \mathrm{O}_{10}\right]$ units, where tetrahedra are linked to octahedra through edge sharing, thus forming an unusual horseshoe-like chain structure $[157,158]$. It is quite difficult to prepare pure $\mathrm{Fe}_{2} \mathrm{~V}_{4} \mathrm{O}_{13}$ since $\mathrm{FeVO}_{4}$ is always observed as an impurity. In addition, during the crystallization of $\mathrm{Fe}_{2} \mathrm{~V}_{4} \mathrm{O}_{13}$ (from the amorphous material), the specific surface area of $\mathrm{Fe}_{2} \mathrm{~V}_{4} \mathrm{O}_{13}$ calculated by BET was found to significantly decrease from 52 to $22 \mathrm{~m}^{2} \cdot \mathrm{g}^{-1}$ while the color of the material changed from brown to light green [159]. In the structure of $\mathrm{Fe}_{2} \mathrm{~V}_{4} \mathrm{O}_{13}$, there is the presence of holes and channels which are interesting for many applications. Indeed, this iron vanadate has been investigated as an efficient cathode for lithium ion batteries as 
well as catalyst for either photooxidation of organic pollutants or photoreduction of $\mathrm{CO}_{2}$. For $\mathrm{LIB}, \mathrm{Fe}_{2} \mathrm{~V}_{4} \mathrm{O}_{13}$ can deliver a discharge capacity of about $154 \mathrm{~mA} \cdot \mathrm{h} \cdot \mathrm{g}^{-1}$ between 1.5 and $4.0 \mathrm{~V}$ after 50 cycles [157]. However, under irradiation, its photocurrent density is about $16 \mu \mathrm{A} \cdot \mathrm{cm}^{-2}$ at $1.23 \mathrm{~V}$ vs. RHE in sodium borate electrolyte. This low value is due to the poor charge transport of this iron vanadate [158]. As a consequence, the IPCE is only $1.5 \%$ under $1.4 \mathrm{~V}$ at $350 \mathrm{~nm}$ [158]. $\mathrm{Fe}_{2} \mathrm{~V}_{4} \mathrm{O}_{13}$ is n-type semiconductor with an optical band gap of $2.3 \mathrm{eV}$ with an absorption edge extending toward the visible light region. The conduction band minimum (CBM) of $\mathrm{Fe}_{2} \mathrm{~V}_{4} \mathrm{O}_{13}$ is determined to be $-0.55 \mathrm{eV}$ (vs. RHE) [160] while the valence band maximum (VBM) is located at $1.69 \mathrm{eV}$.

A less known iron vanadate is $\mathrm{FeV}_{2} \mathrm{O}_{4}$. This spinel compound crystallizes in cubic face-centered structure and belongs to the space group $F d \overline{3} m$. The lattice parameters are as the following: $a=8.32 \AA, b=8.32 \AA, c=8.32 \AA$ and $\alpha=\beta=\gamma=90^{\circ}$ with a cell volume of $588.77 \AA^{3}$ [161]. The iron cations are located in eight tetrahedral sites $\left[\mathrm{FeO}_{4}\right]$ while vanadium ions are situated in 16 octahedral $\left[\mathrm{VO}_{6}\right]$ (the cubic-closed packing structure is based on oxygen anions) [161]. $\mathrm{FeV}_{2} \mathrm{O}_{4}$ is a semiconductor which has a yellow color and it exhibits a direct energy band gap at about $1.9 \mathrm{eV}$ and an indirect one at approximately $2.6 \mathrm{eV}$ [162]. Comparing to iron (III) oxide $\left(\mathrm{Fe}_{2} \mathrm{O}_{3}\right)$ and vanadium (V) oxide $\left(\mathrm{V}_{2} \mathrm{O}_{5}\right), \mathrm{FeV}_{2} \mathrm{O}_{4}$ is a material exhibiting much better electronic properties, i.e., with effective separation of photo-generated charge carriers, thus leading to better and faster charge transfer process at the interface with the liquid or gaseous medium [162]. In addition, the charge transfer resistance (RCT) is $23 \mathrm{~K} \Omega$ which is a relatively low value. Therefore, $\mathrm{FeV}_{2} \mathrm{O}_{4}$ is considered as a suitable photo-electrode material for PEC cell [162]. The photocurrent of this iron vanadate under UV-visible illumination $\left(100 \mathrm{~mW} \cdot \mathrm{cm}^{-2}\right)$ can reach $0.18 \mathrm{~mA} \cdot \mathrm{cm}^{-2}$ at $1.2 \mathrm{~V}$ with an IPCE of $22 \%$ at $320 \mathrm{~nm}$ (in sulfate electrolyte) [162]. Finally, another underrated iron vanadate is $\mathrm{FeV}_{3} \mathrm{O}_{8}$. It has a monoclinic structure with lattice parameters of $\mathrm{a}=12.13 \AA$, $\mathrm{b}=3.679 \AA$ and $\mathrm{c}=6.547 \AA$ and a direct optical band gap of $2.23 \mathrm{eV}$, thus suggesting a potential and promising photoactivity under visible light [163].

\subsubsection{Copper Vanadates}

Different polymorphs of copper vanadate $(\mathrm{CVO})$ have been studied including $\mathrm{CuV}_{2} \mathrm{O}_{6}$, $\mathrm{Cu}_{2} \mathrm{~V}_{2} \mathrm{O}_{7}, \mathrm{Cu}_{3} \mathrm{~V}_{2} \mathrm{O}_{8}$, etc. The preparation of different types of copper vanadate with different stoichiometries can be achieved using different synthesis techniques and different experimental conditions $[164,165]$. The value of stoichiometric ratio strongly influences both physical and chemical properties. This stoichiometry is often determined by the ratio between copper (II) and vanadium (V) oxides, since the crystal structures of many copper vanadates are considered to be composed of $\mathrm{CuO}$ and $\mathrm{V}_{2} \mathrm{O}_{5}$. For example, $\mathrm{CuV}_{2} \mathrm{O}_{6}$, $\mathrm{Cu}_{2} \mathrm{~V}_{2} \mathrm{O}_{7}$, and $\mathrm{Cu}_{3} \mathrm{~V}_{2} \mathrm{O}_{8}$ exhibit molar ratio of $\mathrm{CuO}$ and $\mathrm{V}_{2} \mathrm{O}_{5}$ of 1:1, 2:1, and 3:1, respectively, and other combinations of copper oxide with $\mathrm{V}_{2} \mathrm{O}_{5}$ can lead to various phases of copper vanadate. In addition to the pure phase, surface modifications can be performed using metals and nonmetals, thus improving electrical, optical, and structural properties of the materials by enhancement of charge carrier transport, tuning of the band gap energy, etc. Initially, copper vanadates attracted the interest of scientists due to their high lithiated characteristics and their potential application as cathode in LIB [164]. This is particularly the case of $\mathrm{Cu}_{3} \mathrm{~V}_{2} \mathrm{O}_{8}$ and its composites and doped forms [164]. Crystalline copper vanadates have interesting layered structures which are composed of $\mathrm{Cu}-\mathrm{O}$ layers in octahedral coordination joined by $\mathrm{V}-\mathrm{O}$ tetrahedral layers. In addition, copper vanadates are also semidonductors with interesting optical properties, i.e., the absorption of a large part of natural solar light [164].

$\mathrm{Cu}_{3} \mathrm{~V}_{2} \mathrm{O}_{8}$ is one of the most investigated $\mathrm{CVO}$. It can crystallized in either monoclinic, triclinic, or orthorhombic system, all with a low symmetry. Usually, most of the CVO structures offers a large range of phases [164]. The monoclinic gamma phase $\left(\gamma-\mathrm{Cu}_{3} \mathrm{~V}_{2} \mathrm{O}_{8}\right)$ consists of $\left[\mathrm{VO}_{4}\right]$ tetrahedra and two distinct $\mathrm{Cu}$ units: square-planar $\left[\mathrm{CuO}_{4}\right]$ and squarepyramidal $\left[\mathrm{CuO}_{5}\right]$. It is the most stable phase of this type of copper vanadate. The oxidation states for copper, vanadium and oxygen in $\mathrm{Cu}_{3} \mathrm{~V}_{2} \mathrm{O}_{8}$ are $+2,+5$ and -2 , respectively, thus 
the electronic band structure is mainly composed of $\mathrm{Cu} 3 \mathrm{~d}^{9}, \mathrm{~V} 3 \mathrm{~d}^{0}$, and $\mathrm{O} 2 \mathrm{p}^{6}$ orbitals [166]. Indeed, $\gamma-\mathrm{Cu}_{3} \mathrm{~V}_{2} \mathrm{O}_{8}$ is a n-type semiconductor with an indirect band gap of about $1.8 \mathrm{eV}$ and a direct band gap at approximately $2.7 \mathrm{eV}$ [135]. The predicted $E_{g}$ transitions are from $\mathrm{O} 2 \mathrm{p}$ to $\mathrm{Cu} 3 \mathrm{~d}$ orbitals for direct $E_{g}$ and from $\mathrm{O} 2 \mathrm{p}$ to $\mathrm{V} 3 \mathrm{~d}$ orbitals for indirect energy band gap (Figure 11) [166]. It is worth noting that the valence band exhibits a high degree of hybridization with strong involvement of $\mathrm{O} 2 \mathrm{p}$ orbitals. Furthermore, the Fermi level $\left(E_{F}\right)$ is located at $4.57 \mathrm{eV}$ while VBM and CBM lay at 6.03 and $4.23 \mathrm{eV}$, respectively [166]. These values are relative to the vacuum level (e.g., $E^{0}\left(H^{+} / H_{2}\right)$ is situated at $4.5 \mathrm{eV}$ ). Regarding these properties, $\gamma-\mathrm{Cu}_{3} \mathrm{~V}_{2} \mathrm{O}_{8}$ is attractive for photochemical and electrochemical applications such as lithium ion batteries and photocatalysis [164,165].

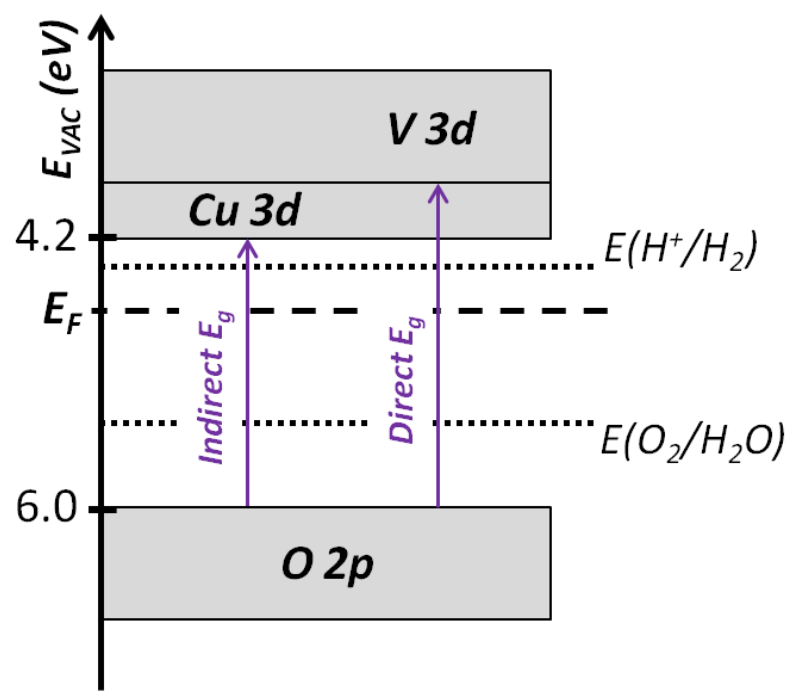

Figure 11. The electronic band structure of $\gamma-\mathrm{Cu}_{3} \mathrm{~V}_{2} \mathrm{O}_{8}$ (related to the vacuum energy).

Concerning the photoelectrochemical properties of $\gamma-\mathrm{Cu}_{3} \mathrm{~V}_{2} \mathrm{O}_{8}$, the photocurrent density is measured at $62 \mu \mathrm{A} \cdot \mathrm{cm}^{-2}$ at $1.23 \mathrm{~V}$ vs. RHE under simulated solar irradiation. In addition, the IPCE of $\gamma-\mathrm{Cu}_{3} \mathrm{~V}_{2} \mathrm{O}_{8}$ reaches only $3 \%$ at $360 \mathrm{~nm}$ [166]. Due to a relatively low energy band gap, there is a fast recombination between the photogenerated charge carriers, thus leading to the weak photoactivity of $\gamma-\mathrm{Cu}_{3} \mathrm{~V}_{2} \mathrm{O}_{8}$. The recombination process, which dominates this copper vanadate, is worsened by short diffusion length. Therefore, although the energy band gap and the physico-chemical stability of $\gamma-\mathrm{Cu}_{3} \mathrm{~V}_{2} \mathrm{O}_{8}$ appear promising, the performance of this material as a photoelectrode in PEC applications is not yet suitable. Further work is required to improve the properties and performance of $\gamma-\mathrm{Cu}_{3} \mathrm{~V}_{2} \mathrm{O}_{8}$ in order to design a next-generation photoanode [166].

Another famous copper vanadate which is also an n-type semiconductor is $\mathrm{Cu}_{2} \mathrm{~V}_{2} \mathrm{O}_{7}$. Indeed, it has been already used as a cathode material for rechargeable LIB, photoelectrode in PEC technologies (for water oxidation) and as a photocatlyst [167]. $\mathrm{Cu}_{2} \mathrm{~V}_{2} \mathrm{O}_{7}$ has a monoclinic crystal structure where $\mathrm{V}^{5+}$ ion is surrounded by four oxygen while $\mathrm{Cu}^{2+}$ ion is coordinated with five oxygens [168]. This semiconductor copper vanadate is also a promising candidate for visible light-driven photocatalysis because of its narrow energy band-gap $(2.0 \mathrm{eV})$ which is an indirect $E_{g}[167,168]$. The photocurrent density achieved by $\mathrm{Cu}_{2} \mathrm{~V}_{2} \mathrm{O}_{7}$ reaches about $120 \mu \mathrm{A} \cdot \mathrm{cm}^{-2}$ at $1.58 \mathrm{~V}$ vs. RHE while the IPCE is $4 \%$ at $400 \mathrm{~nm}$ under $1.23 \mathrm{~V}$ vs. RHE [168]. However, as in the case of $\mathrm{Cu}_{3} \mathrm{~V}_{2} \mathrm{O}_{8}$, the photocatalytic efficiency of $\mathrm{Cu}_{2} \mathrm{~V}_{2} \mathrm{O}_{7}$ is limited because of the fast recombination of photogenerated holes and electrons. Therefore, composites with a Z-scheme structure have been designed in order to prevent this recombination i.e., to efficiently separate the $e^{-} / h^{+}$pairs in the composite [167]. Indeed, a direct Z-scheme system is similar to a type-II heterojunction (Figure 12), but the electrons of the holes of semiconductor No1 (SC1) recombine by physical 
contact with the electrons of semiconductor No2 (SC2), thus the remaining photogenerated electrons and holes of SC1 and SC2, respectively, are spatially separated.
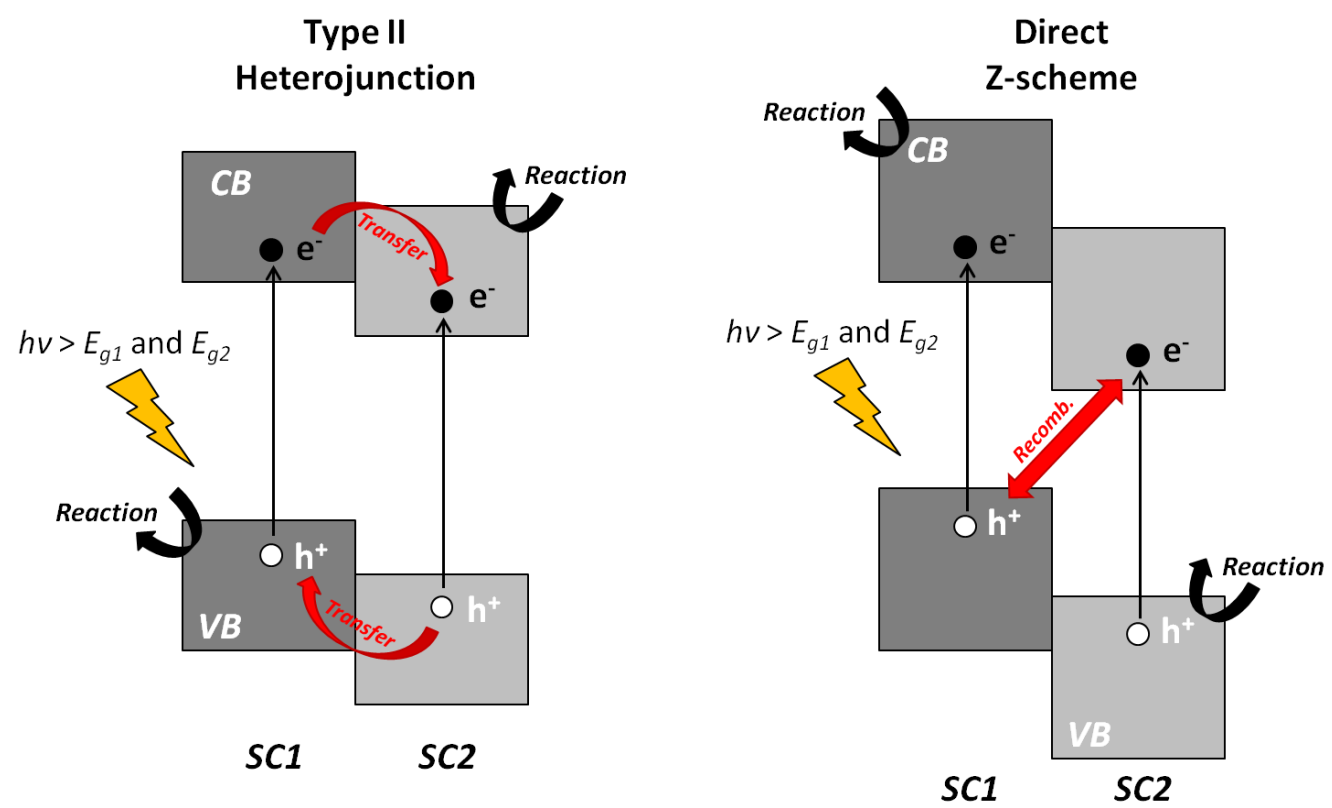

Figure 12. Electronic band structure of type-II heterojunction and direct Z-scheme with the different charge carriers migrations.

\subsubsection{Silver Vanadates}

Among the ternary vanadium oxides that are investigated for photochemical applications, silver vanadates have attracted much attention, mainly because of their narrow band gap and highly dispersed and hybridized valence band. The valence band in silver vanadates is composed of $2 \mathrm{p}$ orbitals of oxygen and $4 \mathrm{~d}$ orbitals of silver and the hydbridization between the $2 \mathrm{p}^{6}$ orbitals with completely filled $4 \mathrm{~d}^{10}$ orbitals leads to a VB located at a more positive energy level than VB in most of the other ternary vanadium oxides. That feature increases the oxidation power of the material. On the other hand, the conduction band consists of hybridized $5 \mathrm{~s}$ orbital of silver with $3 \mathrm{~d}$ orbitals of vanadium. Therefore, silver vanadates exhibit good absorption of low energy photon (e.g., visible light) and high mobility of photogenerated holes, which are crucial characteristics for application in photochemical processes, especially the degradation of organic pollutants (Section 4.2.2) [169].

A variety of ternary oxides based on silver, like $\mathrm{AgSbO}_{3}, \mathrm{AgInO}_{2}, \mathrm{Ag}_{2} \mathrm{Ti}_{4} \mathrm{O}_{9}$, etc., have been recently developed as visible-light responsive photoactive materials [169]. In addition, ternary oxides based on vanadium and with a perovskite structure, such as $\mathrm{SrVO}_{3}$ and $\mathrm{CaVO}_{3}$, are highly stable and transparent oxides. Therefore, silver vanadates have attracted much interest due to their potential applications ranging from photocatalysis to batteries and sensors, and passing through antibacterial agents [170]. Silver vanadates have excellent electrochemical properties making them suitable for primary lithium ion batteries. Indeed, in the form of electrodes, $\mathrm{Ag}_{2} \mathrm{~V}_{4} \mathrm{O}_{11}$ nanowires and $\alpha-\mathrm{AgVO}_{3}$ microrods have exhibited high discharge capacities of $366 \mathrm{~mA} \cdot \mathrm{h} \cdot \mathrm{g}^{-1}$ and $324.1 \mathrm{~mA} \cdot \mathrm{h} \cdot \mathrm{g}^{-1}$, respectively [135]. Silver vanadates have also interesting optical properties with intense absorption bands in the visible region, especially for $\alpha-\mathrm{AgVO}_{3}, \beta-\mathrm{AgVO}_{3}, \mathrm{Ag}_{4} \mathrm{~V}_{2} \mathrm{O}_{7}, \mathrm{Ag}_{2} \mathrm{~V}_{4} \mathrm{O}_{11}$, and $\mathrm{Ag}_{3} \mathrm{VO}_{4}$ [171].

Concerning $\mathrm{AgVO}_{3}$, this ternary vanadium oxide exists in two stable phases, both having a monoclinic structure: $\alpha-\mathrm{AgVO}_{3}$ and $\beta-\mathrm{AgVO}_{3}$. The alpha and beta polymorph belong to space group $\mathrm{C} 2 / \mathrm{c}$ and $\mathrm{Cm}$, respectively $[135,170,172]$. In addition, $\alpha-\mathrm{AgVO}_{3}$ phase can be irreversibly transformed to $\beta-\mathrm{AgVO}_{3}$ at around $200{ }^{\circ} \mathrm{C}$ [170]. The structure of crystalline $\mathrm{AgVO}_{3}$ exhibits silver ions with three different local coordinations corresponding to $\left[\mathrm{AgO}_{x}\right]$ clusters $(x=5,6$, and 7$)$ and vanadium ions coordinated to four oxygen, 
thus forming tetrahedron $\left[\mathrm{VO}_{4}\right][170] . \mathrm{AgVO}_{3}$ materials are p-type semiconductors with a direct energy band gap. The $E_{g}$ of the most stable polymorph, i.e., $\beta-\mathrm{AgVO}_{3}$ is estimated to be about $2.2 \mathrm{eV}[169,173]$. That clearly indicates that $\beta-\mathrm{AgVO}_{3}$ is a visible-light driven photoactive material with promising applications under natural sunlight. As reported in the previous paragraph, the narrow energy band gap of silver vanadates is mainly due to hydridization of $\mathrm{O} 2 \mathrm{p}$ and $\mathrm{Ag} 4 \mathrm{~d}$ orbitals which compose the valence band [169]. In addition, in $\beta-\mathrm{AgVO}_{3}$, there are intermediate energy levels within the band gap which arise from the structural disorder of the building blocks, i.e., $\left[\mathrm{VO}_{4}\right]$ and $\left[\mathrm{AgO} \mathrm{O}_{x}\right]$ clusters. This disorder also enhances the separation of photogenerated electron/hole pairs and implies highly mobile charge carriers [170]. Therefore, the electrochemical performance of $\beta-\mathrm{AgVO}_{3}$ is better than $\alpha-\mathrm{AgVO}_{3}$. This better performance is further improved by the tunnel structure of the beta polymorph, thus allowing better cation insertion, i.e., higher specific capacity values [172].

Another silver vanadate, $\mathrm{Ag}_{2} \mathrm{~V}_{4} \mathrm{O}_{11}$, is widely used as efficient cathode in LIB for advanced biomedical devices such as implantable cardiac defibrillators [172]. Indeed, $\mathrm{Ag}_{2} \mathrm{~V}_{4} \mathrm{O}_{11}$ is a silver vanadate which been successfully commercialized for use as cathode material in LIB [174]. $\mathrm{Ag}_{2} \mathrm{~V}_{4} \mathrm{O}_{11}$ has a monoclinic structure with the space group C2/m [135]. The crystal structure of this silver vanadate is made of $\left[V_{4} \mathrm{O}_{16}\right]$ units which are composed of distorted $\left[\mathrm{VO}_{6}\right]$ octahedra sharing corners in order to form an infinite $\left[\mathrm{V}_{4} \mathrm{O}_{12}\right]_{n}$ quadruple strings [135]. These chains are linked by corner-shared oxygen to provide continuous $\left[V_{4} \mathrm{O}_{11}\right]_{n}$ layers which are separated by silver atoms [135]. $\mathrm{Ag}_{2} \mathrm{~V}_{4} \mathrm{O}_{11}$ is a semiconductor with an indirect band of about $2.0 \mathrm{eV}$. Indeed, the absorption band of $\mathrm{Ag}_{2} \mathrm{~V}_{4} \mathrm{O}_{11}$ almost covers the region from UV to about $600 \mathrm{~nm}$ which corresponds to the visible portion of the natural sunlight [175]. Therefore, $\mathrm{Ag}_{2} \mathrm{~V}_{4} \mathrm{O}_{11}$ is not only an excellent electrochemical material, but also a promising photoactive material. The conduction band of $\mathrm{Ag}_{2} \mathrm{~V}_{4} \mathrm{O}_{11}$ is composed of the V $3 \mathrm{~d}$ and $\mathrm{Ag} 5 \mathrm{~s} 5 \mathrm{p}$ orbitals while the valence band is the result of $\mathrm{O}$ $2 p$ and $A g 4 d$ hydribization as in most of silver vanadates [175]. The energy position of VBM and CBM can be determined theoretically by using the equation related to Mulliken electronegativity and the band gap value of the semiconductor oxide (Equation (11). As a result, the conduction band minimum is determined to be $4.4 \mathrm{eV}$ relative to the vacuum level (which is close to $E\left(H^{+} / H_{2}\right)=4.5 \mathrm{eV}$ ) while the valence band maximum is calculated to be $6.4 \mathrm{eV}$ (using $E_{g}=2.0 \mathrm{eV}$ ) [175].

$$
\mathrm{E}_{\mathrm{CBM}}=X-0.5 E_{g}
$$

where $\mathrm{E}_{\mathrm{CBM}}$ and $E_{g}$ are the $\mathrm{CB}$ edge and band gap energies relative to the vacuum level, respectively, and $X$ is the mean of the Mulliken electronegativity of the constituent atoms in the semiconductor [175].

Concerning the other silver vanadates, pure $\mathrm{Ag}_{4} \mathrm{~V}_{2} \mathrm{O}_{7}$ is difficult to prepare since this phase often coexists with $\mathrm{Ag}_{3} \mathrm{VO}_{4}$ during the synthesis. $\mathrm{Ag}_{4} \mathrm{~V}_{2} \mathrm{O}_{7}$ crystallizes in the orthorhombic system and it exhibits a band gap of about $2.5 \mathrm{eV}$. On the other hand, $\mathrm{Ag}_{3} \mathrm{VO}_{4}$ has also a band gap in the visible region with a value estimated to be $2.2 \mathrm{eV}$ [176]. This phase crystallizes in the monoclinic system [176]. Compared to $\mathrm{Ag}_{4} \mathrm{~V}_{2} \mathrm{O}_{7}$, the energy position of the conduction band in $\mathrm{Ag}_{3} \mathrm{VO}_{4}$ is less negative, thus leading to less efficient reduction ability [177]. Despite most of silver vanadates have narrow energy band gaps, the separation rate of photo-generated electrons and holes remain low, that is the main drawback of these ternary vanadium oxides [176].

\subsubsection{Manganese and Other Transition Metal Vanadates}

There are many other transition metal vanadates, of which manganese ones are among the most documented. Most of manganese vanadates have been firstly studied for their electrochemical properties in LIBs [178]. However, $\mathrm{Mn}_{2} \mathrm{~V}_{2} \mathrm{O}_{7}$ has attracted attention not only for its electrochemical performance but also for its optical properties. There are two phases of this manganese vanadate: monoclinic $\beta-\mathrm{Mn}_{2} \mathrm{~V}_{2} \mathrm{O}_{7}$ and triclinic $\alpha-\mathrm{Mn}_{2} \mathrm{~V}_{2} \mathrm{O}_{7}[178,179]$. $\beta-\mathrm{Mn}_{2} \mathrm{~V}_{2} \mathrm{O}_{7}$ exhibits an energy band gap of about $1.2 \mathrm{eV}$ while $\alpha-\mathrm{Mn}_{2} \mathrm{~V}_{2} \mathrm{O}_{7}$ has a larger $E_{g}$ 
$(1.8 \mathrm{eV})[178,180]$. The structure of $\beta-\mathrm{Mn}_{2} \mathrm{~V}_{2} \mathrm{O}_{7}$ is composed of $\left[\mathrm{MnO}_{6}\right]$ octahedra sharing edges with $\left[\mathrm{V}_{2} \mathrm{O}_{7}\right]$ interlayer while for $\alpha-\mathrm{Mn}_{2} \mathrm{~V}_{2} \mathrm{O}_{7}$, it is often reported as impurity [178]. Another interesting manganese vanadate is $\mathrm{Mn}\left(\mathrm{VO}_{3}\right)_{2}$. It crystallizes in monoclinic structure and exhibits a direct energy band gap of about $3.0 \mathrm{eV} \mathrm{[181].}$

For the other transition metal vanadates, the Table 1 summarizes the most important optical characteristics of such materials, i.e., their photocurrent and band gap energy values, since such properties are crucial for photo-induced chemical processes [180].

Table 1. Measured and calculated energy band gap for different transition metal vanadates along with their produced photocurrent.

\begin{tabular}{cccccc}
\hline \multirow{2}{*}{ Phase } & \multicolumn{2}{c}{ Measured $(\mathbf{e V})$} & \multicolumn{2}{c}{ Calculated (eV) } & $\begin{array}{c}\text { Photocurrent } \\
\left(\mathbf{m A} \cdot \mathbf{c m}^{-2} \text { ) }\right.\end{array}$ \\
\cline { 2 - 4 } & Direct $E_{\boldsymbol{g}}$ & Indirect $\boldsymbol{E}_{\boldsymbol{g}}$ & Direct $E_{\boldsymbol{g}}$ & Indirect $E_{\boldsymbol{g}}$ & \\
\hline $\mathrm{Cr}_{2} \mathrm{~V}_{4} \mathrm{O}_{13}$ & 2.56 & 2.55 & 2.52 & 2.30 & 0.139 \\
$\alpha-\mathrm{CoV}_{2} \mathrm{O}_{6}$ & 2.17 & 2.16 & 2.25 & 2.25 & 0.015 \\
$\mathrm{Co}_{3} \mathrm{~V}_{2} \mathrm{O}_{8}$ & 2.06 & 2.03 & 2.34 & 2.22 & 0.006 \\
$\mathrm{Ni}_{2} \mathrm{~V}_{2} \mathrm{O}_{7}$ & 2.75 & 2.72 & 2.73 & 2.50 & 0.003 \\
$\mathrm{Ni}_{3} \mathrm{~V}_{2} \mathrm{O}_{8}$ & 2.55 & 2.54 & 2.66 & 2.50 & 0.003 \\
$\mathrm{Cu}_{11} \mathrm{~V}_{6} \mathrm{O}_{26}$ & 1.41 & 1.38 & 2.49 & 1.87 & 0.950 \\
$\alpha-\mathrm{Ag}_{3} \mathrm{VO}_{4}$ & 2.07 & 1.70 & 2.38 & 2.14 & 0.062 \\
$\beta-\mathrm{Ag}_{3} \mathrm{VO}_{4}$ & 1.91 & 1.61 & 2.51 & 2.51 & 0.410 \\
\hline
\end{tabular}

\section{Vanadium Oxides in Photochemical Processes for Environmental Applications \\ 4.1. Production of Sustainable Energy}

One of the major concerns for humanity in the 21st century is the environmental changes [164,182]. Therefore, the production of renewable and sustainable energy is a crucial problematic throughout the world. Renewable energy sources can fulfil the requirements of energy without any production of pollution (toxic air pollutants and greenhouse gases), thus it is the best alternative to overcome the currently existing problems $[183,184]$. One of the main sustainable and renewable sources of energy is solar light with its utilization in photocatalysis, photovoltaic cell, etc. [164]. Therefore, besides the degradation of pollutant which is developed in Section 4.2, binary and ternary vanadium oxides can be used in the field of sustainable energy. The two main applications using vanadium oxide based materials in this field are the production of hydrogen by water splitting and the production of electricity using photovoltaic devices. Hydrogen $\left(\mathrm{H}_{2}\right)$, as a fuel, has a great energy yield (122 KJ.g ${ }^{-1}$ ) compared to fossil fuels $\left(40 \mathrm{KJ} \cdot \mathrm{g}^{-1}\right)$ which are known to produce greenhouse gases and particulate matter $(\mathrm{PM})$. A green and sustainable way to produce hydrogen is from the splitting of water molecule for two main reasons: (i) water is abundant on the planet (70\% of Earth area is covered by water); and (ii) such a technology does not produce wastes (only hydrogen and oxygen). Using vanadium oxides materials as semiconductor photocatalysts, water splitting can be photo-assisted. The photosplitting of water has attracted the interest of many environmental chemists since it is considered as the "Holy Grail" in the field of energy: conversion of solar energy into chemical energy [9]. However, since the overall reaction of water splitting (Equations (12)-(14)) has relatively high Gibbs energy $\left(\Delta \mathrm{G}^{0}=237.2 \mathrm{KJ} \cdot \mathrm{mol}^{-1}\right)$, the use of only solar energy is not enough to trigger the production of both hydrogen and oxygen using the actual commercial photocatalysts. Therefore, unless the discovery of an extraordinary green, efficient and inexpensive material, additional energy should be supplied to efficiently break $\mathrm{H}_{2} \mathrm{O}$ molecules into molecular oxygen and hydrogen [185-188]. Therefore, electrical energy coupled to an irradiation (especially solar light) can be used in a photoelectrochemical (PEC) system containing a photoactive electrode (Figure 13). This strategy appears the best solution (so far) to produce green energy by water splitting. PEC is also called electrochemically assisted photocatalysis (electrophotocatalysis). To produce $\mathrm{H}_{2}$ in an economically viable way and to reduce production cost, the electrical energy can derive from renewable sources, such as photovoltaic systems, so the produced hydrogen is entirely "green". In other words, 
photoelectrochemical (PEC) cell is the most advanced way to produce chemical energy (hydrogen) by converting solar energy.

$$
\begin{gathered}
2 \mathrm{H}^{+}+2 \mathrm{e}^{-} \rightarrow \mathrm{H}_{2} ; \quad E^{0}=0 \mathrm{~V} \\
2 \mathrm{H}_{2} \mathrm{O}+4 h^{+} \rightarrow \mathrm{O}_{2}+4 \mathrm{H}^{+} ; \quad E^{0}=1.23 \mathrm{~V} \\
2 \mathrm{H}_{2} \mathrm{O}+h v \rightarrow 2 \mathrm{H}_{2}+\mathrm{O}_{2} ; \quad \Delta E=1.23 \mathrm{~V}
\end{gathered}
$$

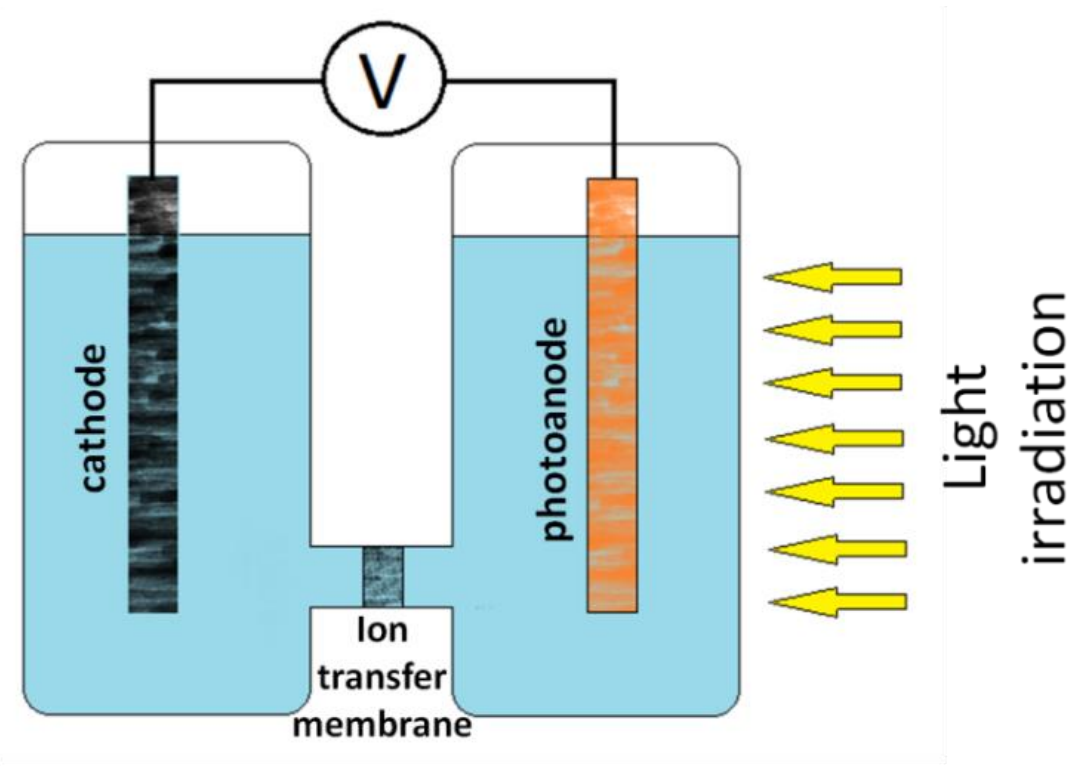

Figure 13. Two-compartment photoelectrochemical cell: the case of photoactive anode.

A PEC system is basically a cell coupled to a potentiostat. The PEC cell is composed of an anode and a cathode in contact with an electrolyte. An electrical voltage is applied between the electrodes. There are several cell configurations with either electrodes in the same compartment or separated by an ion-transfer membrane. For water splitting, the two-compartment PEC cell is the most suitable since $\mathrm{O}_{2}$ and $\mathrm{H}_{2}$ evolve separately, thus avoiding potential explosive mixture and water recombination (Figure 13) [189]. The electrophotocatalytic process for the production of hydrogen by water splitting using a PEC cell and a semiconductor photocatalyst such as vanadium oxides requires that the redox potentials for both water oxidation (Equation (13)) and reduction (Equation (12)) should lie within the energy band gap of the photoactive material (Figure 14) [186-190]. This photo-active material is often an n-type semiconductor photocatalyst like vanadium oxides and it constitutes the anode which is irradiated (photoanode). Since $\Delta \mathrm{E}=1.23 \mathrm{~V}$ (for overall water splitting), the energy band gap of a photocatalyst candidate should be theoretically $1.23 \mathrm{eV}$ in order to photogenerate $e^{-}$and $h^{+}$species of enough energy to trigger the reactions (Equations (13) and (14)) [190]. However, due to overpotential losses, the $E_{g}$ value should be at least $2 \mathrm{eV}$ [185-188]. After the generation of $e^{-} / h^{+}$pair under suitable irradiation, the PEC water splitting process using a photoanode is composed of three main steps: (i) water oxidation in the photoanode compartment, (ii) $e^{-}$transfer through external circuit toward the cathode compartment, where (iii) reduction of water occurs $[186,189]$. 


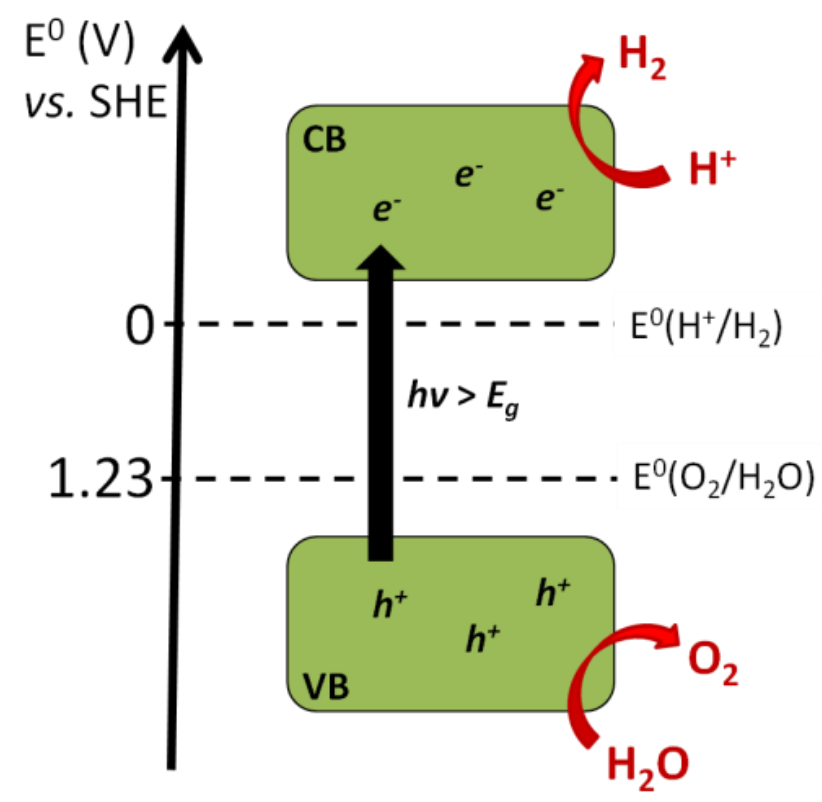

Figure 14. Mechansim of overall water splitting using heterogeneous semiconductor photocatalysis.

The first report on PEC water splitting dates 1972 [191]. In this work, Fujishima and Honda used rutile $\mathrm{TiO}_{2}$ photoanode which is irradiated by UV light in a two-compartment cell. Unlike titanium dioxide which is the most popular photocatalytic material, vanadium oxides are promising candidates for PEC water splitting. One reason is that many vanadium oxides can be photoactivated by visible light. Although $\mathrm{Fe}_{2} \mathrm{O}_{3}, \mathrm{WO}_{3}$, or $\mathrm{CdS}$ are also visible light driven photocatalyst, they cannot be used in this sustainable process due to inappropriate band structure, low photostability, high recombination rate, or high toxicity $[185,186]$. Another reason why vanadium oxides are interesting is their band structure. Indeed, the energy band gap of many vanadium oxides has the suitable energetic position, thus enclosing the redox potentials for water splitting, especially for the production of $\mathrm{H}_{2}[192,193]$ while most of semiconductor transition metal oxides are efficient in partial water splitting, especially water oxidation (oxygen production). Therefore, vanadium oxide photocatalysts can be used without any electrical voltage for the production of hydrogen where $\mathrm{V}_{6} \mathrm{O}_{13}, \mathrm{VO}_{2}(\mathrm{M})$, and $\mathrm{VO}_{2}(\mathrm{~B})$ could produce until $35 \mu \mathrm{mol}$ of hydrogen per gram of catalyst after $12 \mathrm{~h}$ [192]. Supported $\mathrm{VO}_{2}$ nanorods with energy band gap of $2.7 \mathrm{eV}$ are also able to photocatalytically produce hydrogen by water splitting under UV light at room temperature. Indeed, in the presence of ethanol, a maximum value of $\mathrm{H}_{2}$ production rate of $800 \mathrm{mmol} \cdot \mathrm{m}^{-2} \cdot \mathrm{h}^{-1}$ is obtained when the light is incident to the axis of the nanorods (due to vertical alignment of the nanorods) [194]. $\mathrm{V}_{2} \mathrm{O}_{5}$ has also shown interesting photo-induced properties with the generation of $8.9 \mathrm{~mm}^{3} \cdot \mathrm{h}^{-1}$ of hydrogen by water splitting under visible light and in the presence of methanol. The role of alcohols is to trap photogenerated holes, thus improving the electron-hole pair separation where electrons can be efficiently used in the production of hydrogen (Figure 15A). The high efficiency of $\mathrm{V}_{2} \mathrm{O}_{5}$ in photocatalytic water splitting is also explained by the high specific surface area which is controlled by the sol-gel technique where vanadium triethoxide precursor and structure directing agent are employed [195]. In the case of using photo-sensitization process, i.e., using Eosin Y dye, the production of hydrogen can reach almost $20 \mathrm{~mm}^{3} \cdot \mathrm{h}^{-1}$ [195]. Indeed, under irradiation, the excited dye can transfer its electrons to the conduction band of $\mathrm{V}_{2} \mathrm{O}_{5}$ photocatalyst where reduction reaction for the formation of hydrogen occurs (Figure 15B). 

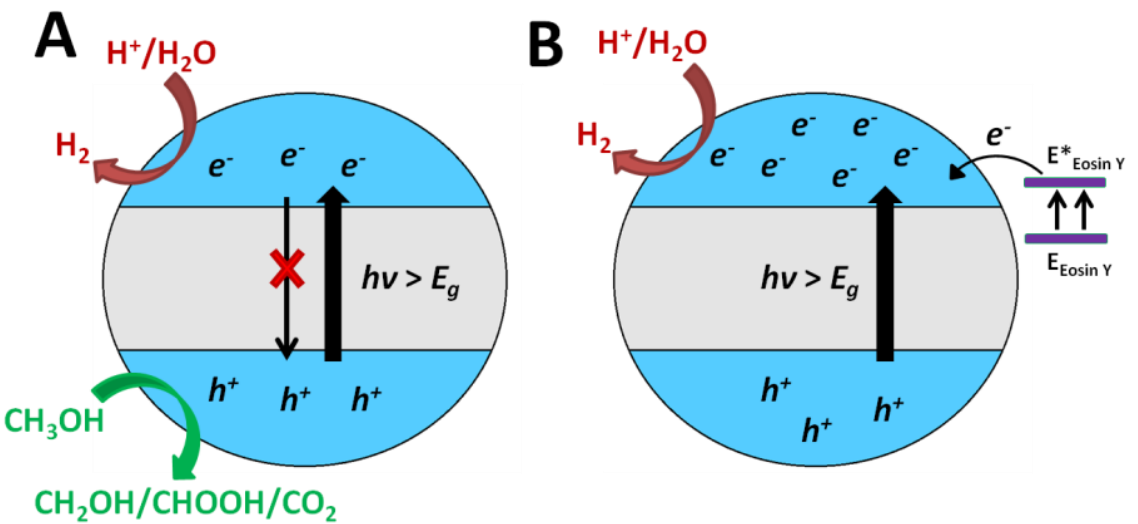

Figure 15. Improvement of hydrogen production using semiconductor photocatalyst by (A) sacrificial agent method (here, methanol) and (B) by dye photosensitization (here, Eosin Y).

However, the production rate of hydrogen using only light energy (without electrical bias) is low. This poor efficiency is mainly due to kinetic issues, limited solar energy conversion (photon to electron), and important charge recombination [196,197]. In addition, some binary and ternary vanadium oxides have a conduction band minimum which is not suitable for hydrogen production via the water splitting. For instance, $\mathrm{BiVO}_{4}$ has a $\mathrm{CBM}$ at $0 \mathrm{~V}$ vs. SHE which makes the generation of $\mathrm{H}_{2}$ experimentally impossible due to overpotential losses. However, $\mathrm{BiVO}_{4}$ is an efficient photocatalyst for water oxidation which is a more challenging reaction than water reduction (four photogenerated holes are required compared to two photogenerated electrons for hydrogen production) [198]. There are potential alternatives to overcome these drawbacks by, for instance, the surface modification of photocatalysts. Indeed, the use of a synergistic co-catalyst is able to decrease the activation energy for $\mathrm{H}_{2}$ production or to improve the charge carriers separation. Another example is the use of a suitable composite photocatalyst (especially a type-II heterojunction) since the photogenerated electrons are accumulated in one semiconductor while the photogenerated holes are collected in the other semiconductor, thus improving the $e^{-} / h^{+}$pair separation under irradiation. This is the case of $\mathrm{FeVO}_{4} / \mathrm{CdS}$ where $400 \mu \mathrm{M}$ of hydrogen $\mathrm{H}_{2}$ is produced after $5 \mathrm{~h}$ under visible light [197] and of $\mathrm{BiVO}_{4} / \mathrm{CdS}$ nanoparticles with a hydrogen production rate of $0.57 \mathrm{mmol} \cdot \mathrm{h}^{-1}$ under visible light [199]. However, the solution which appears the most efficient (so far) is to set up a PEC system (i.e., the use of electric bias) since relatively simple materials with low production cost can be used while the electric bias improves the $e^{-} / h^{+}$pair separation by enforcing the movement of electrons oppositely to that of holes.

In such a PEC configuration, vanadium oxide photoanodes are more efficient, especially $\mathrm{BiVO}_{4}$ due to its appropriate electronic band structure, excellent chemical and thermal stabilities, and environmental friendliness [193,200,201]. Its band gap of $2.4-2.5 \mathrm{eV}$ (absorption edge: $500-520 \mathrm{~nm}$ ) allows the production of $6.2-7.5 \mathrm{~mA} \cdot \mathrm{cm}^{-2}$ photocurrent under simulated solar light. In addition, its valence band maximum which is located at $2.5 \mathrm{~V}$ vs. RHE provides a strong driving force for water oxidation by photogenerated holes [143]. Concerning the production of hydrogen by water splitting, bismuth vanadate photoanode can produce up to $2.5 \mu \mathrm{mol} \cdot \mathrm{min}^{-1}$ of hydrogen depending on the experimental conditions [202]. Since $\mathrm{BiVO}_{4}$ has poor separation ability and slow mobility of carriers, it has limited efficiency in practical applications [200]. Therefore, modifications such as doping, coupling to oxygen evolution cocatalysts (OECs) and fabricating heterostructure composites (using for example $\mathrm{FeVO}_{4}[203,204]$ ) are considered to be the most promising techniques for improving the efficiency of vanadium oxide based materials [200]. Indeed, co-doping of metal and non-metal into ternary iron vanadium oxide could increase the carriers' concentration and decrease the energy band gap, thus enhancing the PEC activities [205]. $\mathrm{BiVO}_{4} / \mathrm{FeVO}_{4}$ heterostructured photoanode exhibits a photocurrent density of $2.5 \mathrm{~mA} \cdot \mathrm{cm}^{2}$ at $1.23 \mathrm{~V}$ vs. RHE, which might be attributed to excellent charge trans- 
fer/transport phenomena (Figure 16) [206]. In addition to thermodynamic parameters, the physical factors including specific surface area, exposed crystal facets, etc., are also crucial to obtain the best photo-induced efficiency. The design of nanostructured vanadium oxides in the form of ultrafine powder, hierarchical structure and porous material is an efficient approach to reach high rates in hydrogen production $[207,208]$.

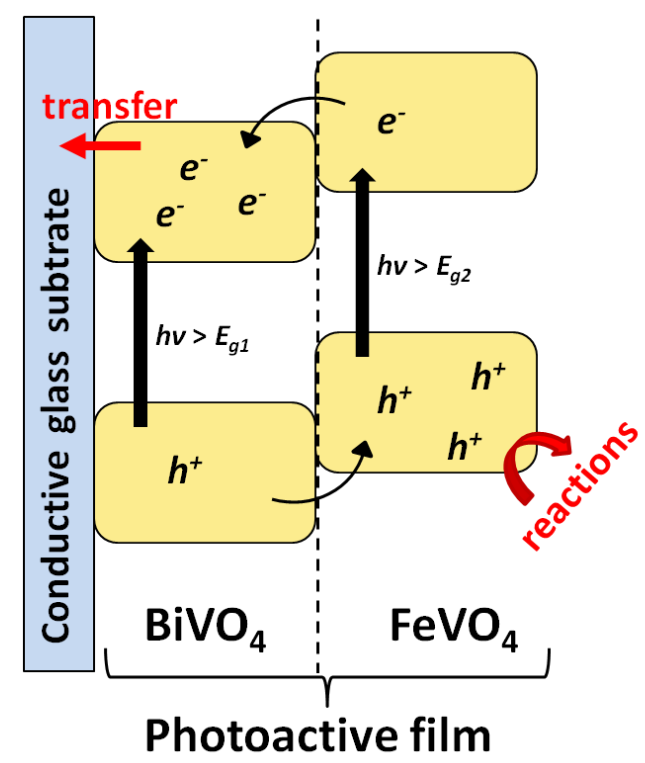

Figure 16. Charge transport of photogenerated holes and electrons in layered $\mathrm{BiVO}_{4} / \mathrm{FeVO}_{4}$ photoanode.

On the other hand, PEC processes using photoanode are also interesting for the degradation of pollutants $[185,186]$. The main advantage in the use of a PEC cell is the reaching of higher mineralization rates $[140,185]$. Since the charge carrier recombination in the photoanode is limited by the vector charge transport along the electrochemical potential gradient, the activation energy for full mineralization is easily achieved $[140,185]$. However, vanadium oxides have high oxidation power, thus, non-assisted photocatalysis is sufficient for efficient degradation of pollutants (Section 4.2).

Another environmental application using the photoinduced properties of vanadium oxides under solar light is the photovoltaic technology. Such devices, especially in the form of organic solar cells, are composed of an anode, a cathode, an active organic layer and interfacial layers [209]. In these latter ones, vanadium oxides are promising. The interfacial layers cover the electrode and are in contact to the organic layer. Their function is to support the transport of photogenerated charges [209]. Usually, as interfacial layer, poly(3,4-ethylenedioxythiophene) poly(styrenesulfonate) (PEDOT:PSS) is employed but its poor long-term stability has pushed the scientists to consider other possibilities to replace PEDOT:PSS such as $\mathrm{V}_{2} \mathrm{O}_{5}$. Vanadium pentoxide can be deposited in ambient conditions, thus avoiding high temperature annealing and other post-treatments [210]. Recently, it is in perovskite solar cells that vanadium oxides exhibited outstanding performance as hole-transport layers [211].

\subsection{Photo-Induced Degradation of Organic Contaminants}

The organic contamination is a critical issue for the natural environment, especially for the hydrosphere. Indeed, many pollutants are accumulated in in the aqueous media, especially the persistent organic pollutants (POPs) and the contaminants of emerging concern (CECs), i.e., pharmaceuticals and personal care products (PPCPs), endocrine-disrupting compounds (EDCs), flame retardants (FRs), pesticides, herbicides, and fungicides, etc. These CECs are frequently detected in wastewater treatment plant (WWTP) effluents. Indeed, the use of conventional treatments are not enough efficient to remove the CECs while these contaminants have a well-known harmful impact not only on the environment, but 
also on the human health. Therefore, the discharge of WWTP effluents (i.e., treated wastewaters) is the main source of contamination of CECs and POPs into the natural environment, thus being a real threat for drinking water source (ground and surface water) [212].

The properties of vanadium oxides are versatile mainly due to the multivalent character of vanadium. Thank to these properties, it is possible to design efficient photo-induced processes (photocatalysis, photo-Fenton, etc.) for environmental remediation, including the removal of organic pollution [83].

\subsubsection{Generalities of Photo-Induced Processes}

One of the most efficient techniques to remediate the environment, especially for the removal of organic contaminants from water, is the advanced oxidation process (AOP). The AOPs are based on the generation of reactive oxygen species (ROS) including inorganic radicals, such as $\mathrm{HO}^{\circ}$. AOPs usually enhance the biodegradation of organic pollutants but it could also lead to degradation intermediates which are more toxic than the original targeted molecules [212]. The activation of the AOPs can be performed either by catalysis, heat, light, or a combination of these means (e.g., photocatalysis and photo-Fenton). It is the technology based on the use of coupled catalysis and solar radiation which is highlighted in this section since the resulting process can reach high remediation efficiency along with sustainable development (i.e., efficient and environmentally friendly process).

In AOPs, the most important active species are hydroxyl radicals $\left(\mathrm{HO}^{\bullet}\right)$. $\mathrm{HO}^{\bullet}$ has two main characteristics. First, it is a strong oxidant with a redox potential $E^{0}\left(\mathrm{HO}^{\bullet} / \mathrm{H}_{2} \mathrm{O}\right)$ of $2.8 \mathrm{~V}$ vs. NHE. Second, it is a nonselective oxidant which is able to react with most of the organic contaminants with high bimolecular kinetic constants $\left(10^{8}-10^{11} \mathrm{M}^{-1} \cdot \mathrm{s}^{-1}\right)$. These characteristics are responsible for the high efficiency of AOPs in the removal of POPs and CECs [213]. The reaction between hydroxyl radicals and organic molecules proceeds mainly by hydrogen abstraction (from $\mathrm{C}-\mathrm{H}, \mathrm{N}-\mathrm{H}$, or $\mathrm{O}-\mathrm{H}$ bonds) and by hydroxyl addition to unsaturated bonds. It is worth noting that the involvement of hydroxyl radicals in organic decontamination process is not easy to demonstrate since the half-life of $\mathrm{HO}^{\bullet}$ is in the order of nanosecond. Therefore, most of their identification are performed using indirect methods such as fluorescence spectroscopy or electron paramagnetic resonance in the presence of suitable probe molecules. In addition to hydroxyl radicals, the photo-induced degradation of organic pollutants involve other radicals like superoxide anion $\left(\mathrm{O}_{2}{ }^{\bullet-}\right)$ and its conjugated form, hydroperoxyl radical $\left(\mathrm{HO}_{2}{ }^{\bullet}\right)$. These radicals are, however, less reactive than $\mathrm{HO}^{\bullet}$ [213].

These photo-induced AOPs are suitable techniques for the degradation of organic contaminants. Among them, direct photolysis, photocatalysis and photo-Fenton reaction are the most used processes. Direct photolysis is based on the sole use of light to break the chemical bonds in the contaminant molecule. Since UVB and UVC irradiations are the most used lights in direct photolysis, this method cannot be considered as sustainable process (and it is not discussed in this section) while photocatalytic and photo-Fenton processes are developed hereafter.

\section{Photocatalysis}

The photocatalysis is a photo-induced process combining the use light irradiation and catalysis. Therefore, the compounds which are employed in such a process are called photocatalysts like vanadium oxide based materials. In this case, the process is referred as heterogeneous photocatalysis since solid semiconductors are used. Prior to describe how heterogeneous photocatalysis is operating, a brief historical background, and some basic principles should be introduced. Although the definition of a semiconductor is in Section 3.1.2, the term semiconducting was first used by Alessandro Volta in 1782 and it is at the beginning of the 20th century that Johan Koenigsberger classified materials into conductor, insulator, and semiconductor. On the other hand, the concept of photoconductivity appeared in 1874 [164]. Indeed, an electron can move from valence band (VB) to conduction band $(\mathrm{CB})$ when the supplied energy to the semiconductor is higher than the 
energy band gap $\left(E_{g}\right)$-also known as forbidden energy band—which is the energy gap between the VB and the CB. The value of the energy band gap is an intrinsic value, thus varying from one material to another. In other words, under incident light of sufficient energy, the electrons move from $\mathrm{VB}$ to $\mathrm{CB}$ while holes have an opposite motion, thus generating a current [164].

A key parameters in the selection of a semiconductor photocatalyst is the value of the energy band gap along with the stability of the material. The principle of heterogeneous photocatalysis using semiconductors is based on the generation of electrons and holes, i.e., the $e^{-} / h^{+}$pairs (Equation (15)). Indeed, once the $e^{-} / h^{+}$pairs are photogenerated under an incident irradiation of energy $(h v)$ equal or larger than the energy band gap, these charge carriers are responsible in the formation of reactive oxygen species (Equations (16)-(22)) which, subsequently, degrade organic contaminants. The primary ROS are formed by the reaction of electron and hole with oxygen and water, respectively. However, the mechanism of hydroxyl radical generation is still the matter of discussions since the photogenerated holes can react also with surface hydroxyl function present at the surface of the photocatalyst. The degradation of pollutants can also occur directly through photogenerated holes (which are oxidant), but this reaction is not kinetically favored due to the strong reactivity of ROS with organic molecules. The formation of ROS does not only include the generation of superoxide and hydroxyl radicals, but also other species such as hydroperoxyl radicals and hydrogen peroxide, which is an important precursor of $\mathrm{HO}^{\bullet}$ (Equations (16)-(22)) [33]. $\mathrm{H}_{2} \mathrm{O}_{2}$ is also a key precursor in Fenton-based processes (Section Photo-Fenton and Fenton-Based Processes).

$$
\begin{gathered}
\text { Semiconductor }+h v \rightarrow e^{-}+h^{+} \\
\mathrm{OH}^{-}+h^{+} \rightarrow \mathrm{HO}^{\bullet} \\
\mathrm{H}_{2} \mathrm{O}+h^{+} \rightarrow \mathrm{HO}^{\bullet}+\mathrm{H}^{+} \\
\mathrm{O}_{2}+e^{-} \rightarrow \mathrm{O}_{2}^{\bullet-} \\
\mathrm{O}_{2}^{\bullet-}+\mathrm{H}^{+} \rightarrow \mathrm{HO}_{2}^{\bullet} \\
2 \mathrm{HO}^{\bullet} \rightarrow \mathrm{H}_{2} \mathrm{O}_{2} \\
\mathrm{H}_{2} \mathrm{O}_{2}+e^{-} \rightarrow \mathrm{HO}^{\bullet}+\mathrm{OH}^{-} \\
\mathrm{H}_{2} \mathrm{O}+\mathrm{O}_{2}^{\bullet-} \rightarrow \mathrm{HO}_{2} \bullet+\mathrm{OH}^{-}
\end{gathered}
$$

However, several conditions should be fulfilled to observe the above mentioned photocatalytic reactions. In addition to the fact that the $e^{-} / h^{+}$pair generation is in competition with the recombination process (releasing the absorbed energy in the form of either light or heat), the photogeneation of the charge carriers (electrons and holes) should reach the surface of the photocatalyst where they react with adsorbed reactants, since the photocatalysis is a surface dependent process (Langmuir-Hinshelwood model). In addition, the redox potential of the photocatalytic reaction (e.g., the generation of ROS) has to lie within the energy band gap (Figure 17). Therefore, the feasibility of a photocatalytic reaction depends mainly on the energetic position of the valence band maximum (VBM) and the conduction band minimum (CBM) of the semiconductor photocatalyst [33]. 


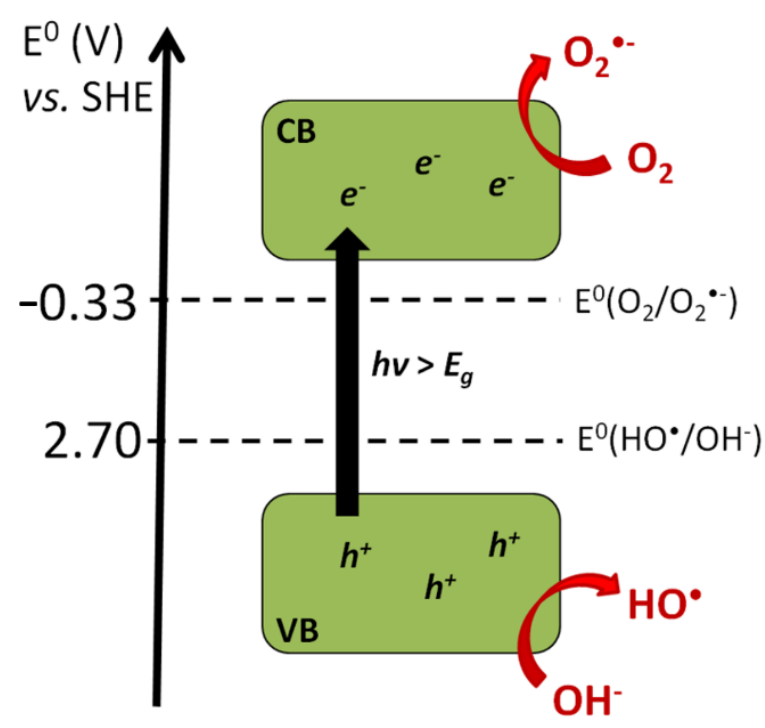

Figure 17. Mechanism of primary ROS generation by heterogeneous semiconductor photocatalysis.

Photo-Fenton and Fenton-Based Processes

Another important photo-induced process is the photo-Fenton reaction. Usually, this process describes the generation of ROS in the presence of iron. Indeed, the classical Fenton reaction was discovered in 1894 by H. J. H. Fenton whom observed the oxidation of tartaric acid in the presence of iron and hydrogen peroxide [214]. About 100 years later, the heterogeneous Fenton reaction was observed (Equations (23) and (24)). Compared to the homogeneous system, heterogeneous Fenton reaction can be used over a wider range of $\mathrm{pH}$ (e.g., environmental $\mathrm{pH}$ ) since there is no need to use acidic condition to avoid the production of sludge (from iron coagulation/precipitation). However, the mechanism of heterogeneous Fenton is still unresolved. This complexity is due to various interactions between the surface of the material with hydrogen peroxide, organic molecules (and their degradation byproducts), and the generated ROS [213]. It is admitted the main ROS are $\mathrm{HO}^{\bullet}$ and $\mathrm{HO}_{2} \bullet / \mathrm{O}_{2}^{\bullet-}$ which are either generated at the surface of the materials or at the close surroundings of the surface through possibly leached iron (i.e., homogeneous Fenton reaction) [213].

$$
\begin{gathered}
\equiv \mathrm{Fe}^{\mathrm{II}}+\mathrm{H}_{2} \mathrm{O}_{2} \rightarrow \equiv \mathrm{Fe}^{\mathrm{III}} \mathrm{OH}+\mathrm{HO}^{\bullet} \\
\equiv \mathrm{Fe}^{\mathrm{III}}+\mathrm{H}_{2} \mathrm{O}_{2} \rightarrow \equiv \mathrm{Fe}^{\mathrm{II}}+\mathrm{H}^{+}+\mathrm{HOO}^{\bullet}
\end{gathered}
$$

On the other hand, heterogeneous photo-Fenton reaction is considered as viable alternative to classical heterogeneous Fenton, since there is no need to add hydrogen peroxide to the system (Equation (25)). Indeed, the generation of inorganic radicals such as hydroxyl and superoxide radicals occurs via the photolysis of iron (III) where electron transfers occur with adsorbed water molecules, i.e., a ligand to metal charge transfer (LMCT). The AOPs generated by heterogeneous photo-Fenton reaction are efficient in the degradation of organic contaminants including pharmaceuticals, pesticides/herbicides, etc. $[215,216]$. Furthermore, it allows the possibility of using natural solar light, thus increasing the sustainibility of such a process.

$$
\equiv \mathrm{Fe}^{\mathrm{III}}+\mathrm{H}_{2} \mathrm{O}+h v \rightarrow \equiv \mathrm{Fe}^{\mathrm{II}}+\mathrm{H}^{+}+\mathrm{HO}^{\bullet}
$$

However, other transition metals can also trigger Fenton-type reactions. To increase the environmentally friendliness of these processes, it is possible to use elements that are abundant in the Earth's crust. Intense research is actually focused on these iron-free Fenton processes [217]. One important element is aluminum which has a stronger ability to convert $\mathrm{H}_{2} \mathrm{O}_{2}$ to $\mathrm{HO}^{\bullet}$ through $e^{-}$transfer due to more negative redox potential $\left(E^{0}\left(A l^{3+} / A l^{0}\right)=-1.66 \mathrm{~V}\right)$ than iron $\left(E^{0}\left(F e^{3+} / F e^{2+}\right)=+0.776 \mathrm{~V}\right)$. However, the main disad- 
vantage of using zero-valent aluminum is the formation of $\mathrm{Al}_{2} \mathrm{O}_{3}$ layer which is hard to remove, thus requiring strong acidic conditions to avoid the inhibition of the Fenton process. The generation of ROS in such a system mainly occurs through the in situ production of hydrogen peroxide by electron transfer to dissolved oxygen. The hydrogen peroxide is then subsequently decomposed to generate hydroxyl radicals (Figure 18) [217].

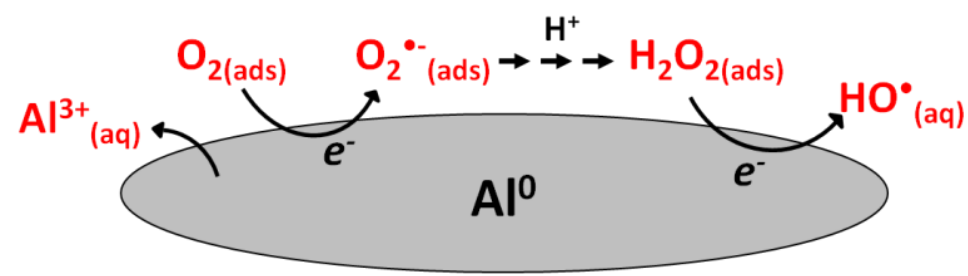

Figure 18. Generation of primary ROS at the surface of aluminum.

Another interesting element with high natural occurrence is manganese due to its versatility in oxidation states ranging from 0 to +VII. Among them, only Mn (II), Mn (III), and Mn (IV) can be used in Fenton-based processes. Mn (II) species are predominantly present in soluble form while $\mathrm{Mn}$ (III) and Mn (IV) exist in the form of oxides and hydroxides, such as $\mathrm{Mn}_{3} \mathrm{O}_{4}, \mathrm{Mn}_{2} \mathrm{O}_{3}, \mathrm{MnOOH}$, and $\mathrm{MnO}_{2}$. The latter is already known as oxidizing material for direct degradation (neither light nor radical precursor assistance) of adsorbed organic contaminants. In this iron-free Fenton process involving manganese, the mechanism is complex and it is not yet resolved. However, it is assumed that hydrogen peroxide is activated by interconversion between $\mathrm{Mn}^{2+}$ and $\mathrm{Mn}^{4+}$ via intermediate $\mathrm{Mn}^{3+}$. According to the type and the form of the oxide used, the main ROS are either hydroxyl radicals or superoxide radicals. The main advantage of this Mn-based Fenton process is a significant efficiency at circum-neutral conditions, especially for $\mathrm{pH}$ ranging from 4 to 8 [217].

Copper is the element which is the most analogeous to iron in Fenton-based processes. Indeed, like Fe (II) and Fe (III), monovalent and divalent copper can activate hydrogen peroxide to generate reactive oxygen species, especially $\mathrm{HO}^{\bullet}$ and $\mathrm{HO}_{2}{ }^{\bullet}$ (Equations (26) and (27)). The main advantage of copper oxides over iron ones is their stability ( $\mathrm{Cu}$ leaching is limited), thus allowing this iron-free Fenton reaction to run out at circum-neutral $\mathrm{pH}$. However, $\mathrm{Cu}$ (I) is readily oxidized into $\mathrm{Cu}$ (II) by oxygen, thus, its reaction with hydrogen peroxide is inhibited. This is a strong drawback which limits practical application of this system. Excess of $\mathrm{H}_{2} \mathrm{O}_{2}$ has to be used which increases the cost of this iron-free Fenton process but decrease the oxidation efficiency (by scavenging the generated $\mathrm{HO}^{\bullet}$ ) [217].

$$
\begin{aligned}
& \equiv \mathrm{Cu}^{\mathrm{II}}+\mathrm{H}_{2} \mathrm{O}_{2} \rightarrow \equiv \mathrm{Cu}^{\mathrm{I}}+\mathrm{H}^{+}+\mathrm{HOO}^{\bullet} \\
& \equiv \mathrm{Cu}^{\mathrm{I}}+\mathrm{H}_{2} \mathrm{O}_{2} \rightarrow \equiv \mathrm{Cu}^{\mathrm{II}}+\mathrm{OH}^{-}+\mathrm{HO}^{\bullet}
\end{aligned}
$$

Finally, vanadium is also an element which is active in Fenton-type reactions. Among the multiple oxidation states of vanadium, only V (V) to V (IV) can trigger a Fenton-like reaction (Equation (28)), but in the form of oxo-cations. Such reactions are observed in biochemical process involving vanadium [134], but also at the surface of vanadium oxide based materials [218]. It is worth noting that cerium, a lanthanide element, in soluble or solid form $\left(\mathrm{Ce}^{3+} /{ }^{4+}\right.$ or $\left.\mathrm{CeO}_{2}\right)$ can trigger Fenton-based processes on the same scheme as in the case of iron (Equations (29) and (30)). However, considering the toxicity of cerium, it cannot be implemented in applications for the treatment of water from organic contaminants [217].

$$
\begin{aligned}
& \mathrm{VO}^{2+}+\mathrm{H}_{2} \mathrm{O}_{2} \rightarrow \mathrm{VO}_{2}^{+}+\mathrm{H}^{+}+\mathrm{HO}^{\bullet} \\
& \equiv \mathrm{Ce}^{\mathrm{III}}+\mathrm{H}_{2} \mathrm{O}_{2} \rightarrow \equiv \mathrm{Ce}^{\mathrm{IV}}+\mathrm{OH}^{-}+\mathrm{HO}^{\bullet} \\
& \equiv \mathrm{Ce}^{\mathrm{IV}}+\mathrm{H}_{2} \mathrm{O}_{2} \rightarrow \equiv \mathrm{Ce}^{\mathrm{III}}+\mathrm{H}^{+}+\mathrm{HOO}^{\bullet}
\end{aligned}
$$


The mechanism using these transition metals in the photo-Fenton process has not been yet clearly demonstrated. However, since hydrogen peroxide can be in situ photochemically generated (e.g., by photocatalysis), the iron-free Fenton-based processes appear to have a significant contribution in photocatalytic systems based, for instance, on binary and ternary vanadium oxides.

\subsubsection{Binary Vanadium Oxides $\mathrm{V}_{2} \mathrm{O}_{5}$}

As discussed in Section 3.1, $\mathrm{V}_{2} \mathrm{O}_{5}$ materials are usually studied for applications in electrochemical devices, especially for Li-ion batteries. However, during the last decades, there is a growing interest of the use of vanadium pentoxide in photocatalytic applications, especially for the degradation of organic pollutants and the production of hydrogen by water splitting. In order to be thermodynamically feasible, the valence band maximum should be more positive than the redox potential of hydroxyl radical generation $\left(E^{0}\left(\mathrm{HO}^{\bullet} / \mathrm{H}_{2} \mathrm{O}\right)=2.8 \mathrm{~V}\right)$ and the conduction band minimum should be more negative than the redox potential of hydrogen formation $\left(E^{0}\left(\mathrm{H}^{+} / \mathrm{H}_{2}\right)=0 \mathrm{~V}\right)$, respectively [219]. Indeed, the $\mathrm{VBM}$ and $\mathrm{CBM}$ of $\mathrm{V}_{2} \mathrm{O}_{5}$ is about 2.6-3.0 V and from -0.1 to $+1.0 \mathrm{~V}$, respectively. Therefore, the band structure of $\mathrm{V}_{2} \mathrm{O}_{5}$ is suitable for these photocatalytic processes. It is worth noting that the generation of superoxide radical is theoretically not feasible $\left(E^{0}\left(\mathrm{O}_{2} / \mathrm{O}_{2}{ }^{\bullet-}\right)=-0.33 \mathrm{~V}\right)$, but $\mathrm{V}_{2} \mathrm{O}_{5}$ presents surface defects in the form of $\mathrm{V}^{4+}$ which allows the generation of superoxide radicals [219].

Vanadium pentoxide can be synthesized using different experimental methods and prepared in different forms (powders, films, etc.). Most of the preparation techniques involved wet chemical methods which allow the use of structure directing agent (Triton $\mathrm{X}-100$, polyvinylpyrrolidone, polyethylen glycol, etc.) in order to design a particular morphology. Whatever the method employed, all the prepared $\mathrm{V}_{2} \mathrm{O}_{5}$ photocatalysts require an annealing process in order to get crystalline materials, usually at temperature about $500{ }^{\circ} \mathrm{C}$.

Supported photocatalysts can be prepared using the sol-gel method along with the vanadium triisopropoxide oxide as precursor [220,221]. Another preparation procedure of supported $\mathrm{V}_{2} \mathrm{O}_{5}$ is the hydrothermal method [222]. Such a solvothermal method often implies ammonium metavanadate $\left(\mathrm{NH}_{4} \mathrm{VO}_{3}\right)$ as precursor, but bulk $\mathrm{V}_{2} \mathrm{O}_{5}$ powder can be also directly used as precursor. Indeed, in the presence of a reducing agent such as oxalic acid, $\mathrm{VO}_{2}$ (B) film is prepared (Equations (31) and (32)) which is subsequently converted into $\mathrm{V}_{2} \mathrm{O}_{5}$ with the appropriate morphology [222].

$$
\begin{aligned}
\mathrm{V}_{2} \mathrm{O}_{5}+3 \mathrm{H}_{2} \mathrm{C}_{2} \mathrm{O}_{4} & \rightarrow 2 \mathrm{VOC}_{2} \mathrm{O}_{4}+3 \mathrm{H}_{2} \mathrm{O}+2 \mathrm{CO}_{2} \\
\mathrm{VOC}_{2} \mathrm{O}_{4} & \rightarrow \mathrm{VO}_{2}+\mathrm{CO}_{2}+\mathrm{CO}
\end{aligned}
$$

By this mean, $\mathrm{V}_{2} \mathrm{O}_{5}$ films with different morphologies (including hierarchical nanostructures, nanorods, nanowires, etc.) can be deposited on different substrates such as sapphire, indium tin oxide (ITO) coated glass, etc. [220,222]. The thickness of the films can be regulated by the number of deposited layers on the substrate, and that can have an impact on the quality and the efficiency of the supported photocatalyst [220]. The calculated energy band gap $\left(E_{g}\right)$ is about $2.1 \mathrm{eV}$, so the $\mathrm{V}_{2} \mathrm{O}_{5}$ photocatalytic films can be used in the degradation of organic pollutants in aqueous or gaseous phases under simulated sunlight [220-222]. For instance, $\mathrm{V}_{2} \mathrm{O}_{5}$ nanowires films can degrade around $98 \%$ of toluidine blue $\mathrm{O}$, an organic dye, after 50 min under UV light [220]. Flower like nonastructure films are able to remove up to $74 \%$ and $63 \%$ of methylene blue under UV and visible light, respectively, after $200 \mathrm{~min}$ [222]. In addition, 51\% of this organic dye is mineralized into $\mathrm{CO}_{2}$ and $\mathrm{H}_{2} \mathrm{O}$ in the case of $\mathrm{UV}$ irradiation. Gaseous pollutants can be also efficiently degraded by $\mathrm{V}_{2} \mathrm{O}_{5}$ photocatalysis, such as for example 1,2-dichlobenzene [221]. Under visible light, about $45 \%$ of this organic contaminants can be degraded after $7 \mathrm{~h}$ 
irradiation in presence of $\mathrm{V}_{2} \mathrm{O}_{5}$ [221]. The excellent photocatalytic properties of $\mathrm{V}_{2} \mathrm{O}_{5}$ films are ascribed to large specific surface area and efficient visible light utilization [221,222].

On the other hand, $\mathrm{V}_{2} \mathrm{O}_{5}$ powders can be also preprared. As in the case of supported photocatalysts, sol-gel, and hydrothermal methods are often chosen to synthesize $\mathrm{V}_{2} \mathrm{O}_{5}$ powders using $\mathrm{NH}_{4} \mathrm{VO}_{3}$ and $\mathrm{H}_{2} \mathrm{O}_{2}$ as precursors [223,224]. In addition, co-precipitation can be also used in the presence of $\mathrm{NH}_{4} \mathrm{VO}_{3}$ and $\mathrm{HNO}_{3}$ [225]. The energy band gap of the synthesized $\mathrm{V}_{2} \mathrm{O}_{5}$ powders is about $2.3 \mathrm{eV}$ while the specific surface area is high for nanostructured powders [223-225]. Nanostructured powders can degrade efficiently rhodamine 6G, congo red, and methyl orange under visible light with removal extents of $78 \%, 99 \%$, and $82 \%$, respectively, after $180 \mathrm{~min}$ irradiation time [223,224]. Phenolic contaminants such as phenol, pyrocatechol (2-HP), 2-chlorophenol (2-CP) 2-nitrophenol (2-NP), and 2-aminophenol (2-AP) are also degraded by $\mathrm{V}_{2} \mathrm{O}_{5}$ photocatalysis under natural sunlight [225]. Although the degradation extents for phenol, 2-HP, 2-CP, 2-NP, and 2-AP are $13 \%, 40 \%, 68 \%, 81 \%$, and $37 \%$, the mineralization is lower with extents about $8 \%, 16 \%$, $42 \%, 29 \%$, and $27 \%$, respectively [225]. The high efficiency of $\mathrm{V}_{2} \mathrm{O}_{5}$ powder photocatalysts is due mainly to the high specific surface area, relatively good utilization of visible light and excellent electron-hole pair separation $[223,224]$. Indeed, based on the produced photocurrent and compared to commercial micro-sized $\mathrm{V}_{2} \mathrm{O}_{5}$ powder, the number of charge carriers reaching the surface of the nanostructured materials (where reactions occur) is higher [224]. In addition, the exposition of $\mathrm{V}_{2} \mathrm{O}_{5}$ to irradiation induces the formation of surface defects which are composed of $\mathrm{V}^{4+}$ states, thus improving the lifetime of charge carriers by electron trapping phenomenon [225]. Moreover, the reproducibility of the photocatalytic experiments is also excellent with almost no change in removal rate after repeated runs [223]. Furthermore, $\mathrm{V}_{2} \mathrm{O}_{5}$ nanopowders are also efficient antimicrobial agents with improved removal of Escherichia coli and Staphylococcus aureus bacteria [223]. Recently, the effect of various extra-drying process (e.g., vacuum, freeze, oven) during the preparation of $\mathrm{V}_{2} \mathrm{O}_{5}$ nanoparticles through wet chemical methods has shown a limitation in the particle aggregation, thus increasing the reactivity of the photocatalyst [226]. Indeed, the nanoparticles size are in the range of $30-40 \mathrm{~nm}$ and the specific surface area is in the range of $125-205 \mathrm{~m}^{2} \cdot \mathrm{g}^{-1}$ [226]. Therefore, the synthesis procedure is crucial in the preparation of efficient photocatalysts.

Concerning the mechanism of any photo-induced degradation of organic contaminants, the blank and dark experiments should be always performed, i.e., direct photolysis and adsorption, respectively. $\mathrm{V}_{2} \mathrm{O}_{5}$ cannot efficiently remove organic pollution via adsorption processes while solar and visible light has not enough energy to photolyze most of the organic contaminants [220]. The photocatalytic mechanism is a surface-dependent process following the model of Langmuir-Hinshelwood, thus requiring the adsorption of the target molecule onto the surface of the photocatalyst. Many studies have shown that the photocatalytic degradation of organic contaminants using $\mathrm{V}_{2} \mathrm{O}_{5}$ occurs mainly via the primary $\mathrm{ROS}$ which are superoxide and hydroxyl radicals [221,223-225]. Indeed, hydroxyl radicals are form by reaction of photogenerated holes with surface hydroxyl group or adsorbed water molecule $[221,225]$. However, the involvement of $\mathrm{O}_{2}{ }^{\bullet-}$ species is contradictory among the published works. Some scientists claim the reaction of photogenerated electrons with dissolved oxygen and subsequently, hydrogen peroxide and hydroxyl radicals can be formed by a cascade of reactions (Equations (19), (33)-(35)) according to the $\mathrm{pH}[221,224,225]$. However, regarding the band structure of $\mathrm{V}_{2} \mathrm{O}_{5}$, especially the conduction band minimum, the formation of $\mathrm{O}_{2}{ }^{--}$is not thermodynamically feasible [225]. A viable tool for the identification of ROS, particularly for $\mathrm{HO}^{\bullet}$ and $\mathrm{O}_{2}{ }^{\bullet-}$, is the electron paramagnetic resonance (EPR). Indeed, the signals of $\mathrm{DMPO}-\mathrm{HO}^{\bullet}$ and $\mathrm{DMPO}^{-\mathrm{O}_{2}}{ }^{-}$spin adducts have a characteristics hyperfine structure [224]. By this mean, the photocatalytic degradation of organic contaminant in the presence of $\mathrm{V}_{2} \mathrm{O}_{5}$ suggests a negligible contribution of the superoxide radicals [224].

$$
\begin{gathered}
\mathrm{HO}_{2}{ }^{\bullet}+\mathrm{HO}_{2} \bullet \rightarrow \mathrm{H}_{2} \mathrm{O}_{2}+\mathrm{O}_{2} \\
\mathrm{O}_{2}^{\bullet-}+\mathrm{H}_{2} \mathrm{O}_{2} \rightarrow \mathrm{OH}^{\bullet}+\mathrm{OH}^{-}+\mathrm{O}_{2}
\end{gathered}
$$




$$
\mathrm{H}_{2} \mathrm{O}_{2}+h v \rightarrow 2 \mathrm{OH}^{\bullet}
$$

The degradation of aromatic compounds results in ring opening through the oxidation by $\mathrm{HO}^{\bullet}$, and ultimately leads to smaller species such as acetate and maleate [221]. In the case of organic dye, degradation occurs via $\mathrm{N}$-deethylation, thus giving rise to smaller intermediates such as benzoic acid, hydroxybenzoic acid, etc. [223]. It is important to mention that the $\mathrm{pH}$ of the system is a crucial parameter [223,225]. Indeed, the ionic form of the organic pollutants (which is related to its $p K_{a}$ ) and the charge surface properties of the material are dependent to the $\mathrm{pH}$, thus impacting the interactions pollutant/photocatalyst. In addition, the $\mathrm{pH}$ affect also the generation of ROS [225]. For instance, at low $\mathrm{pH}$, superoxide radicals form hydroperoxyl radicals (Equation (19)) and subsequently hydrogen peroxide (Equations (33) and (37)) which is a precursor for the generation of hydroxyl radicals (Equations (21), (34), and (35)) [225].

To resume, vanadium pentoxide nanostructured materials are promising solar light driven photocatalysts for the remediation of water from organic contaminants. So far, many studies have been focused on the removal of organic dyes, thus, the self-sensitization of the photocatalyst for the generation of ROS is possibly involved. Therefore, further works on colorless POPs and CECs are necessary in order to draw a better overview on the efficiency of $\mathrm{V}_{2} \mathrm{O}_{5}$ photocatalysis.

\section{$\mathrm{VO}_{2}$}

Vanadium dioxide is thoroughly investigated for applications as smart windows due to its thermochromic properties (Section 2.2). The study of its photocatalytic properties is not yet well documented although it is a promising photoactive material. Among the different polymorphs of vanadium dioxide, $\mathrm{VO}_{2}(\mathrm{~B})$ exhibits interesting photocatalytic properties although it is a semiconductor which is not thermochromic and which has a slightly larger energy band gap than that of $\mathrm{V}_{2} \mathrm{O}_{5}$, with a value of $2.8 \mathrm{eV}$ [227]. Supported $\mathrm{VO}_{2}(\mathrm{~B})$ can be prepared by an aqueous sol-gel method using $\mathrm{V}_{2} \mathrm{O}_{5}$ and hydrogen peroxide as precursors. The deposition of the sol-gel should be performed on substrates that will not react with the vanadium oxide layer (such as $\mathrm{Si} / \mathrm{SiO}_{2}$ and sapphire) since on lime glass, contamination by ion diffusion could occur during the annealing process [228]. Layered $\mathrm{VO}_{2}(\mathrm{~B})$ is obtained by annealing in reducing conditions, e.g., in $\mathrm{H}_{2}$ / $\mathrm{Ar}$ atmosphere or in vacuum in order to reduce $\mathrm{V}_{2} \mathrm{O}_{5}$ to mixed valence $\mathrm{V}_{4} \mathrm{O}_{9}$ and ultimately to $\mathrm{VO}_{2}$. The photocatalytic activity of $\mathrm{VO}_{2}$ (B) films is considerably better than that of $\mathrm{V}_{2} \mathrm{O}_{5}$ with a more efficient removal of Rhodamine B under UVA light [227]. The higher photocatalytic efficiency could be ascribe to the defect at the surface of vanadium oxide since the reductive annealing leads to more oxygen vacancies which are beneficial for the $e^{-} / h^{+}$pairs separation.

Since the literature on single phase $\mathrm{VO}_{2}$ photocatalysts is scarce, composites containing $\mathrm{VO}_{2}$ is also discussed in this section. Usually, the synthesis procedure of such materials involves hydrothermal methods using $\mathrm{V}_{2} \mathrm{O}_{5}$ and a reducing agent such as citric and oxalic acid [229-233]. By this mean, $\mathrm{VO}_{2}(\mathrm{~B})$ and $\mathrm{VO}_{2}(\mathrm{M})$ can be prepared according to the experimental conditions. Then heterojunctions with another semiconductor metal oxide can be formed using, for instance, dispersion of $\mathrm{VO}_{2}$ powder into a metal alkoxide sol-gel $[230,231,233] . \mathrm{VO}_{2}(\mathrm{~B}) / \mathrm{CeO}_{2}$ photocatalysts in the form of nanoparticles exhibit efficient photo-induced properties for the removal of Rhodamine $\mathrm{B}$ with a removal extent reaching up to $66 \%$ in 180 min under UV irradiation. Similarly, $\mathrm{VO}_{2}$ alone can remove only $29 \%$ of this dye under the same experimental conditions [229]. The better photocatalytic properties of $\mathrm{VO}_{2}(\mathrm{~B}) / \mathrm{CeO}_{2}$ is explained by a smaller energy band gap $\left(E_{g}=3.25 \mathrm{eV}\right)$ compared to that of pure $\mathrm{VO}_{2}\left(E_{g}=3.5 \mathrm{eV}\right)$. This shift toward lower values is due to the presence of $\mathrm{CeO}_{2}$ which absorbs larger extent of the visible light [229]. $\mathrm{VO}_{2}(\mathrm{M}) / \mathrm{ZnO}$ composite is a photocatalyst with high specific surface area and energy band gap of $2.67 \mathrm{eV}$ [231]. Indeed, in the form of a hierarchical structure, $\mathrm{VO}_{2}(\mathrm{M}) / \mathrm{ZnO}$ gives rise to a specific surface area of about $70 \mathrm{~m}^{2} \cdot \mathrm{g}^{-1}$ which is a two-fold increase compared to the single component, thus, increasing the number of photocatalytic sites. In such a composite, $\mathrm{ZnO}$ is responsible to the widening of $E_{g}$ due its energy band gap of $2.7 \mathrm{eV}$ 
compared to $2.3 \mathrm{eV}$ for pure $\mathrm{VO}_{2} . \mathrm{VO}_{2}(\mathrm{M}) / \mathrm{ZnO}$ photocatalyst can degrade up to $80 \%$ Rhodamine $\mathrm{B}$ under solar like irradiation after $20 \mathrm{~min}$, which is significantly better than the single components [231]. In addition, the reproducibility after repeated photocatalytic runs is excellent while the composite remains stable without any dissolution of the material. Another efficient composite photocatalyst is $\mathrm{VO}_{2}(\mathrm{M}) / \mathrm{TiO}_{2}$ which is able to degrade completely methylene blue within 10 min under UV light and about 70\% of Rhodamine B after $2.5 \mathrm{~h}$ under solar irradiation $[230,231,233]$. However, the purpose of this latter composite is to design thermochromic and self-cleaning coating by combining the properties of $\mathrm{TiO}_{2}$ and $\mathrm{VO}_{2}$. Therefore, the photocatalytic properties are ascribed only to $\mathrm{TiO}_{2}$, thus, assuming a negligible contribution of $\mathrm{VO}_{2}$ in the photocatalytic mechanism [230,233].

The mechanism of photocatalytic degradation of organic pollutant in the presence of $\mathrm{VO}_{2}$ based photocatalysts involves the generation of primary ROS (i.e., $\mathrm{HO} \mathrm{\bullet}^{\bullet}$ and $\mathrm{O}_{2}{ }^{\bullet-}$ ) by reaction of water and oxygen with photogenerated holes and electrons, respectively [229]. These strong oxidizing radicals are the main reactive species in the mineralization of organic contaminants. In addition, in the case of $\mathrm{VO}_{2}(\mathrm{~B}) / \mathrm{CeO}_{2}, \mathrm{CeO}_{2}$ plays the role of an electron trap, thus, the photogenerated $e^{-}$are accumulated in there, that improves the $e^{-} / h^{+}$pairs separation [229]. It is also plausible that $\mathrm{CeO}_{2}$ induces Fenton-type reactions which would explain the excellent efficiency of this composite photocatalyst. For $\mathrm{VO}_{2}(\mathrm{M}) / \mathrm{ZnO}$ photocatalyst, photocorrosion of $\mathrm{ZnO}$ was expected (Equation (36)) but in this type-II hetrojunction, the photogenerated holes are accumulated in $\mathrm{VO}_{2}$ while electrons are transferred to $\mathrm{ZnO}$, thus, reducing the photocorrosion and limiting the recombination of $e^{-} / h^{+}$pairs [231].

$$
\mathrm{ZnO}+2 h^{+} \rightarrow \mathrm{Zn}^{2+}+1 / 2 \mathrm{O}_{2}
$$

Vanadium dioxide can be also combined with ternary oxides such as silver vanadate $\left(\mathrm{Ag}_{3} \mathrm{VO}_{4}\right)$ [232]. $\mathrm{VO}_{2} / \mathrm{Ag}_{3} \mathrm{VO}_{4}$ composite prepared by hydrothermal method exhibits efficient utilization of both UVA and visible light (at $\lambda<420 \mathrm{~nm}$ ) since about $73 \%$ of Rhodamine $\mathrm{B}$ is removed after $90 \mathrm{~min}$ irradiation time. The reproducibility and stability of this composite is also stable. To explain the excellent photocatalytic efficiency of $\mathrm{VO}_{2} / \mathrm{Ag}_{3} \mathrm{VO}_{4}$, $\mathrm{VO}_{2}$ is ascribed as the key component, since in this composite, it acts as electron trap, thus improving the $e^{-} / h^{+}$pairs separation [232].

\section{Mixed Valence Vanadium Oxides}

Mixed valence vanadium oxides are attractive materials for many applications. Among these oxides, $\mathrm{V}_{4} \mathrm{O}_{9}$ and $\mathrm{V}_{6} \mathrm{O}_{13}$ are the most investigated in photocatalytic applications. One of the first works about the photocatalytic properties of such bynary vanadium oxides appeared in 1990 where the photo-induced degradation of isopropanol was 2.5-fold enhanced under UV-visible light [234]. Indeed, $\mathrm{V}_{2} \mathrm{O}_{5}$ is already a good photocatalyst in the degradation of organic contaminants, but the amount of electronic defects (i.e., the presence of $\mathrm{V}^{4+}$ at $\mathrm{V}_{2} \mathrm{O}_{5}$ surface) is assumed to play a key role in the photocatalytic efficiency. Thus, by extending this hypothesis, vanadium oxides of mixed V (IV) and V (V) should exhibit improved photocatalytic properties [234,235]. Although such oxides are promising, they are much less studied than $\mathrm{V}_{2} \mathrm{O}_{5}$ and $\mathrm{VO}_{2}$ [236]. Usually $\mathrm{V}_{4} \mathrm{O}_{9}$ and $\mathrm{V}_{6} \mathrm{O}_{13}$ are synthesized from $\mathrm{V}(\mathrm{V})$ precursors such as $\mathrm{V}_{2} \mathrm{O}_{5}$ and $\mathrm{NH}_{4} \mathrm{VO}_{3}$ which are reduced by heat treatment in either vacuum or reducing atmosphere [234-236].

$\mathrm{V}_{6} \mathrm{O}_{13}$ is probably the most documented mixed valence vanadium oxides [234-236]. This photocatalyst can oxidize completely 3-hexanol under visible light $(\lambda=460 \mathrm{~nm})$ while in the dark or using photo-activated $\mathrm{VO}_{2}$ and $\mathrm{V}_{2} \mathrm{O}_{5}$, the degradation of this alcohol is negligible [236]. In addition, the photocatalytic degradation of primary alcohols including 1-pentanol, 1-hexanol, 1-octanol, 1-nonanol, and 1-decanol is also efficient using $\mathrm{V}_{6} \mathrm{O}_{13}$ photocatalyst. It is worth noting that this photocatalytic degradation is selective since about $70 \%$ of the alcohols is oxidized in aldehyde [236]. Furthermore, the photocatalytic degradation of secondary alcohols using $\mathrm{V}_{6} \mathrm{O}_{13}$ leads to more than $70 \%$ selectivity in the formation of ketones. $\mathrm{V}_{6} \mathrm{O}_{13}$ photocatalyst can also efficiently degrade saturated hydrocarbons, especially aromatics, such as xylene and toluene [236]. In the form of a composite, 
$\mathrm{V}_{6} \mathrm{O}_{13}$ is also an efficient photocatalyst [235]. Indeed, $\mathrm{VO}_{2} / \mathrm{V}_{6} \mathrm{O}_{13}$ can remove organic contaminants, such as atrazine and methylene blue under visible light with an excellent reproducibility after repeated runs, thus indicating the stability of the photocatalyst. This photoactive nanostructured $\mathrm{VO}_{2} / \mathrm{V}_{6} \mathrm{O}_{13}$ is able to completely mineralize atrazine after $2 \mathrm{~h}$ irradiation while $75 \%$ of methylene blue can be degraded within $1 \mathrm{~h}$, which is significantly better than $\mathrm{V}_{2} \mathrm{O}_{5}$ and $\mathrm{VO}_{2}$ photocatalysis [235]. The $\mathrm{VO}_{2} / \mathrm{V}_{6} \mathrm{O}_{13}$ exhibits high specific surface area (about $25 \mathrm{~m}^{2} \cdot \mathrm{g}^{-1}$ ) and an energy band gap of $2.4 \mathrm{eV}$. It is worth noting that, in the $\mathrm{VO}_{2} / \mathrm{V}_{6} \mathrm{O}_{13}$, the band structure is modified due to the formation of heterojunction, thus extending the light absorption in the visible part of the spectrum [235].

Concerning the degradation mechanisms, the presence of $\mathrm{V}$ (IV) leads to the formation of oxygen vacancies which (i) enhanced the adsorption of the organic molecule at the surface of the material and (ii) improved the $e^{-} / h^{+}$pairs separation [234]. The photoinduced generation of primary ROS such as hydroxyl and superoxide radicals operates more efficiently due to the presence of V (IV) at the surface of the photocatalyst [234]. An alternative mechanism of photocatalytic degradation of organic molecules proceeds via chemisorption of the contaminant onto the surface of the material followed by excitation of the V-O-C bonding [236]. This phenomenon causes the elimination of protons in alpha position, and ultimately to the production of byproducts. This mechanistic scheme is different from the conventional photocatalytic mechanism [236]. In composite photocatalyst like $\mathrm{VO}_{2} / \mathrm{V}_{6} \mathrm{O}_{13}$, the adsorption of organic pollutants at the surface of the material is improved, thus being one reason of the excellent photocatalytic efficiency. In addition, the presence of both V (IV) and V (IV) improves the separation of charge carriers, namely the photogenerated electrons and holes, thus giving rise to higher production of primary reactive oxygen species that lead to the mineralization of organic contaminants into $\mathrm{CO}_{2}$ and $\mathrm{H}_{2} \mathrm{O}$ [235].

Another popular mixed valence vanadium oxide is $\mathrm{V}_{4} \mathrm{O}_{9}$ [237]. This compound has shown efficient but smaller photo-induced properties than $\mathrm{V}_{6} \mathrm{O}_{13}$. Indeed, $\mathrm{V}_{4} \mathrm{O}_{9}$ photocatalyst can degrade Rhodamine B under visible light with a removal extent of $45 \%$ after $3 \mathrm{~h}$ irradiation. The energy band gap of $\mathrm{V}_{4} \mathrm{O}_{9}$ is about $2.13 \mathrm{eV}$. It is also interesting to note that this mixed valence oxide is not often mentioned in the literature as a photocatalyst for several reasons. The first one is that $\mathrm{V}_{4} \mathrm{O}_{9}$ has similar photocatalytic efficiency as $\mathrm{V}_{2} \mathrm{O}_{5}$ which is easier to prepare. The second one is the similar crystalline structure between $\mathrm{V}_{2} \mathrm{O}_{5}$ and $\mathrm{V}_{4} \mathrm{O}_{9}$ which both have an orthorhombic system, thus resulting in very similar diffractions during the characterization by XRD [237]. Consequently, it is plausible that $\mathrm{V}_{4} \mathrm{O}_{9}$ has been confused with $\mathrm{V}_{2} \mathrm{O}_{5}$. The mechanism of photocatalytic degradation of organic pollutants using $\mathrm{V}_{4} \mathrm{O}_{9}$ exhibits predominant role of superoxide radicals and photogenerated holes [237].

\subsubsection{Ternary Vanadium Oxides \\ Bismuth Vanadates}

Among ternary vanadium oxides based on vanadium, $\mathrm{BiVO}_{4}$ is probably the most studied one due to bismuth which broadens the response of the material in the visible light, thus increasing its applicability for photocatalysis under sunlight. In addition, $\mathrm{BiVO}_{4}$ is stable and non-toxic which highlight its environmental compatibility $[149,238]$. Bismuth vanadate exists in three polymoprhs (Section 2.1) where the monoclinic scheelite phase is the most photocatalytically efficient [33]. Indeed, it is a promising visible light driven semiconductor photocatalyst which is mainly investigated in suspended systems and supported materials. The latter is more convenient for environmental applications since the immobilization of the photocatalyst on supports such as glass and polymer is beneficial for post-treatment separation [33]. $\mathrm{BiVO}_{4}$ with different morphologies can be designed using wet chemical methods, especially hydrothermal techniques [238]. By this mean, different hierarchical structures can be prepared by varying experimental conditions including $\mathrm{pH}$, temperature, type of precursor, and presence of structure directing agent $[238,239]$. Prior to develop the applications of $\mathrm{BiVO}_{4}$ in photo-induced processes for the degradation 
of organic pollutants, it is worth mentioning that the photocatalytic efficiency in the degradation of organic pollutants differs from one work to another. These differences are due to the way of synthesis of $\mathrm{BiVO}_{4}$, the type of incident radiation and the kind of targeted pollutant [33].

Most of the literature is devoted to the degradation of organic dyes. Although they are not considered as suitable model pollutants, organic dyes are environmentally relevant contaminants and they provide an overview on the feasibility of the tested material in the removal of organic pollutants. Nanostructured $\mathrm{BiVO}_{4}$ with $1 \mathrm{D}$ and $2 \mathrm{D}$ morphology can degrade up to $93 \%$ of methylene blue and $86 \%$ of methyl orange after 60 and $150 \mathrm{~min}$ visible light irradiation, respectively. In addition, $\mathrm{BiVO}_{4}$ nanotubes are able to completely remove Rhodamine B after only 15 min irradiation. These excellent removal extents are mainly ascribed to the high specific surface area which is ranging from 5 to $45 \mathrm{~m}^{2} \cdot \mathrm{g}^{-1}$ for such nanostructures. These values are considerably higher than those of bulk $\mathrm{BiVO}_{4}$ (about $0.5 \mathrm{~m}^{2} \cdot \mathrm{g}^{-1}$ ) [238]. The high specific surface area is associated with the increase of active site number and better adsorption properties. Furthermore, the recombination rate between $e^{-} / h^{+}$pairs is smaller than in bulk structure due to better transfer of charge carriers at the surface (i.e., shorter pathway resulted from smaller particle size) [238]. Other structures such as hierarchical ones are also efficient in the degradation of organic pollutants. For example, denditric, hollow sphere and olive-like $\mathrm{BiVO}_{4}$ can degrade under visible light more than $80 \%$ of a wide range of organic dyes (e.g., Rhodamine B and methylene blue) after short irradiation times [238]. Like 1D and 2D nanostructured $\mathrm{BiVO}_{4}$, the main advantage of hierarchical structures is their high specific surface area (higher than $2 \mathrm{~m}^{2} \cdot \mathrm{g}^{-1}$ ) [238].

Since the decolorization of organic dyes provides only basic knowledge of the feasibility of the photocatalytic reactions using recent materials, deeper insights into $\mathrm{BiVO}_{4}$ mediated photo-induced processes for the removal of organic contaminants are required [33]. To this end, two strategies are possible: (i) the study of the degradation pathway and mineralization extent of organic dyes; and (ii) the use of uncolored model pollutants in order to avoid self-sensitization process (i.e., in order to study the intrinsic properties of the photoactive material). The mineralization of the contaminants is crucial since incomplete removal could lead to more toxic intermediate byproducts [33]. Concerning the first strategy, total organic carbon and mass spectrometry studies have shown that $\mathrm{BiVO}_{4}$ is able to mineralize $65 \%$ of methylene blue under visible light while the intermediate degradation products are composed of hydroxylated aromatics [33]. In addition, the complete removal of Rhodamine $\mathrm{B}$ by the visible light driven $\mathrm{BiVO}_{4}$ photocatalyst is associated to only $40 \%$ mineralization extent after $100 \mathrm{~h}$ irradiation time [240]. The degradation of Rhodamine B follows two main pathways which are the deethylation process and the removal of the chromophore since the identified intermediates are ethylbenzene, xylene, etc. [240]. Concerning the second strategy, pharmaceutical compounds are often used such as ibuprofen (IBP) and ciprofloxacin (CIP) [241,242]. Indeed, under UVA light, $\mathrm{BiVO}_{4}$ can degrade about $90 \%$ of IBP and $65 \%$ of $\mathrm{CIP}$. $\mathrm{BiVO}_{4}$ photocatalyst is also efficient in the degradation of phenolic compounds such as nonyl- and octyl-phenols which are well known endocrine disruptor compounds [243]. In this latter case, the alkyl chain of the phenolic compounds plays the role of an anchor on the surface of $\mathrm{BiVO}_{4}$, thus improving its adsorption onto the surface of the photocatalyst and improving the degradation reaction. Apart from aqueous pollutants, $\mathrm{BiVO}_{4}$ can also degrade contaminants in gaseous phase including isopropyl alcohol and nitrogen oxides [244,245]. For instance, under visible light, $\mathrm{BiVO}_{4}$ is able to convert $25 \%$ of $\mathrm{N}_{2} \mathrm{O}$ after $12 \mathrm{~h}$ irradiation time. To improve the photocatalytic efficiency of $\mathrm{BiVO}_{4}$, besides doping and preparation of composite, an interesting strategy is to use simultaneously different contaminants which are removed by reduction and oxidation processes. Indeed, the case of dual phenol and chromium (VI) pollution can be efficiently treated using $\mathrm{BiVO}_{4}$ since phenol can be oxidized and mineralized into $\mathrm{CO}_{2}$ and $\mathrm{H}_{2} \mathrm{O}$ while $\mathrm{Cr}$ (VI) can be reduced in Cr (III) (which is much less toxic) [246]. Concretely, after $3 \mathrm{~h}$ irrdiation time under visible light, complete removal of $\mathrm{Cr}$ (VI) is achieved and $60 \%$ of phenol is mineralized by the $\mathrm{BiVO}_{4}$ photocatalysis. For comparison, at similar experimental condition and using 
phenol alone, only $10 \%$ of the pollutant is completely removed. Another interesting strategy to enhance the photocatalytic ability of $\mathrm{BiVO}_{4}$ is to prepare or anneal the material in reducing atmosphere $\left(\mathrm{H}_{2}\right)$ in order to generate oxygen vacancies which improve the charge carrier transport, thus resulting in better photocatalytic efficiency [247]. Under visible light, hydrogenated $\mathrm{BiVO}_{4}$ can degrade up to $98 \%$ of tetracycline which is significantly higher than the $52 \%$ achieved using pristine $\mathrm{BiVO}_{4}$.

The mechanism of degradation of organic pollutants using $\mathrm{BiVO}_{4}$ is crucial and several contradictions are present in the literature. Indeed, the identification of the main reactive oxygen species gives rise to different results from one work to another. Some researchers have stated the main ROS are hydroxyl radicals while other ones have found the main contribution in organic pollutant degradation is from superoxide radicals. These differences are due to misinterpretation of results that arises from unreliable employed method to identify the primary ROS such as the scavenging method. Therefore, more sophisticated methods should be employed like for instance the electron paramagnetic resonance (EPR). By EPR, it has been proven that $\mathrm{BiVO}_{4}$ photocatalytically generates neither hydroxyl radicals nor superoxide radicals [248]. Indeed, the theoretical band structure of monoclinic scheelite $\mathrm{BiVO}_{4}$ (at normal conditions) exhibits a conduction band minimum and valence band maximum of $0 \mathrm{~V}$ and $2.4 \mathrm{~V}$ vs. NHE, respectively (Figure 19). Therefore, the redox potential for the formation of primary ROS, i.e., $E^{0}\left(\mathrm{O}_{2} / \mathrm{O}_{2}{ }^{\bullet-}\right)$ and $E^{0}\left(\mathrm{OH}^{\bullet} / \mathrm{H}_{2} \mathrm{O}\right)$ are not within the energy band gap of $\mathrm{BiVO}_{4}$, thus, the production of these radicals is thermodynamically not favored $[33,198,239,248]$.

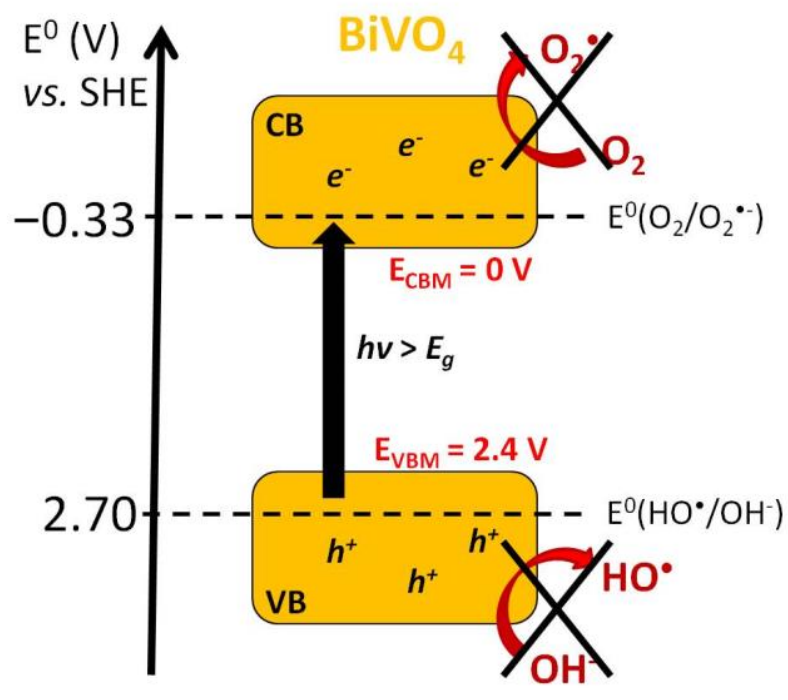

Figure 19. Energy diagram of the band structure of $\mathrm{BiVO}_{4}$ photocatalyst.

However, why $\mathrm{HO} \bullet$ is often detected in $\mathrm{BiVO}_{4}$ photocatalytic systems? One reason is the $\mathrm{pH}$ value of the reaction system. The theoretical band structure of $\mathrm{BiVO}_{4}$ is for $\mathrm{pH}=0$ while in practice, the $\mathrm{pH}$ is so-called natural. Therefore, an increase of $\mathrm{pH}$ leads to a shift of the bands toward negative values, thus allowing the formation of superoxide radicals. These $\mathrm{O}_{2}{ }^{\bullet-}$ can be converted into $\mathrm{HO}^{\bullet}$ via the generation of $\mathrm{H}_{2} \mathrm{O}_{2}$ during the photocatalytic process according to the chemical reaction (Equations (21) and (37)) [240,241,249]. It is worth noting that even at natural $\mathrm{pH}$, the generation of hydroxyl radicals by photogenerated holes from $\mathrm{BiVO}_{4}$ is even less favored [241].

$$
\mathrm{O}_{2}^{\cdot-}+2 \mathrm{H}^{+}+e^{-} \rightarrow \mathrm{H}_{2} \mathrm{O}_{2}
$$

The second reason is when organic dyes are used. In this case, sensitization of $\mathrm{BiVO}_{4}$ occurs by transfer of electrons from the excited state of the dye to the conduction band of the photocatalyst (Equations (38) and (39)). Therefore, the resulted improvement of the 
photocatalytic process is not due to the intrinsic photo-induced properties of $\mathrm{BiVO}_{4}$. Indeed, the injected electrons in the $\mathrm{BiVO}_{4}$ react with oxygen to produce superoxide radicals, thus following the reaction scheme above (Equations (18), (19), (33)-(35) and (37)), i.e., the generation of $\mathrm{H}_{2} \mathrm{O}_{2}$ and subsequently $\mathrm{HO}^{\bullet}$ [240].

$$
\begin{gathered}
\mathrm{RhB}+h v \rightarrow \mathrm{RhB}^{*} \\
\mathrm{BiVO}_{4}+\mathrm{RhB}^{*} \rightarrow \mathrm{RhB}^{\bullet+}+\mathrm{BiVO}_{4}\left(e^{-}\right)
\end{gathered}
$$

The production of hydroxyl radicals is strongly dependent of the $\mathrm{pH}$ which is the key factor. Some researchers stated that the generation of hydroxyl radicals from superoxide radicals is favored at low $\mathrm{pH}$ while other scientists discussed that the alkaline $\mathrm{pH}$ might be more favorable due to the presence of $\mathrm{OH}^{-}$, which is easily convertible into $\mathrm{HO}$ ' by reaction with photogenerated holes. However, the latter case has been demonstrated to be thermodynamically not feasible. Although $\mathrm{BiVO}_{4}$ is a promising photocatalyst for environmental remediation, further studies are required to develop its application for degradation of a wider range of contaminants and to clear out the uncertainties of its degradation mechanism.

Other bismuth vanadates such as $\mathrm{Bi}_{4} \mathrm{~V}_{2} \mathrm{O}_{11}$ and $\mathrm{Bi}_{8} \mathrm{~V}_{2} \mathrm{O}_{17}$ are also used as visible light driven photocatalysts $[250,251]$. The preparation methods of these materials are similar to that for $\mathrm{BiVO}_{4}$, thus $\mathrm{BiVO}_{4}$ is often present as impurity, i.e., pure mixed valence bismuth vanadate is not easily prepared. However, their use in the removal of organic pollutants is efficient under visible light. For instance, $\mathrm{BiVO}_{4} / \mathrm{Bi}_{4} \mathrm{~V}_{2} \mathrm{O}_{11}$ can be efficiently degrade and mineralize sulfamethazine with degradation and mineralization extents of $95 \%$ and $50 \%$, respectively [250]. The main primary ROS are identified as superoxide radicals.

\section{Iron Vanadates}

Iron vanadates, especially $\mathrm{FeVO}_{4}$, are interesting materials for the photo-induced degradation of organic pollutants. Indeed, due to their semiconducting properties and the presence of iron, both photocatalytic and photo-Fenton processes can be triggered using these photoactive materials. Although iron vanadates are gaining stronger interest within the photochemical community, few works on pure single phase are reported, thus, composite materials based on iron vanadates are also discussed in this section.

$\mathrm{FeVO}_{4}$ is a semiconductor with an energy band gap of about $2.15 \mathrm{eV}$, thus absorbing visible light [156]. The conduction band minimum is positioned at $-0.65 \mathrm{eV}$ while the valence band maximum is at $1.50 \mathrm{eV}$. $\mathrm{FeVO}_{4}$ can be synthesized by wet chemical methods using iron nitrate and ammonium metavanadate as precursors, and structure-directing agents (e.g., PEG and PVP) to design a particular morphology [132,156]. According to the morphology, the $E_{g}$ varies from 2.1 to $3.0 \mathrm{eV}$ where nanostructures exhibit higher energy band gap than bulk ones [132,156,252-254]. The specific surface area is found to vary between 15 and $30 \mathrm{~m}^{2} \cdot \mathrm{g}^{-1}[132,254]$. $\mathrm{FeVO}_{4}$ photocatalysts are efficient for the removal of organic dyes under UVA light with removal extents of about $90 \%$ for Rhodamine B and $50 \%$ for phenol red after $300 \mathrm{~min}$ and $120 \mathrm{~min}$ irradiation time, respectively [156,252,254]. However, under visible light, the photocatalytic efficiency is lower $[156,254]$. Indeed, about $70 \%$ of Rhdomaine B can be degraded after $5 \mathrm{~h}$ irradiation time with less than $10 \%$ mineralization rate [151,156,253,254].

Due to the presence of iron in the material, $\mathrm{FeVO}_{4}$ can also triggered Fenton-type reactions. For instance, in the presence of $\mathrm{H}_{2} \mathrm{O}_{2}$, the degaradtion of Rhodmaine $\mathrm{B}$ is almost completed under visible light [254]. Compared to classical heterogeneous Fenton catalysts such as hematite $\left(\alpha-\mathrm{Fe}_{2} \mathrm{O}_{3}\right)$, magnetite $\left(\mathrm{Fe}_{3} \mathrm{O}_{4}\right)$, and goethite $(\gamma-\mathrm{FeOOH}), \mathrm{FeVO}_{4}$ is able to efficiently activate $\mathrm{H}_{2} \mathrm{O}_{2}$ into hydroxyl radicals with the removal of more than $90 \%$ of methyl orange after $1 \mathrm{~h}$ reaction [152]. Under visible light, photo-Fenton is also triggered by $\mathrm{FeVO}_{4}$ with subsequent activation of peroxymonosulfate $\left(\mathrm{HSO}_{5}{ }^{-}\right)$into sulfate radicals $\left(\mathrm{SO}_{4}{ }^{\bullet-}\right)$, thus leading, after $1 \mathrm{~h}$ of irradiation time, to the degradation of $96 \%$ of sulfamethoxazole, an antibiotic substance often detected in wastewater effluents [255]. 
However, the performance of this photo-induced process is rather low due to weak photolysis rates for iron and vanadium and unstable cycle between high and low valences species, i.e., $\mathrm{Fe}(\mathrm{III}) / \mathrm{Fe}(\mathrm{II})$ and $\mathrm{V}(\mathrm{V}) / \mathrm{V}(\mathrm{IV})$ [255].

Therefore, composite materials based on $\mathrm{FeVO}_{4}$ can be prepared to increase the efficiency of the photo-induced processes. $\mathrm{ZnO} / \mathrm{FeVO}_{4}$ material triggers simultaneously, under UVA light and in the presence of $\mathrm{H}_{2} \mathrm{O}_{2}$, photocatalytic and Fenton processes with synergetic efficiency, thus achieving 93\% degradation extent of sodium dodecyl sulfate within $1 \mathrm{~h}$ [256]. Similarly, $\mathrm{FeVO}_{4} / \mathrm{CeO}_{2}$ is also a material combining photocatalytic and photo-Fenton processes which are efficient in the removal of 4-nitrophenol [257]. In this case, the contribution of Fenton reaction, i.e., measured in the dark with the presence of hydrogen peroxide, has led to a $9 \%$ degradation extent after $1 \mathrm{~h}$ reaction while with both visible light and $\mathrm{H}_{2} \mathrm{O}_{2}$, the removal extent reached 94\% [257]. In addition, such photoactive materials can be reused since efficiency after repeated runs is stable while the photo-induced processes, especially the Fenton reaction, do not required highly acidic conditions to be efficient. These multi-photoactive materials are efficient in the treatment of real wastewaters, thus highlighting their potential applications at industrial level [256]. On the other hand, many $\mathrm{FeVO}_{4}$ based composites are studied regarding only the photocatalytic process without taking into account the potential contribution of the photo-Fenton process. $\mathrm{FeVO}_{4} / \mathrm{V}_{2} \mathrm{O}_{5}, \mathrm{FeVO}_{4} / \mathrm{BiVO}_{4}$, and $\mathrm{FeVO}_{4} / \mathrm{Fe}_{2} \mathrm{O}_{3}$ are interesting composites which have exhibited excellent photocatalytic activity in the removal of many organic dyes, including Rhodamine B, phenol red, methyl violet, and methylene blue $[133,258,259]$. In such composites, direct Z-scheme or type-II heterojunction (Figure 12 in Section 3.2.3) improves the $e^{-} / h^{+}$pair separation, thus the photogenerated charge carriers react more efficiently (for the formation of ROS), but also enhances the absorption of visible light (i.e., a shift of the $E_{g}$ toward shorter wavelengths). Compared to the single components, the use of composite photocatalysts under either UVA or visible light irradiation leads to an increase in the removal extents of organic pollutants from $+10 \%$ to $+80 \%$ according to the experimental conditions $[133,258,259]$.

Concerning the photo-induced mechanisms for the degradation of organic pollutants, the photocatalytic and photo-Fenton are both involved. For photocatalysis using pure $\mathrm{FeVO}_{4}$, the band structure of this semiconductor allows the formation of superoxide radicals from the reaction of dissolved oxygen with the photogenerated electron since $E^{0}\left(\mathrm{O}_{2}{ }^{\bullet-} / \mathrm{O}_{2}\right)$ is situated within the energy band gap of $\mathrm{FeVO}_{4}$. The photogenerated holes cannot produce hydroxyl radicals since $E^{0}\left(\mathrm{H}_{2} \mathrm{O} / \mathrm{HO} \mathrm{O}^{\bullet}\right)$ is more positive than the valence band maximum [132]. However, the $h^{+}$can oxidize water to produce hydrogen peroxide (Equation (40)) which, subsequently, reacts with $e^{-}$to produce hydroxyl radicals (Equation (21)) [156]. The production of $\mathrm{H}_{2} \mathrm{O}_{2}$ following this reaction path is not significant in the presence of an organic dye due to the photo-sensitization process (Equations (38) and (39)). Therefore, $\mathrm{O}_{2}{ }^{--}$is the main primary ROS in the degradation of organic contaminants.

$$
2 \mathrm{H}_{2} \mathrm{O}+2 h^{+} \rightarrow \mathrm{H}_{2} \mathrm{O}_{2}+2 \mathrm{H}^{+}
$$

In $\mathrm{FeVO}_{4}$ composites, the choice of the second component is crucial. In $\mathrm{FeVO}_{4} / \mathrm{CeO}_{2}$, the $\mathrm{CBM}$ of $\mathrm{FeVO}_{4}$ and $\mathrm{CeO}_{2}$ are $-0.45 \mathrm{eV}$ and $-0.32 \mathrm{eV}$, respectively, and their $\mathrm{VBM}$ are at $1.55 \mathrm{eV}$ and $2.45 \mathrm{eV}$ [257]. Therefore, under UVA, the photogenerated $e^{-}$are accumulated in the $\mathrm{CB}$ of $\mathrm{CeO}_{2}$ while $h^{+}$are transferred in the $\mathrm{VB}$ of $\mathrm{FeVO}_{4}$, thus defining the principle of the type-II heterojunction with increase of charge carriers' lifetime (Figure 12 in Section 3.2.3). If $\mathrm{FeVO}_{4}$ is decorated by $\mathrm{CeO}_{2}$, the latter acts rather as an electron scavenger, thus also enhancing the $e^{-} / h^{+}$pair separation. Once the surface Ce (IV) trapped an electron, the reduced $\mathrm{Ce}$ (III) is an efficient ion for the generation of superoxide radicals from dissolved $\mathrm{O}_{2}$ [257]. Therefore, the use of $\mathrm{CeO}_{2}$ with its $\mathrm{Ce}^{3+} / \mathrm{Ce}^{4+}$ cycle is an efficient method to improve the photocatalytic efficiency of $\mathrm{FeVO}_{4}$ for the degradation of organic compounds. Additionally, a type-II heterojunction, direct Z-scheme like $\mathrm{FeVO}_{4} / \mathrm{Fe}_{2} \mathrm{O}_{3}$ works on the same principle: to limit the charge carrier recombination. In a direct $\mathrm{Z}$ scheme, the mechanism could be viewed as an "extreme" type-II heterojunction but with 
the energetic level of CBM of the first component close to that of the VBM of the second component (Figure 12 in Section 3.2.3). In $\mathrm{FeVO}_{4} / \mathrm{Fe}_{2} \mathrm{O}_{3}$, under incident light of suitable energy, the photogenerated electrons and holes in the $\mathrm{CB}$ of $\mathrm{FeVO}_{4}$ and $\mathrm{VB}$ of $\mathrm{Fe}_{2} \mathrm{O}_{3}$ can react rapidly to generate primary $\mathrm{ROS}$ since the $e^{-}$and $h^{+}$in the $\mathrm{CB}$ of $\mathrm{Fe}_{2} \mathrm{O}_{3}$ and $\mathrm{VB}$ of $\mathrm{FeVO}_{4}$ are combined fastly. This direct $\mathrm{Z}$-scheme mechanism was confirmed by scavenging experiments, where the main active species for the degradation of organic pollutants are identified as $\mathrm{HO}^{\bullet}$ and $h^{+}$(Figure 20). Indeed, such results could not be observed in the case of a type-II heterojunction mechanism, where the configuration would lead to the inability to generate any primary ROS (Figure 20) [259].

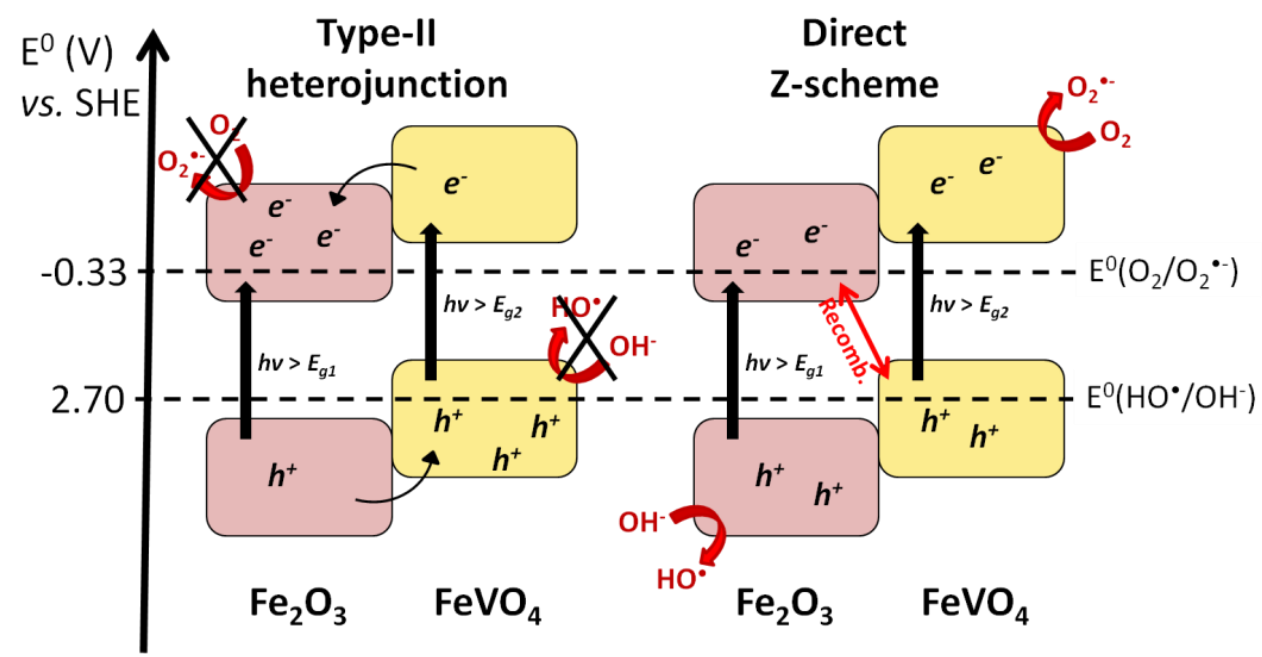

Figure 20. The band structure of $\mathrm{FeVO}_{4} / \mathrm{Fe}_{2} \mathrm{O}_{3}$ composite and the generation of primary ROS following either a type-II heterojunction or a direct Z-scheme mechanism.

The photo-Fenton mechanism, in presence of $\mathrm{H}_{2} \mathrm{O}_{2}$ and $\mathrm{FeVO}_{4}$, occurs by following a two-way reaction scheme [152,257]. Indeed, the activation of hydrogen peroxide into peroxyl radicals is performed using surface iron (III) and vanadium (V) according to the Fenton-like reactions (Equations (24) and (42)). Subsequently, the reduced species, i.e., $\mathrm{Fe}$ (II) and V (IV) generate hydroxyl radicals (Equations (23) and (41)). These Fenton-type pathways are still the matter of discussion within the photochemical community since the use of light irradiation could play a preponderant role [152]. Indeed, since the Fenton-like reaction are slower than Fenton reactions, the recycling of iron and vanadium species is slow, thus requiring the presence of incident light which could increase the photolysis of $\mathrm{Fe}(\mathrm{III})$ and $\mathrm{V}(\mathrm{V})$ into reduced species $[152,255]$. The main active species during the degradation of organic contaminants using $\mathrm{FeVO}_{4} / \mathrm{H}_{2} \mathrm{O}_{2}$ /light system are $\mathrm{HO} \bullet[152,255]$. In addition, the generation of hydroxyl radicals increases by increasing the amount of surface vanadium (V) [152]. It is worth noting that instead of $\mathrm{H}_{2} \mathrm{O}_{2}$, peroxymonosulfate $\left(\mathrm{HSO}_{5}{ }^{-}\right)$ could be used to generate other efficient radicals for the degradation of organic pollutants: the sulfate radicals $\left(\mathrm{SO}_{4}{ }^{-}\right.$) [255]. The production of the sulfate radicals (Equation (43)) could also lead to the generation of hydroxyl radicals by reaction with hydroxide anions (Equation (44)). In addition, singlet oxygen which is an excellent oxidant could be formed in such a photochemical system (Equations (45) and (46)) [255]. From these reactions, it is clear that there is a synergy with the photocatalytic process since photogenerated electrons are involved in several crucial reaction steps. In the form of a composite, especially $\mathrm{FeVO}_{4} / \mathrm{CeO}_{2}$, a third reaction pathway appears [152,257]. Indeed, surface Ce (IV) in $\mathrm{CeO}_{2}$ can activate Fenton-type processes (Equations (29) and (30)), thus generating hydroxyl radicals [257].

$$
\begin{aligned}
& \equiv \mathrm{V}^{\mathrm{IV}}+\mathrm{H}_{2} \mathrm{O}_{2} \rightarrow \equiv \mathrm{V}^{\mathrm{V}}+\mathrm{OH}^{-}+\mathrm{HO}^{\bullet} \\
& \equiv \mathrm{V}^{\mathrm{V}}+\mathrm{H}_{2} \mathrm{O}_{2} \rightarrow \equiv \mathrm{V}^{\mathrm{IV}}+\mathrm{H}^{+}+\mathrm{HOO}^{\bullet}
\end{aligned}
$$




$$
\begin{gathered}
\mathrm{Fe}^{2+} / \mathrm{V}^{4+}+\mathrm{HSO}_{5}{ }^{-} \rightarrow \mathrm{SO}_{4}{ }^{--}+\mathrm{OH}^{-}+\mathrm{Fe}^{3+} / \mathrm{V}^{5+} \\
\mathrm{SO}_{4}{ }^{\bullet-}+\mathrm{OH}^{-} \rightarrow \mathrm{SO}_{4}{ }^{2-}+\mathrm{HO}^{\bullet} \\
\mathrm{HSO}_{5}{ }^{-}+\mathrm{SO}_{5}{ }^{\bullet-}+e^{-} \rightarrow \mathrm{HSO}_{4}{ }^{-}+\mathrm{SO}_{4}{ }^{2-}+{ }^{1} \mathrm{O}_{2} \\
2 \mathrm{SO}_{5}{ }^{\bullet-}+\mathrm{H}_{2} \mathrm{O} \rightarrow 3 / 2^{1} \mathrm{O}_{2}+2 \mathrm{HSO}_{4}{ }^{-}
\end{gathered}
$$

Regarding the combined photo-induced processes in $\mathrm{FeVO}_{4}$ based systems, most of the published works referred to addition of $\mathrm{H}_{2} \mathrm{O}_{2}$ which requires the use of chemical and potentially increases the cost of implementation (or scale up) of such a photo-induced process for the removal of organic contaminants. Therefore, a key point in the research of simultaneously combined photocatalytic and photo-Fenton processes is to focus on in situ generation of $\mathrm{H}_{2} \mathrm{O}_{2}$ and to study the contribution of each involved process and their potential synergy.

On the other hand, other iron vanadates are gaining stronger interest in the photochemical community. It is the case of $\mathrm{Fe}_{2} \mathrm{~V}_{4} \mathrm{O}_{13}$ which is a visible light driven photocatalyst with an energy band gap in the range of $2.2-2.8 \mathrm{eV}[260,261]$. The energy levels of conduction band minimum and valence band maximum are $-2.05 \mathrm{eV}$ and $0.15 \mathrm{eV}$, respectively [261]. Therefore, the photoctalytic reduction ability of $\mathrm{Fe}_{2} \mathrm{~V}_{4} \mathrm{O}_{13}$ is relatively strong. Indeed, this iron vanadate is able to remove $\mathrm{Cr}(\mathrm{VI})$ by reduction reaction using photogenerated electrons (Equation (47)) [260]. The conversion extent of $\mathrm{Cr}$ (VI) into non-toxic $\mathrm{Cr}$ (III) reaches up to $98 \%$ which is significantly higher than that in presence of $\mathrm{TiO}_{2}$ (about $\left.40 \%\right)$. The performance of $\mathrm{Fe}_{2} \mathrm{~V}_{4} \mathrm{O}_{13}$ can be also ascribed to its higher specific surface area [260,261].

$$
\mathrm{Cr}_{2} \mathrm{O}_{7}{ }^{2-}+14 \mathrm{H}^{+}+6 e^{-} \rightarrow 2 \mathrm{Cr}^{3+}+7 \mathrm{H}_{2} \mathrm{O}
$$

In the form of composite, $\mathrm{Fe}_{2} \mathrm{~V}_{4} \mathrm{O}_{13} / \mathrm{ZnO}$ can degrade $90 \%$ of methyl orange under simulated solar light [261]. This enhanced removal extent compared to pristine $\mathrm{Fe}_{2} \mathrm{~V}_{4} \mathrm{O}_{13}$ is due to the formation of a type-II heterojunction where, under light irradiation, the photogenerated electrons are accumulated in the conduction band of $\mathrm{ZnO}$ while $h^{+}$are transferred into the valence band of $\mathrm{Fe}_{2} \mathrm{~V}_{4} \mathrm{O}_{13}$. Since the $\mathrm{CBM}$ of $\mathrm{ZnO}$ in this system is at $-0.35 \mathrm{eV}$, the production of superoxide radicals is favored. However, the VBM are not enough positive to allow the production of hydroxyl radical by reaction with the photogenerated holes. Furthermore, the $h^{+}$has weak oxidation ability to directly degrade the organic dye and, therefore, the main primary $\mathrm{ROS}_{\text {are }} \mathrm{O}_{2}{ }^{\bullet-}$.

$\mathrm{Fe}_{2} \mathrm{~V}_{4} \mathrm{O}_{13}$ can also act as a multi-Fenton catalyst. Similar to $\mathrm{FeVO}_{4}$, a two way reaction scheme occurs in the presence of $\mathrm{H}_{2} \mathrm{O}_{2}$ which is activated into reactive oxygen species as described above (Equations (23), (24), (41), and (42)). Therefore, $\mathrm{Fe}_{2} \mathrm{~V}_{4} \mathrm{O}_{13}$ can degrade more than $90 \%$ of methyl orange associated with a mineralization extent of $40 \%$ [159]. The mechanism involves the cycle of redox couples Fe(III)/Fe(II) and V(V)/V(IV). By comparison with $\mathrm{FeVO}_{4} / \mathrm{V}_{2} \mathrm{O}_{5}$ and $\mathrm{Fe}_{2} \mathrm{O}_{3} / \mathrm{V}_{2} \mathrm{O}_{5}$ systems where two compounds are combined, the best results are achieved using $\mathrm{Fe}_{2} \mathrm{~V}_{4} \mathrm{O}_{13}$, thus highlighting a synergy in the Fenton activity induced by iron and vanadium species [159]. $\mathrm{Fe}_{2} \mathrm{~V}_{4} \mathrm{O}_{13}$ has been also tested in the degradation of real wastewater effluents spiked by organic dyes. As expected, a decrease of efficiency is observed compared to synthetic wastewater (removal extent $<50 \%$ ) due to the consumption of $\mathrm{H}_{2} \mathrm{O}_{2}$ by the organic matter which is present in higher extents [159].

Finally, another interesting iron vanadate is $\mathrm{FeV}_{3} \mathrm{O}_{8}$. This materials is a semiconductor which is a promising visible light driven photocatalyst $\left(E_{g}=2.23 \mathrm{eV}\right)$ [163]. Indeed, depending on its morphology, the specific surface area can reach more than $150 \mathrm{~m}^{2} \cdot \mathrm{g}^{-1}$ (for ultrathin nanostructured material), thus giving rise to good adsorption properties. In addition, under visible light, $\mathrm{FeV}_{3} \mathrm{O}_{8}$ can remove up to $92 \%$ of methyl orange after only 30 min irradiation time [163]. In such a photoactive system, the main primary ROS are identified as both superoxide and hydroxyl radicals, but further studies are required to confirm this observation since the exact role of photogenerated holes are not clearly elucidated. 


\section{Other Transition Metal Vanadates}

Among the other transition metal vanadates, the most promising ones are summarized in the Table 2 . These ternary oxides are semiconductor photocatalysts which could be activated either under visible or UVA light. Although they are promising materials, their use in photo-induced processes for the removal of organic contaminants are far less documented than bismuth and iron vanadates. In addition, these atypic vanadates are often coupled with another oxide to form a composite. Therefore, deeper research is necessary to elucidated the photocatalytic mechanism (of both pure and composite materials) and to highlight potentially other photo-induced processes like the Fenton-type reactions which probably occur in metal vanadates based on $\mathrm{Ce}, \mathrm{Cu}$, and $\mathrm{Mn}$.

Table 2. Overview of different transition metal vanadate in the photo-induced degradation of organic pollutants.

\begin{tabular}{|c|c|c|c|c|c|}
\hline System & $E_{g}(e V)$ & Pollutant & $\begin{array}{l}\text { Incident } \\
\text { Irradiation }\end{array}$ & Degradation Extent & Ref. \\
\hline $\mathrm{ZnV}_{2} \mathrm{O}_{4}$ & 2.1 & $\mathrm{CO}_{2}$ & Visible light & $\sim 80 \%$ conversion into $\mathrm{CO}$ & [262] \\
\hline $\mathrm{AgVO}_{3} / \mathrm{BiVO}_{4}$ & $2.32-2.43$ & Rhodamine B & Visible light & $93 \%$ after $120 \mathrm{~min}$ & [263] \\
\hline $\mathrm{CeO}_{2} / \mathrm{CeVO}_{4} / \mathrm{V}_{2} \mathrm{O}_{5}$ & $2.26-2.93$ & Methylene blue & Visible light & $\begin{array}{c}93 \% \text { after } 4 \mathrm{~h}(189 \mu \mathrm{mol} \text { of } \\
\left.\text { produced } \mathrm{H}_{2}\right)\end{array}$ & [264] \\
\hline $\mathrm{Ag}_{4} \mathrm{~V}_{2} \mathrm{O}_{7} / \mathrm{BiVO}_{4}$ & $2.36-2.41$ & $\begin{array}{l}\text { Methylene blue } \\
\text { and NO }\end{array}$ & Visible light & $\begin{array}{l}98 \% \text { for } \mathrm{MB} \text { and } 53 \% \text { for } \mathrm{NO} \\
\text { after } 30 \mathrm{~min}\end{array}$ & [265] \\
\hline $\mathrm{Cu}_{3} \mathrm{~V}_{2} \mathrm{O}_{7}(\mathrm{OH})_{2} \cdot 2 \mathrm{H}_{2} \mathrm{O}$ & 2.1 & Methylene blue & Visible light & $\sim 90 \%$ after $150 \mathrm{~min}$ & [266] \\
\hline $\mathrm{Cu}_{3} \mathrm{~V}_{2} \mathrm{O}_{8}$ & - & Methyl orange & UVA light & $72 \%$ after $100 \mathrm{~min}$ & [267] \\
\hline $\mathrm{Cu}_{2} \mathrm{~V}_{2} \mathrm{O}_{7}\left(+\mathrm{H}_{2} \mathrm{O}_{2}\right)$ & 2.17 & Evans blue & UVA light & $77 \%$ after $120 \mathrm{~min}$ & [268] \\
\hline $\mathrm{Cu}_{2} \mathrm{~V}_{2} \mathrm{O}_{7} / \mathrm{g}-\mathrm{C}_{3} \mathrm{~N}_{4}$ & $2.0-2.7$ & $\mathrm{CO}_{2}$ & Visible light & - & [167] \\
\hline $\mathrm{Cu}_{3} \mathrm{~V}_{2} \mathrm{O}_{8}$ & $2.05-2.10$ & Methyl orange & UVA light & $78 \%$ after $120 \mathrm{~min}$ & [135] \\
\hline $\mathrm{Mn}\left(\mathrm{VO}_{3}\right)_{2}$ & 3.05 & Methyl orange & UVA light & $84 \%$ after $80 \mathrm{~min}$ & [181] \\
\hline $\mathrm{Mn}_{2} \mathrm{~V}_{2} \mathrm{O}_{7}$ & 2.79 & Methylene blue & Solar light & $90 \%$ after $4 \mathrm{~h}$ & [179] \\
\hline
\end{tabular}

\section{Conclusions}

Binary and ternary vanadium oxides in single and mixed valence states are promising materials for environmental applications. Based on the versatile behaviour of vanadium, the electronic and optical properties of semiconducting vanadium oxides can be tuned, thus giving rise to interesting photo-induced properties. Therefore, vanadium oxide-based materials can trigger photochemical processes for the environmental purposes including the splitting of water for hydrogen production and the photocatalytic and photo-Fenton processes for the removal of organic pollutants in water. Such problematics are highly relevant for the current and next generations. This review article provides a useful tool for scientific research and pedagogical knowledge where the comprehensive description of the structure and intrinsic properties of vanadium oxides are related to their photochemical efficiency in environmental processes.

Author Contributions: Conceptualization, writing: original draft preparation, writing: review and editing, supervision, O.M.; writing: original draft preparation, writing: review and editing, P.P. All authors have read and agreed to the published version of the manuscript.

Funding: This research received no external funding.

Institutional Review Board Statement: Not applicable.

Informed Consent Statement: Not applicable. 
Data Availability Statement: No new data were created or analyzed in this study. Data sharing is not applicable to this article.

Conflicts of Interest: The authors declare no conflict of interest.

\section{References}

1. Weeks, M.E. The Discovery of the Elements. VII. Columbium, Tantalum, and Vanadium. J. Chem. Educ. 1932, 9, 863-884. [CrossRef]

2. Gustafsson, J.P. Vanadium geochemistry in the biogeosphere speciation, solid-solution interactions, and ecotoxicity. Appl. Geochem. 2019, 102, 1-25. [CrossRef]

3. Safstrom, N.G. Sur Le Vanadium, Métal Nouveau, Trouvé Dans Du Fer En Barres De Eckersholm, Forge Qui Tire Sa Mine De Taberg, Dans Le Smaland. Ann. Chim. Phys. 1831, 46, 105-111.

4. Baharum, H.; Chu, W.C.; Teo, S.S.; Ng, K.Y.; Rahim, R.A.; Ho, C.L. Molecular cloning, homology modeling and site-directed mutagenesis of vanadium-dependent bromoperoxidase (GcVBPO1) from Gracilaria changii (Rhodophyta). Phytochemistry 2013, 92, 49-59. [CrossRef] [PubMed]

5. Adriano, D.C. Trace Elements in the Terrestrial Environment; Springer: New York, NY, USA, 1986; pp. 470-501.

6. Moskalyk, R.R.; Alfanti, A.M. Processing of vanadium: A review. Miner. Eng. 2003, 16, 793-805. [CrossRef]

7. Imtiaz, M.; Rizwan, M.S.; Xiong, S.; Li, H.; Ashraf, M.; Shahzad, S.M.; Shahzad, M.; Rizwan, M.; Tu, S. Vanadium, recent advancements and research prospects: A review. Environ. Int. 2015, 80, 79-88. [CrossRef] [PubMed]

8. Baroch, E.F. Vanadium and vanadium alloys. In Kirk-Othmer Encyclopedia of Chemical Technology; Wiley: New York, NY, USA, 2013; pp. 1-18.

9. Liu, M.; Su, B.; Tang, Y.; Jiang, X.; Yu, A. Recent Advances in Nanostructured Vanadium Oxides and Composites for Energy Conversion. Adv. Energy Mater. 2017, 7, 1700885. [CrossRef]

10. Rehder, D. The potentiality of vanadium in medicinal applications. Future Med. Chem. 2012, 4, 1823. [PubMed]

11. World Health Organization. International Programme on Chemical Safety, Environmental Health, Criteria 61, Vanadium. Available online: http:/ / www.inchem.org/documents/ehc/ehc/ehc81.htm (accessed on 26 December 2020).

12. Korbecki, J.; Baranowska-Bosiacka, I.; Gutowska, I.; Chlubek, D. Biochemical and medical importance of vanadium compounds. Acta Biochim. Pol. 2012, 59, 195. [CrossRef]

13. Barceloux, D.G. Vanadium. J. Toxicol. Clin. Toxicol. 1999, 37, 265-278. [CrossRef]

14. Rehder, D. Vanadium. Its role for humans. Met. Ions Life Sci. 2013, 13, 139-169. [PubMed]

15. Wright, M.T.; Belitz, K. Factors controlling the regional distribution of vanadium in groundwater. Groundwater 2010, 48, 515-525. [CrossRef] [PubMed]

16. Vouk, V.B.; Piver, W.T. Metallic elements in fossil fuel combustion products. Environ. Health Perspect. 1983, 47, $2111-2225$.

17. Miramand, P.; Fowler, S.W. Bioaccumulation and transfer of vanadium in marine organisms. In Vanadium in the Environment: Part 1. Chemistry and Biochemistry; Nriagu, S.W., Ed.; Wiley: New York, NY, USA, 1998; pp. 167-169.

18. Kiss, T.; Kiss, E.; Garribba, E.; Sakurai, H. Speciation of insulin-mimetic VO (IV)-containing drugs in blood serum. J. Inorg. Biochem. 2000, 80, 65-73. [CrossRef]

19. Hansen, T.V.; Aaseth, J.; Alexander, J. The effect of chelating agents on vanadium distribution in the rat body and on uptake by human erythrocytes. Arch. Toxicol. 1982, 50, 195-202. [CrossRef]

20. Rehder, D. The bioinorganic chemistry of vanadium. Angew. Chem. Int. Ed. Engl. 1991, 30, 148-167.

21. Granqvist, C.G. Spectrally selective coatings for energy efficiency and solar applications. Phys. Scr. 1985, 32, 401-407. [CrossRef]

22. Lamsal, C.; Ravindra, N.M. Vanadium Oxides: Synthesis, Properties, and Applications. In Semiconductors; Pech-Canul, M., Ravindra, N., Eds.; Springer Nature: Cham, Switzerland, 2019; pp. 127-218.

23. Parker, J.C., Jr.; Geiser, U.W.; Lam, D.J.; Xu, Y.; Ching, W.Y. Optical properties of the vanadium oxides $\mathrm{VO}_{2}$ and $\mathrm{V}_{2} \mathrm{O}_{5}$. J. Am. Ceram. Soc. 1990, 73, 3206-3208. [CrossRef]

24. Chang, T.C.; Cao, X.; Bao, S.H.; Ji, S.D.; Luo, H.J.; Jin, P. Review on thermochromic vanadium dioxide based smart coatings: From lab to commercial application. Adv. Manuf. 2018, 6, 1-19. [CrossRef]

25. Azenha, E.; Romeiro, A.; Sarakha, M. Photodegradation of pesticides and photocatalysis in the treatment of water and waste. In Applied Photochemistry; Evans, R.C., Douglas, P., Burrows, H.D., Eds.; Springer: Dordrecht, The Netherlands, 2013 ; pp. $247-266$.

26. Gaya, U.I. Heterogeneous Photocatalysis Using Inorganic Semiconductor Solids; Springer: Dordrecht, The Netherlands, 2014.

27. Hinojosa-Reyes, L.; Guzman-Mar, J.L.; Villanueva-Rodriguez, M. Semiconductormaterials for photocatalytic oxidation of organic pollutants in wastewater. In Photocatalytic Semiconductors; Hernandez-Ramirez, A., Medina-Ramirez, I., Eds.; Springer: Cham, Switzerland, 2015; pp. 187-228.

28. Larsson, D.G.J. Pollution from drug manufacturing: Review and perspectives. Philos. Trans. R. Soc. B 2014, 369, 71-78. [CrossRef]

29. Sauvé, S.; Desrosiers, M. A review of what is an emerging contaminant. Chem. Cent. J. 2014, 8, 15-21. [CrossRef] [PubMed]

30. Deblonde, T.; Cossu-Leguille, C.; Hartemann, P. Emerging pollutants in wastewater: A review of the literature. Int. J. Hyg. Environ. Health 2011, 214, 442-448. [CrossRef] [PubMed]

31. Bolong, N.; Ismail, A.F.; Salim, M.R.; Matsuura, T. A review of the effects of emerging contaminants in wastewater and options for their removal. Desalination 2009, 239, 229-246. [CrossRef] 
32. Petrie, B.; Barden, R.; Kasprzyk-Hordern, B. A review on emerging contaminants in watewaters and the environment: Current knowledge, understudied areas and recommendations for future monitoring. Water Res. 2015, 72, 3-27. [CrossRef] [PubMed]

33. Monfort, O.; Plesch, G. Bismuth vanadate-based semiconductor photocatalysts: A short critical review on the efficiency and the mechanism of photodegradation of organic pollutants. Environ. Sci. Pollut. Res. Int. 2018, 25, 19362-19379. [CrossRef]

34. Langeslay, R.R.; Kaphan, D.M.; Marshall, C.L.; Stair, P.C.; Sattelberger, A.P.; Delferro, M. Catalytic Applications of Vanadium: A Mechanistic Perspective. Chem. Rev. 2019, 119, 2128-2191. [CrossRef]

35. Cotton, F.A.; Wilkinson, G.; Murillo, C.A.; Bochmann, M. Advanced Inorganic Chemistry, 6th ed.; Wiley: New York, NY, USA, 1999.

36. Baess, C.F.; Mesmer, R.E. Hydrolysis of cations. Ber. Bunsen. Phys. Chem. 1976, 81, 245-246.

37. Livage, J. Hydrothermal Synthesis of Nanostructured Vanadium Oxides. Materials 2010, 3, 4175-4195. [CrossRef]

38. Sadoc, A.; Messaoudi, S.; Furet, E.; Gautier, R.; Le Fur, E.; Le Pollès, L.; Pivan, J.Y. Structure and stability of VO $_{2}{ }^{+}$in aqueous solution: A car-parrinello and static ab initio study. Inorg. Chem. 2007, 46, 4835-4843. [CrossRef]

39. Bouhedja, L.; Steunou, N.; Maquet, J.; Livage, J. Synthesis of polyoxovanadates from aqueous solutions. J. Solid State Chem. 2001, 162, 315-321. [CrossRef]

40. Thompson, K.H.; Orvig, C. Metal complexes in medicinal chemistry: New vistas and challenges in drug design. Dalton Trans. 2006, 761-764. [CrossRef] [PubMed]

41. Rehder, D. The coordination chemistry of vanadium as related to its biological functions. Coord. Chem. Rev. 1999, 182, 297-322. [CrossRef]

42. Pessoa, J.C.; Etcheverry, S.; Gambino, D. Vanadium compounds in medicine. Coord. Chem. Rev. 2005, 301-302, 24-48. [CrossRef] [PubMed]

43. Kanamori, K.; Tsuge, K. Inorganic Chemistry of Vanadium. In Vanadium Biochemical and Molecular Biological Approaches; Michibata, H., Ed.; Springer: Dordrecht, The Netherlands, 2012; pp. 3-31.

44. Mukherjee, B.; Patra, B.; Mahapatra, S.; Banerjee, P.; Tiwari, A.; Chatterjee, M. Vanadium-An element of atypical biological significance. Toxicol. Lett. 2004, 150, 135-143. [CrossRef]

45. Almeida, M.; Filipe, S.; Humanes, M.; Maia, M.F.; Melo, R.; Severino, N.; Silva, J.A.L.; Fraústo da Silva, J.J.R.; Wever, R. Vanadium haloperoxidases from brown algae of the Laminariaceae family. Photochemistry. 2001, 57, 633-642. [CrossRef]

46. Menon, A.S.; Rau, M.; Ramasarma, T.; Crane, F.L. Vanadate inhibits mevalonate synthesis and activates NADH oxidation in microsomes. FEBS Lett. 1980, 114, 139-141. [CrossRef]

47. Golden, M.H.; Golden, B.E. Trace Elements: Potential Importance in Human Nutrition with Particular Reference to Zinc and Vanadium. Br. Med. Bull. 1981, 37, 3731-3736. [CrossRef]

48. Byrne, A.R.; Kosta, L. Vanadium in foods and in human body fluids and tissues. Sci. Total Environ. 1978, 10, 17-30. [CrossRef]

49. Heinemann, G.; Fichtl, B.; Vogt, W. Pharmacokinetics of vanadium in humans after intravenous administration of a vanadium containing albumin solution. Br. J. Clin. Pharmacol. 2003, 55, 241-245. [CrossRef]

50. Willsky, G.R.; Chi, L.H.; Godzala, M.; Kostyniak, P.J.; Smee, J.J.; Trujillo, A.M.; Alfano, J.A.; Ding, W.J.; Hu, Z.H.; Crans, D.C. Anti-diabetic effects of a series of vanadium dipicolinate complexes in rats with streptozotocin-induced diabetes. Coord. Chem. Rev. 2011, 255, 2258-2269. [CrossRef]

51. Thompson, K.H.; Lichter, J.; LeBel, C.; Scaife, M.C.; McNeil, J.H.; Orvig, C. Vanadium treatment of type 2 diabetes: A view to the future. J. Inorg. Biochem. 2009, 103, 554. [CrossRef] [PubMed]

52. Ray, R.S.; Basu, M.; Ghosh, B.; Samanta, K.; Chatterjee, M. Vanadium, a Versatile Biochemical Effector in Chemical Rat Mammary Carcinogenesis. Nutr. Cancer. 2005, 51, 184-196. [CrossRef] [PubMed]

53. Ray, R.S.; Rana, B.; Swami, B.; Venu, V.; Chatterjee, M. Vanadium mediated apoptosis and cell cycle arrest in MCF7 cell line. Chem.-Biol. Interact. 2006, 163, 239-247. [CrossRef]

54. Parasuraman, A.; Lim, M.T.; Menictas, C.; Kazacos, M.S. Review of material research and development for vanadium redox flow battery applications. Electrochim. Acta 2013, 101, 27-40.

55. Swette, L.; Jalan, V. Development of Electrodes for the NASA Iron/Chromium Redox System and Factors Affecting Their Performance; Giner Inc.: Waltham, MA, USA, 1984. Available online: https://ntrs.nasa.gov/api/citations/19850027158/downloads/19850027158.pdf (accessed on 26 December 2020).

56. Savinell, R.F.; Liu, C.C.; Galasco, R.T.; Chiang, S.H.; Coetzee, J.F. Discharge characteristics of a soluble Iron-Titanium battery system. J. Electrochem. Soc. 1979, 126, 357. [CrossRef]

57. Kioseoglou, E.; Petanidis, S.; Gabriel, C.; Salifoglou, A. The chemistry and biology of vanadium compounds in cancer therapeutics. Coord. Chem. Rev. 2015, 301-302, 87-105. [CrossRef]

58. Schwendt, P.; Tatiersky, J.; Krivosudsky, L.; Simunekova, M. Peroxido complexes of vanadium. Coord. Chem. Rev. 2016, 318, 135-157. [CrossRef]

59. Nomura, K.; Zhang, S. Design of Vanadium Complex Catalysts for Precise Olefin Polymerization. Chem. Rev. 2011, 111, 2342-2362. [CrossRef]

60. Nomura, K.; Zhang, W. (Imido)vanadium(V)-alkyl, -alkylidene complexes exhibiting unique reactivity towards olefins and alcohols. Chem. Sci. 2010, 1, 161-173. [CrossRef]

61. Wischang, D.; Brucher, O.; Hartung, J. Bromoperoxidases and Functional Enzyme Mimics as Catalysts for Oxidative BrominationA Sustainable Synthetic Approach. Coord. Chem. Rev. 2011, 255, 2204-2217. [CrossRef] 
62. Kumar, S.; Jain, A.; Ichikawa, T.; Kojima, Y.; Dey, G.K. Development of vanadium based hydrogen storage material: A review. Renew. Sust. Energy Rev. 2017, 72, 791-800. [CrossRef]

63. Sakintuna, B.; Lamari-Darkrim, F.; Hirscher, M. Metal hydride materials for solid hydrogen storage: A review. Int. J. Hydrogen Energy 2007, 32, 1121-1140. [CrossRef]

64. Marban, G.; Solis, T.V. Towards the hydrogen economy? Int. J. Hydrogen Energy 2007, 32, 1625-1637. [CrossRef]

65. Ma, Y.D.; Dai, Y.; Guo, M.; Niu, C.W.; Zhu, Y.T.; Huang, B.B. Evidence of the existence of magnetism in pristine VX2 monolayers $(\mathrm{X}=\mathrm{S}, \mathrm{Se})$ and their strain-induced tunable magnetic properties. ACS Nano 2012, 6, 1695-1701. [CrossRef] [PubMed]

66. Chmiola, J.; Largeot, C.; Taberna, P.L.; Simon, P.; Gogotsi, Y. Monolithic Carbide-Derived Carbon Films for Micro-Supercapacitors. Science 2010, 328, 480. [CrossRef]

67. Miller, J.R.; Outlaw, R.A.; Holloway, B.C. Graphene Double-Layer Capacitor with ac Line-Filtering Performance. Science 2010, 329, 1637. [CrossRef]

68. Bae, S.; Kim, H.; Lee, Y.; Xu, X.; Park, J.S.; Zheng, Y.; Balakrishnan, J.; Lei, T.; Kim, R.H.; Song, Y.I.; et al. Roll-to-roll production of 30-inch graphene films for transparent electrodes. Nat. Nanotechnol. 2010, 5, 574. [CrossRef]

69. Weckhuysen, B.M.; Keller, D.E. Chemistry, spectroscopy and the role of supported vanadium oxides in heterogeneous catalysis. Catal. Today 2003, 78, 25-46. [CrossRef]

70. Dummer, N.F.; Bartley, J.K.; Hutchings, G.J. Vanadium Phosphate Materials as Selective Oxidation Catalysts. Adv. Catal. 2011, 54, 189-247.

71. Khodakov, A.; Olthof, B.; Bell, A.T.; Iglesia, E. Structure and catalytic properties of supported vanadium oxides: Support effects on oxidative dehydrogenation reactions. J. Catal. 1999, 181, 205-216. [CrossRef]

72. Wu, C.; Feng, F.; Xie, Y. Design of vanadium oxide structures with controllable electrical properties for energy applications. Chem. Soc. Rev. 2013, 42, 5157-5183. [CrossRef] [PubMed]

73. Prasadam, V.P.; Bahlawane, N.; Mattelaer, F.; Rampelberg, G.; Detavernier, C.; Fang, L.; Jiang, Y.; Martens, K.; Parkin, I.P.; Papakonstantinou, I. Atomic layer deposition of vanadium oxides: Process and application review. Mater. Today Chem. 2019, 12, 396-423. [CrossRef]

74. Delmas, C.; Cognacauradou, H.; Cocciantelli, J.M.; Menetrier, M.; Doumerc, J.P. The LixV2O5 system-An overview of the structure modifications induced by the lithium intercalation. Solid State Ion. 1994, 69, 257-264. [CrossRef]

75. Ostreng, E.; Gandrud, K.B.; Hu, Y.; Nilsen, O.; Fjellvag, H. High power nanostructured V2O5 thin film cathodes by atomic layer deposition. J. Mater. Chem. 2014, 2, 15044-15051. [CrossRef]

76. Xie, Y.; Wu, C.Z. Design of nanoarchitectured electrode materials applied in new-generation rechargeable lithium ion batteries. Dalton Trans. 2007, 5235, 5235. [CrossRef]

77. Wan, Z.; Zou, Z.; Wang, J.; Long, F.; Wu, Y. Synthesis and Electrochemical Properties of Flower-like Na-doped V6O13 Cathode Materials for Li-ion Batteries. Int. J. Electrochem. Sci. 2018, 13, 6565-6576. [CrossRef]

78. Kucharczyk, D.; Niklewski, T. Accurate X-ray determination of the lattice parameters and the thermal expansion coefficients of VO2 near the transition temperature. J. Appl. Cryst. 1979, 12, 370-373. [CrossRef]

79. Jerominek, H.; Picard, F.; Vincent, D. Vanadium oxide films for optical switching and detection. Opt. Eng. 1993, 32, 2092-2099. [CrossRef]

80. Cavalleri, A.; Dekorsy, T.; Chong, H.H.W.; Kieffer, J.C.; Schoenlein, R.W. Evidence for a structurally-driven insulator-to-metal transition in $\mathrm{VO}_{2}$ : A view from the ultrafast timescale. Phys. Rev. B 2004, 70, 161102. [CrossRef]

81. Granqvist, C.G. Recent progress in thermochromics and electrochromics: A brief survey. Thin Solid Films 2016, 614, 90-96. [CrossRef]

82. Gupta, A.; Aggarwal1, R.; Gupta, P.; Dutta, T.; Narayan, R.J.; Narayan, J. Semiconductor to metal transition characteristics of VO2 thin films grown epitaxially on Si (001). Appl. Phys. Lett. 2009, 95, 111915. [CrossRef]

83. Darling, R.B.; Iwanaga, S. Structure, properties, and MEMS and microelectronic applications of vanadium oxides. Sadhana 2009, 34, 531-542. [CrossRef]

84. Niklaus, F.; Decharat, A.; Jansson, C.; Stemme, G. Performance model for uncooled infrared bolometer arrays and performance predictions of bolometers operating at atmospheric pressure. Infrared Phys. Technol. 2008, 51, 168-177. [CrossRef]

85. Wood, R.A.; Han, C.J.; Kruse, P.W. Integrated uncooled infrared detector imaging arrays. IEEE Workshop Solid-State Sencor Actuator 1992. [CrossRef]

86. Mattelaer, F.; Geryl, K.; Rampelberg, G.; Dobbelaere, T.; Dendooven, J.; Detavernier, C. Atomic layer deposition of vanadium oxides for thin-film lithium-ion battery applications. RSC Adv. 2006, 6, 114658-114665. [CrossRef]

87. Mattelaer, F.; Geryl, K.; Rampelberg, G.; Dendooven, J.; Detavernier, C. Amorphous and crystalline vanadium oxides as highenergy and high-power cathodes for three-dimensional thin-film lithium ion batteries. ACS Appl. Mater. Interfaces 2017, 9, 13121-13131. [CrossRef]

88. Cao, A.M.; Hu, J.S.; Liang, H.P.; Wan, L.J. Self-Assembled Vanadium Pentoxide $\left(\mathrm{V}_{2} \mathrm{O}_{5}\right)$ Hollow Microspheres from Nanorods and Their Application in Lithium-Ion Batteries. Angew. Chem. Int. Ed. 2005, 44, 4391. [CrossRef]

89. Adler, D. Mechanisms for metal-nonmetal transitions in transition-metal oxides and sulfides. Rev. Mod. Phys. 1968, 40, 714-736. [CrossRef]

90. Muhr, H.J.; Krumeich, F.; Schonholzer, U.P.; Bieri, F.; Niederberger, M.; Gauckler, L.J.; Nesper, R. Vanadium Oxide Nanotubes-A New Flexible Vanadate Nanophase. Adv. Mater. 2000, 12, 231. [CrossRef] 
91. Pinna, N.; Wild, U.; Urban, J.; Schlogl, R. Divanadium Pentoxide Nanorods. Adv. Mater. 2003, 15, 329. [CrossRef]

92. Eyert, V.; Hoch, K.-H. Electronic structure of $\mathrm{V}_{2} \mathrm{O}_{5}$ : Role of octahedral deformations. Phys. Rev. B 1998, 57, 12727-12737. [CrossRef]

93. Zhang, X.F.; Wang, K.X.; Wei, X.; Chen, J.S. Carbon-Coated $\mathrm{V}_{2} \mathrm{O}_{5}$ Nanocrystals as High Performance Cathode Material for Lithium Ion Batteries. Chem. Mater. 2011, 23, 5290. [CrossRef]

94. Hermann, K.; Chakrabarti, A.; Druzinic, R.; Witko, M. Ab initio density functional theory studies of hydrogen adsorption at the $\mathrm{V}_{2} \mathrm{O}_{5}(010)$ surface. Phys. Stat. Sol. 1999, 173, 195-208. [CrossRef]

95. Liu, L.; Cao, F.; Yao, T.; Xu, Y.; Zhou, M.; Qu, B.; Pan, B.; Wu, C.; Wei, S.; Xie, Y. New-phase VO2 micro/nanostructures: Investigation of phase transformation and magnetic property. New J. Chem. 2012, 36, 619. [CrossRef]

96. Xie, J.; Wu, C.; Hu, S.; Dai, J.; Zhang, N.; Feng, J.; Yang, J.; Xie, Y. Ambient rutile VO2(R) hollow hierarchitectures with rich grain boundaries from new-state nsutite-type VO2, displaying enhanced hydrogen adsorption behavior. Phys. Chem. Chem. Phys. 2012, 14, 4810. [CrossRef] [PubMed]

97. Cavalleri, A.; Toth, C.; Siders, C.W.; Squier, J.A.; Raksi, F.; Forget, P.; Kieffer, J.C. Femtosecond structural dynamics in VO 2 during an ultra fast solid-solid phase transition. Phys. Rev. Lett. 2001, 87, 237401. [CrossRef] [PubMed]

98. Zhang, S.; Shang, B.; Yang, J.; Yan, W.; Wei, S.; Xie, Y. From VO2 (B) to VO2 (A) nanobelts: First hydrothermal transformation, spectroscopic study and first principles calculation. Phys. Chem. Chem. Phys. 2011, 13, 15873. [CrossRef] [PubMed]

99. Liu, M.; Hwang, H.Y.; Tao, H.; Strikwerda, A.C.; Fan, K.B.; Keiser, G.R.; Sternbach, A.J.; West, K.G.; Kittiwatanakul, S.; Lu, J.W.; et al. Terahertz-field-induced insulator-to-metal transition in vanadium dioxide metamaterial. Nature 2012, 487, 345-348. [CrossRef]

100. Cornell, R.M.; Schwertmann, U. The Iron Oxides: Structure, Properties, Reactions, Occurrences and Uses, 2nd ed.; Wiley VCH: Weinheim, Germany, 2003.

101. Yu, P.; Cardona, M. Fundamentals of Semiconductors: Physics and Materials Properties; Springer: Heidelberg, Germany, 2010; pp. 17-106.

102. Batista, C.; Ribeiro, R.M.; Teixeira, V. Synthesis and characterization of VO2-based thermochromic thin films for energy-efficient windows. Nanoscale Res. Lett. 2011, 6, 301. [CrossRef]

103. Parker, J.C.; Lam, D.J.; Xu, Y.N.; Ching, W.Y. Optical properties of vanadium pentoxide determined from ellipsometry and band-structure calculations. Phys. Rev. B 1990, 42, 5289-5293. [CrossRef]

104. Wang, Y.; Takahashi, K.; Shang, H.; Cao, G. Synthesis and Electrochemical Properties of Vanadium Pentoxide Nanotube Arrays. J. Phys. Chem. B Lett. 2005, 109, 3085-3088. [CrossRef] [PubMed]

105. Alsawafta, M.; Almoabadi, A.; Badilescu, S.; Truong, V.V. Improved Electrochromic Properties of Vanadium Pentoxide Nanorods Prepared by Thermal Treatment of Sol-Gel Dip-Coated Thin Films. J. Electrochem. Soc. 2015, 162, H466-H472. [CrossRef]

106. Talledo, A.; Andersson, A.M.; Granqvist, C.G. Structure and optical absorption of Liy $\mathrm{V}_{2} \mathrm{O}_{5}$ thin films. J. Appl. Phys. 1991, 69, 3261-3265. [CrossRef]

107. Nadkarni, G.S.; Shirodkar, V.S. Experiment and theory for switching in Al/V2O5/Al devices. Thin Solid Films 1983, 105, 115-129. [CrossRef]

108. Chain, E.E. Optical properties of vanadium dioxide and vanadium pentoxide thin films. Appl. Opt. 1991, 30, 2782-2787. [CrossRef]

109. Livage, J. Optical and electrical properties of vanadium oxides synthesized from alkoxides. Coord. Chem. Rev. 1999, 190, 391-403. [CrossRef]

110. Xu, G.; Jin, P.; Tazawa, M.; Yoshimura, K. Thickness dependence of optical properties of $\mathrm{VO}_{2}$ thin films epitaxially grown on sapphire (0001). Appl. Surf. Sci. 2005, 244, 449-452. [CrossRef]

111. Borisov, B.S.; Koretkaya, S.T.; Mokerov, V.G.; Rakov, A.V.; Solovev, S.G. Electrical and optical properties of VO2 near semiconductor-semimetal transition point. Sov. Phys. Solid State (Engl. Transl.) 1971, 12, 1763-1766.

112. Biermann, S.; Poteryaev, A.; Lichtenstein, A.I.; Georges, A. Dynamical singlets and correlation-assisted peierls transition in $\mathrm{VO}_{2}$. Phys. Rev. Lett. 2005, 94, 026404. [CrossRef]

113. Adler, D.; Brooks, H. Theory of semicondutor to metal transitions. Phys. Rev. 1967, 155, 826-840. [CrossRef]

114. Granqvist, C.G. Handbook of Inorganic Electrochromic Materials; Elsevier: Amsterdam, The Netherlands, 1995 ; pp. $237-295$.

115. Zylbersztejn, A.; Mott, N.F. Metal-insulator transition in vanadium dioxide. Phys. Rev. B 1975, 11, 4383-4395. [CrossRef]

116. Becker, M.; Buckman, A.B.; Walser, R.M. Femtosecond laser excitation dynamics of the semiconductor-metal phase transition in $\mathrm{VO}_{2}$. Appl. Phys. Lett. 1996, 79, 2404-2408. [CrossRef]

117. Shao, Z.; Luo, H.; Jin, P. Recent progress in the phase-transition mechanism and modulation of vanadium dioxide materials. NPG Asia Mater. 2018, 10, 581-605. [CrossRef]

118. Aetukuri, N.B.; Aetukuri, N.B.; Gray, A.X.; Drouard, M.; Cossale, M.; Gao, L.; Reid, L.; Kukreja, R.; Ohldag, H.; Jenkins, C.A.; et al. Control of the metal-insulator transition in vanadium dioxide by modifying orbital occupancy. Nat. Phys. 2013, 9, 661-666. [CrossRef]

119. Ardakani, A.H.; Nie, A.; Marley, P.M.; Zhu, Y.; Phillips, P.J.; Singh, S.; Mashayek, M.; Sambandamurthy, G.; Low, K.; Klie, R.B.; et al. Atomic origins of monoclinic-tetragonal (rutile) phase transition in doped VO2 nanowires. Nano Lett. 2015, 15, 7179-7188. [CrossRef]

120. Booth, J.M.; Casey, P.S. Anisotropic structure deformation in the VO2 metalinsulator transition. Phys. Rev. Lett. 2009, 103, 086402. [CrossRef] 
121. Marezio, M.; McWhan, D.B.; Remeika, J.P.; Dernier, P.D. Structural aspects of the metal-insulator transitions in Cr-doped VO2. Phys. Rev. B 1972, 5, 2541. [CrossRef]

122. Brückner, W.; Gerlach, U.; Thuss, B. Phase diagram of V1-xAlxO2. Phys. Status Solidi 1977, 40, K131-K134. [CrossRef]

123. Thomas, G.A.; Rapkine, D.H.; Carter, S.A.; Millis, A.J.; Rosenbaum, T.F.; Metcalf, P.; Honig, J.M. Observation of the gap and kinetic energy in a correlated insulator. Phys. Rev. Lett. 1994, 73, 1529-1532. [CrossRef]

124. Saha-Dasgupta, T.; Andersen, O.K.; Nuss, J.; Poteryaev, A.I.; Georges, A.; Lichtenstein, A.I. Electronic structure of V2O3: Wannier orbitals from LDA-NMTO calculations. arXiv 2009, arXiv:0907.2841.

125. Surnev, S.; Ramsey, M.G.; Netzer, F.P. Vanadium oxide surface studies. Prog. Surf. Sci. 2003, 73, 117-165. [CrossRef]

126. Yamazaki, S.; Li, C.; Ohoyama, K.; Nishi, M.; Ichihara, M.; Ueda, H.; Ueda, Y. Synthesis, structure and magnetic properties of V4O9-A missing link in binary vanadium oxides. J. Solid State Chem. 2010, 183, 1496-1503. [CrossRef]

127. Zhang, Y.; Liu, X.; Xie, G.; Yu, L.; Yi, S.; Hu, M.; Huang, C. Hydrothermal synthesis, characterization, formation mechanism and electrochemical property of V3O7·H2O single-crystal nanobelts. Mater. Sci. Eng. B 2010, 175, 164-171. [CrossRef]

128. Zakharova, G.S.; Volkov, V.L.; Täschner, C.; Hellmann, I.; Leonhardt, A.; Klingeler, R.; Büchner, B. Synthesis and characterization of V3O7.H2O nanobelts. Solid State Commun. 2009, 149, 814-817. [CrossRef]

129. Cristopher, M.; Karthick, P.; Sivakumar, R.; Gopalakrishnan, C.; Sanjeeviraja, C.; Jeyadheepan, K. On the preparation of Tri-vanadium hepta-oxide thin films for electrochromic applications. Vacuum 2019, 160, 238-245. [CrossRef]

130. Mjejri, I.; Rougier, A. Color Switch in V3O7.H2O cycled in Li and Na based electrolytes: Novel vanadium oxide based electrochromic material. J. Mater. Chem. C 2020, 8, 3631-3638. [CrossRef]

131. Chen, X.; Shen, S.; Guo, L.; Mao, S.S. Semiconductor based photocatalytic hydrogen generation. Chem. Rev. 2010, 110, 6503. [CrossRef] [PubMed]

132. Mosleh, M. Nanocrystalline iron vanadate: Facile morphology-controlled preparation, characterization and investigation of optical and photocatalytic properties. J. Mater. Sci. Mater. Electron. 2017, 28, 5866-5871. [CrossRef]

133. Ghiyasiyan-Arani, M.; Salavati-Niasari, M.; Naseh, S. Enhanced photodegradation of dye in waste water using iron vanadate nanocomposite; ultrasound-assisted preparation and characterization. Ultrason. Sonochem. 2017, 39, 494-503. [CrossRef]

134. Heydari, A.; Sheykhan, M.; Sadeghi, M.; Radfar, I. Nano-Rods of FeVO4: An Efficient Heterogeneous Catalyst for Chemo-Selective Oxidation of Benzylic Alcohols. Inorg. Nano-Metal Chem. 2016, 47, 248-255. [CrossRef]

135. Zhang, S.; Sun, Y.; Li, C.; Ci, L. Cu3V2O8 hollow spheres in photocatalysis and primary lithium batteries. Solid State Sci. 2013, 25, 15-21. [CrossRef]

136. Kumada, N.; Takei, T.; Haramoto, R.; Yonesaki, Y.; Dong, Q.; Kinomura, N.; Nishimoto, S.; Kameshima, Y.; Miyake, M. Preparation and crystal structure of a new bismuth vanadate, Bi3.33(VO4)2O2. Mater. Res. Bull. 2011, 46, 962-965. [CrossRef]

137. Gan, J.; Lu, X.; Tong, Y. Towards highly efficient photoanodes: Boosting sun light-driven semiconductor nanomaterials for water oxidation. Nanoscale 2014, 6, 7142. [CrossRef] [PubMed]

138. Tolod, K.R.; Hernandez, S.; Russo, N. Recent advances in the BiVO4 photo catalyst for sun-driven water oxidation: Top-performing photoanodes and scale-up challenges. Catalysts 2017, 7, 13. [CrossRef]

139. Park, Y.; McDonald, K.J.; Choi, K.-S. Progress in bismuth vanadate photo anodes for use in solar water oxidation. Chem. Soc. Rev. 2013, 42, 2321. [CrossRef]

140. Teoh, W.Y.; Scott, J.A.; Amal, R. Progress in heterogeneous photocatalysis: From classical radical chemistry to engineering nanomaterials and solar reactors. J. Phys. Chem. Lett. 2012, 3, 629-639. [CrossRef]

141. Tachikawa, T.; Ochi, T.; Kobori, Y. Crystal-face-dependent charge dynamics on a BiVO4 photocatalyst revealed by single-particle spectroelectrochemistry. ACS Catal. 2016, 6, 2250-2256. [CrossRef]

142. Tan, H.L.; Wen, X.; Amal, R.; Ng, Z.H. BiVO4 $\{010\}$ and $\{110\}$ relative exposure extent: Governing factor of surface charge population and photocatalytic activity. J. Phys. Chem. Lett. 2016, 7, 1400-1405. [CrossRef]

143. Ma, Y.; Pendlebury, S.R.; Reynal, A.; Le Formal, F.; Durrant, J.R. Dynamics of photogenerated holes in undoped BiVO4 photoanodes for solar water oxidation. Chem. Sci. 2014, 5, 2964-2973. [CrossRef]

144. Ravensbergen, J.; Abdi, F.F.; Santen, J.H.; Frese, R.N.; Dam, B.; Krol, R.; Kennis, J.T.M. Unraveling the Carrier Dynamics of BiVO4: A Femtosecond to Microsecond Transient Absorption Study. J. Phys. Chem. C 2014, 118, 27793-27800. [CrossRef]

145. Vannier, N.; Pernot, E.; Anne, M.; Isnard, O.; Nowogrocki, G.; Mairesse, G. Bi4V2O11 polymorph crystal structures related to their electrical properties. Solid State Ion. 2003, 157, 147-153. [CrossRef]

146. Mairesse, G.; Roussel, P.; Vannier, R.N.; Anne, M.; Pirovano, C.; Nowogrocki, G. Crystal structure determination of $\alpha, \beta$ and $\gamma$-Bi4V2O11 polymorphs. Part I: $\gamma$ and $\beta$-Bi4V2O11. Solid State Sci. 2003, 5, 851-859. [CrossRef]

147. Mairesse, G.; Roussel, P.; Vannier, R.N.; Anne, M.; Nowogrocki, G. Crystal structure determination of $\alpha, \beta$ and $\gamma$-Bi4V2O11 polymorphs. Part II: Crystal structure of $\alpha$-Bi4V2O11. Solid State Sci. 2003, 5, 861-869. [CrossRef]

148. Lakkepally, S.; Kalegowda, Y.; Ramarao, V.; Hanumantharayappa, E.; Siddaramanna, A. Room temperature synthesis of amorphous Bi4V2O11 as cathode material for Li secondary batteries. Mater. Res. Express 2018, 5, 115501. [CrossRef]

149. Liang, M.; Yang, Z.; Mei, Y.; Zhou, H.; Yang, S. Dye-Sensitized-Assisted, Enhanced Photocatalytic Activity of TiO2/Bi4V2O11. NANO Brief Rep. Rev. 2018, 13, 1850028. [CrossRef]

150. Nithya, V.D.; Selvan, R.K.; Sanjeeviraja, C.; Radheep, D.M.; Arumugam, S. Synthesis and characterization of FeVO4 nanoparticles. Mater. Res. Bull. 2011, 46, 461654-461658. [CrossRef] 
151. Baeis, M.G.; Mousavi, S.H.; Jeddy, M.R. Controlled synthesis and characterization of iron vanadate magnetic nanoparticles: Investigation it's photodegradation of Rhodamine B. J. Mater. Sci. Mater. Electron. 2017, 28, 1480-1484. [CrossRef]

152. Deng, J.H.; Jiang, J.Y.; Zhang, Y.Y.; Lin, X.P.; Du, C.M.; Xiong, Y. FeVO4 as a highly active heterogeneous Fenton-like catalyst towards the degradation of Orange II. Appl. Catal. B 2008, 84, 468-473. [CrossRef]

153. Ozturk, B.; Soylu, G.S.P. Synthesis of surfactant-assisted FeVO4 nanostructure: Characterization and photocatalytic degradation of phenol. J. Mol. Catal. A Chem. 2015, 398, 65-71. [CrossRef]

154. Zhang, M.; Ma, Y.; Friedrich, D.; Krol, R.; Wong, L.H.; Abdi, F.F. Elucidation of opto-electronic and photoelectrochemical properties of FeVO4 photoanodes for solar water oxidation. J. Mater. Chem. A 2018, 6, 548-555. [CrossRef]

155. Arunachalam, M.; Yun, G.; Ahn, K.S.; Kang, S.H. Revealing the beneficial effects of FeVO4 nanoshell layer on the BiVO4 inverse opal core layer for photoelectrochemical water oxidation. J. Phys. Chem. C 2017, 121, 7625-7634. [CrossRef]

156. Dutta, D.P.; Ramakrishnan, M.; Roy, M.; Kumar, A. Effect of transition metal doping on the photocatalytic properties of FeVO4 nanoparticles. J. Photochem. Photobiol. A 2017, 335, 102-111. [CrossRef]

157. Lakkepally, S.; Kalegowda, Y.; Ganganagappa, N.; Siddaramanna, A. A new and effective approach for Fe2V4O13 nanoparticles synthesis: Evaluation of electrochemical performance as cathode for lithium secondary batteries. J. Alloy. Compd. 2018, 737, 665-671. [CrossRef]

158. Tang, D.; Rettie, A.J.E.; Mabayoje, O.; Wygant, B.R.; Lai, Y.; Liu, Y.; Mullins, C.B. Facile Growth of Porous Fe2V4O13 Films for Photoelectrochemical Water Oxidation. J. Mater. Chem. A 2016, 4, 3034-3042. [CrossRef]

159. Zhang, Y.Y.; Deng, J.H.; He, C.; Huang, S.S.; Tian, S.H.; Xiong, Y. Application of Fe2V4O13 as a new multi-metal heterogeneous Fenton-like catalyst for the degradation of organic pollutants. Environ. Technol. 2010, 31, 145-154. [CrossRef]

160. Li, P.; Zhou, Y.; Li, H.; Xu, Q.; Meng, X.; Wang, X.; Xiao, M.; Zou, Z. All-solid-state Z-scheme system arrays of Fe $\mathrm{V}_{4} \mathrm{O}_{13} / \mathrm{RGO} \mathrm{CdS}$ for visible light-driving photocatalytic $\mathrm{CO}_{2}$ reduction into renewable hydrocarbon fuel. Chem. Commun. 2015, 51, 800-803. [CrossRef]

161. Maggay, I.V.B.; Juan, L.M.Z.; Lu, J.S.; Nguyen, M.T.; Yonezawa, T.; Chan, T.S.; Liu, W.R. Electrochemical properties of novel FeV2O4 as an anode for Na-ion batteries. Sci. Rep.-UK 2018, 8, 8839. [CrossRef]

162. Mandal, H.; Shyamal, S.; Hajra, P.; Bera, A.; Sariket, D.; Kundu, S.; Bhattacharya, C. Development of ternary iron vanadium oxide semiconductors for their applications in Photoelectrochemical Water Oxidation. RSC Adv. 2016, 6, 4992-4999. [CrossRef]

163. Zhang, L.F.; Zhou, J.; Zhang, C.Y. pH-controlled growth of ultrathin iron vanadium oxide (FeV3O8) nanoplatelets with high visible-light photo-catalytic activity. J. Mater. Chem. A 2014, 2, 14903. [CrossRef]

164. Hassan, A.; Iqbal, T.; Tahir, M.B.; Afsheen, S. A review on copper vanadate-based nanostructures for photocatalysis energy production. Int. J. Energy Res. 2019, 43, 9-28. [CrossRef]

165. Ghiyasiyan-Arani, M.; Masjedi-Arani, M.; Salavati-Niasari, M. Facile synthesis, characterization and optical properties of copper vanadate nanostructures for enhanced photocatalytic activity. J. Mater. Sci. Mater. Electron. 2016, 27, 4871-4878. [CrossRef]

166. Jiang, C.M.; Farmand, M.; Wu, C.H.; Liu, Y.S.; Guo, J.; Drisdell, W.S.; Cooper, J.K.; Sharp, I.D. Electronic Structure, Optoelectronic Properties, and Photoelectrochemical Characteristics of $\gamma$-Cu3V2O8 Thin Films. Chem. Mater. 2017, 29, 3334-3345. [CrossRef]

167. Truc, N.T.T.; Hanh, N.T.; Nguyen, M.V.; Chi, N.T.P.L.; Noi, N.V.; Tran, D.T.; Ha, M.N.; Trung, D.Q.; Pham, T.D. Novel direct Z-scheme Cu2V2O7/g-C3N4 for visible light photocatalytic conversion of CO2 into valuable fuels. Appl. Surf. Sci. 2018, 457, 968-974. [CrossRef]

168. Guo, W.; Chemelewski, W.D.; Mabayoje, O.; Xiao, P.; Zhang, Y.; Mullins, C.B. Synthesis and Characterization of CuV2O6 and Cu2V2O7: Two Photoanode Candidates for Photoelectrochemical Water Oxidation. J. Phys. Chem. C 2015, 119, 27220-27227. [CrossRef]

169. Shi, H.; Zhou, C.; Zhang, C. Silver vanadate nanowires: Photocatalytic properties and theoretical calculations. Res. Chem. Intermed 2015, 41, 7725-7737. [CrossRef]

170. Oliveira, C.R.; Assis, M.; Teixeira, M.M.; Silva, M.D.P.; Li, M.S.; Andres, J.; Gracia, L.; Longo, E. An Experimental and Computational Study of $\beta$-AgVO3: Optical Properties and Formation of Ag Nanoparticles. J. Phys. Chem. C 2016, 120, 12254-12264. [CrossRef]

171. $\mathrm{Hu}, \mathrm{X}$; Hu, C.; Qu, J. Preparation and visible-light activity of silver vanadate for the degradation of pollutants. Mater. Res. Bull. 2008, 43, 2986-2997. [CrossRef]

172. McNulty, D.; Ramasse, Q.; O’Dwyer, C. The Structural Conversion from $\alpha$-AgVO3 to $\beta$-AgVO3: Ag Nanoparticle Decorated Nanowires with Application as Cathode Materials for Li-ion Batteries. Nanoscale 2016, 8, 16266-16275. [CrossRef]

173. Xu, J.; Hu, C.; Xi, Y.; Wan, B.; Zhang, C.; Zhang, Y. Synthesis and visible light photocatalytic activity of b-AgVO3 nanowires. Solid State Sci. 2012, 14, 535-539. [CrossRef]

174. Cao, X.; Zhan, H.; Xie, J.; Zhou, Y. Synthesis of Ag2V4O11 as a cathode material for lithium battery via a rheological phase method. Mater. Lett. 2006, 60, 435-438. [CrossRef]

175. Shi, H.; Li, Z.; Kou, J.; Ye, J.; Zou, Z. Facile Synthesis of Single-Crystalline Ag2V4O11 Nanotube Material as a Novel Visible-LightSensitive Photocatalyst. J. Phys. Chem. C 2011, 115, 145-151. [CrossRef]

176. Xu, H.; Li, H.; Sun, G.; Xia, J.; Wu, C.; Ye, Z.; Zhang, Q. Photocatalytic activity of La2O3-modified silver vanadates catalyst for Rhodamine B dye degradation under visible light irradiation. Chem. Eng. J. 2010, 160, 33-41. [CrossRef]

177. Ren, C.; Fan, J.; Liu, S.; Li, W.; Wang, F.; Li, H.; Liu, X.; Chang, Y. One-step hydrothermal synthesis of the novel Ag3VO4/Ag4V2O7 composites for enhancing visible-light photocatalytic performance. RSC Adv. 2016, 6, 95156-95164. [CrossRef] 
178. Xia, D.; Xu, S.; Wang, W.; Wang, D.; Wu, M.; Gong, F. Pure-phase $\beta$-Mn2V2O7 interconnected nanospheres as high performance lithium ion battery anode. Chem. Commun. 2020, 56, 8043-8046. [CrossRef]

179. Pei, L.Z.; Lin, N.; Wei, T.; Yu, H.Y. Synthesis of manganese vanadate nanobelts and their visible light photocatalytic activity for methylene blue. J. Exp. Nanosci. 2016, 11, 197-214. [CrossRef]

180. Yan, Q.; Yu, J.; Suram, S.K.; Zhou, L.; Shinde, A.; Newhouse, P.F.; Chen, W.; Li, G.; Persson, K.A.; Gregoire, J.M.; et al. Solar fuels photoanode materials discovery by integrating high-throughput theory and experiment. Proc. Natl. Acad. Sci. 2017, 114, 3040-3043. [CrossRef] [PubMed]

181. Nasiri, A.; Nasiri, M. Manganese vanadate nanostructure: Facile precipitation preparation, characterization, and investigation of their photocatalyst activity. J. Mater. Sci. Mater. Electron. 2017, 28, 9096-9101. [CrossRef]

182. Tsai, Y.C. Desalination plants and renewables combined to solve power and water issues. Energy 2016, 113, 1018-1030. [CrossRef]

183. Yaqoot, M.; Diwan., P.; Kandpal, T.C. Review of barriers to the dissemination of decentralized renewable energy systems. Renew. Sustain. Energy Rev. 2016, 58, 477-490. [CrossRef]

184. Benedek, J.; Sebestyén, T.T.; Bartók, B. Evaluation of renewable energy sources in peripheral areas and renewable energy-based rural development. Renew. Sustain. Energy Rev. 2018, 90, 516-535. [CrossRef]

185. Arnaut, L.G.; Barroso, M.; Serpa, C. Solar energy conversion. In Applied Photochemistry; Giacomo, B., Serena, S., Eds.; Springer: Dordrecht, The Netherlands, 2013; pp. 267-304.

186. Chiarello, G.L.; Selli, E. Photocatalytic hydrogen production. Recent Pat. Eng. 2010, 4, 155. [CrossRef]

187. Ismail, A.A.; Bahnemann, D.W. Photochemical splitting of water for hydrogen production by photocatalysis: A review. Sol. Energy Mater. Sol. Cells 2014, 128, 85. [CrossRef]

188. Gholipour, M.R.; Dinh, C.-T.; Beland, F.; Do, T.-O. Nanocomposite hetero junctions as sunlight-driven photocatalysts for hydrogen production from water splitting. Nanoscale 2015, 7, 8187. [CrossRef]

189. Liao, C.-H.; Huang, C.-W.; Wu, J.C.C. Hydrogen production from semicon ductor-based photocatalysis via water splitting. Catalysts 2012, 2, 490-516. [CrossRef]

190. Ibhadon, A.O.; Fitzpatrick, P. Heterogeneous photocatalysis: Recent advances and applications. Catalysts 2013, 3, 189-218. [CrossRef]

191. Fujishima, A.; Honda, K. Electrochemical photolysis of water at a semicon ductor electrode. Nature 1972, 238, 37-38. [CrossRef]

192. Shena, T.F.-R.; Lai, M.H.; Yang, T.C.K.; Fu, I.P.; Liang, N.Y.; Chen, W.T. Photocatalytic production of hydrogen by vanadium oxides under visible light irradiation. J. Taiwan Inst. Chem. Eng. 2012, 43, 95-101. [CrossRef]

193. Monfort, O.; Lianos, O.; Plesch, G. Design of Bismuth Vanadate-Based Materials: New Advanced Photoanodes for Solar Hydrogen Generation. In Photoelectrochemical Solar Cells; Sankir, N.D., Sankir, M., Eds.; Wiley-Scrivener: Beverly, MA, USA, 2019; pp. 219-249.

194. Wang, Y.; Zhang, Z.; Zhu, Z.; Li, Z.; Vajtai, R.; Ci, L.; Ajayan, P.M. Nanostructured VO2 Photocatalysts for Hydrogen Production. ACS Nano 2008, 2, 1492-1496. [CrossRef]

195. Puangpetch, T.; Chavadej, S.; Sreethawong, T. Mesoporous-assembled V2O5 nanosheet synthesized via a surfactant-modified sol-gel technique and its photocatalytic H2 production activity under visible light irradiation. Powder Technol. 2011, $208,37-41$. [CrossRef]

196. Ran, J.; Zhang, J.; Yu, J.; Jaroniec, M.; Qiao, S.Z. Earth-abundant cocatalysts for semiconductor-based photocatalytic water splitting. Chem. Soc. Rev. 2014, 43, 7787. [CrossRef]

197. Zhang, L.; Jin, Z.; Ma, X.; Zhang, Y.; Wang, H. Property of iron vanadate over CdS nanorod for efficient photocatalytic hydrogen production. New J. Chem. 2019, 43, 3609-3618. [CrossRef]

198. Tan, H.L.; Amal, R.; Ng, Y.H. Alternative Strategies in Improving the Photocatalytic and Photoelectrochemical Activities of Visible Light-driven BiVO4: A Review. J. Mater. Chem. A 2017, 5, 16498-16521. [CrossRef]

199. Zou, L.; Wang, H.; Wang, X. High Efficient Photodegradation and photocatalytic Hydrogen Production of CdS/BiVO4 Heterostructure through Z-Scheme Process. ACS Sustain. Chem. Eng. 2017, 5, 303-309. [CrossRef]

200. Li, N.; Wu, X.; Wang, M.; Huang, K.; He, J.; Ma, W.; Chen, H.; Li, Y.; Feng, S. Facile preparation of BiVO4/FeVO4 heterostructure for efficient water-splitting applications. Int. J. Hydrogen Energy 2019, 44, 23046-23053. [CrossRef]

201. Abdi, F.F.; Han, L.; Smets, A.H.M.; Zeman, M.; Dam, B.; Krol, R. Efficient solar water splitting by enhanced charge separation in a bismuth vanadate-silicon tandem photoelectrode. Nat. Commun. 2013, 4, 2195. [CrossRef]

202. Monfort, O.; Pop, L.-C.; Sfaelou, S.; Plecenik, T.; Roch, T.; Dracopoulos, V.; Stathatos, E.; Plesch, G.; Lianos, P. Photoelectrocatalytic hydrogen production by water splitting using BiVO4 photoanodes. Chem. Eng. J. 2016, 286, 91. [CrossRef]

203. Biswas, S.K.; Baeg, J.O. Enhanced photoactivity of visible light responsive W incorporated FeVO4 photoanode for solar water splitting. Int. J. Hydrogen Energy 2013, 38, 14451-14457. [CrossRef]

204. Morton, C.D.; Slipper, I.J.; Thomas, M.J.K.; Alexander, B.D. Synthesis and characterisation of Fe-V-O thin film photoanodes. Photochem. Photobiol. 2010, 216, 209-214. [CrossRef]

205. Wang, W.; Zhang, Y.; Wang, L.; Bi, Y. Facile synthesis of Fe3+/Fe2+ self-doped nanoporous FeVO4 photoanodes for efficient solar water splitting. J. Mater. Chem. A 2017, 5, 2478-2482. [CrossRef]

206. Moniz, S.J.A.; Zhu, J.; Tang, J. 1D Co-Pi modified BiVO4/ZnO junction cascade for efficient photoelectrochemical water cleavage. Adv. Energy Mater. 2014, 4, 1301590. [CrossRef] 
207. Li, G.; Zhang, D.; Yu, J.C. Ordered Mesoporous BiVO4 through Nanocasting: A Superior Visible Light-Driven Photocatalyst. Chem. Mater. 2008, 20, 3983. [CrossRef]

208. Monfort, O.; Sfaelou, S.; Satrapinskyy, L.; Plecenik, T.; Roch, T.; Plesch, G.; Liano, P. Comparative study between pristine and $\mathrm{Nb}$-modified BiVO4 films employed for photoelectrocatalytic production of $\mathrm{H} 2$ by water splitting and for photocatalytic degradation of organic pollutants under simulated solar light. Catal. Today 2017, 280, 51-57. [CrossRef]

209. Gunes, S.; Neugebauer, H.; Sariciftci, N.S. Conjugated Polymer-Based Organic Solar Cells. Chem. Rev. 2007, 107, 1324. [CrossRef] [PubMed]

210. Zilberberg, K.; Trost, S.; Meyer, J.; Kahn, A.; Behrendt, A.; Lützenkirchen-Hecht, D.; Frahm, R.; Riedl, T. Inverted Organic Solar Cells with Sol-Gel Processed High Work-Function Vanadium Oxide Hole-Extraction Layers. Adv. Funct. Mater. 2011, $21,4776$. [CrossRef]

211. Sun, H.; Hou, X.; Wei, Q.; Liu, H.; Yang, K.; Wang, W.; An, Q.; Rong, Y. Low-temperature solution-processed p-type vanadium oxide for perovskite solar cells. Chem. Commun. 2016, 52, 8099.

212. Salimi, M.; Esrafili, A.; Gholami, M.; Jafari, A.J.; Kalantary, R.R.; Farzadkia, M.; Kermani, M.; Sobhi, H.R. Contaminants of emerging concern: A review of new approach in AOP Technologies. Environ. Monit. Assess. 2017, 189, 414.

213. He, J.; Yang, X.; Men, B.; Wang, D. Interfacial mechanisms of heterogeneous Fenton reactions catalyzed by iron-based materials: A review. J. Environ. Sci. 2016, 39, 97-109. [CrossRef]

214. Fenton, H.J.H. Oxidation of tartaric acid in the presence of iron. J. Chem. Soc. Trans. 1894, 65, 899-910. [CrossRef]

215. Clarizia, L.; Russo, D.; Di Somma, I.; Marotta, R.; Andreozzi, R. Homogeneous photo-Fenton processes at near neutral pH: A review. Appl. Catal. B 2017, 209, 358-371. [CrossRef]

216. Pouran, S.R.; Aziz, A.R.A.; Daud, W.M.A.W. Review on the main advances in photo-Fenton oxidation system for recalcitrant wastewaters. J. Ind. Eng. Chem. 2015, 21, 53-69. [CrossRef]

217. Bokare, A.D.; Choi, W. Review of iron-free Fenton-like systems for activating H2O2 in advanced oxidation processes. J. Hazard. Mater. 2014, 275, 121-135. [CrossRef] [PubMed]

218. Zhang, M.; Niu, Y.; Xu, Y. Heterogeneous Fenton-like magnetic nanosphere coated with vanadium oxide quantum dots for enhanced organic dyes decolorization. J. Colloid Interface Sci. 2020, 579, 269-281. [CrossRef]

219. Le, T.K.; Kang, M.; Kim, S.W. A review on the optical characterization of V2O5 micro-nanostructures. Ceram. Int. 2019, 45, 15781-15798. [CrossRef]

220. Shahid, M.; Rhen, D.S.; Shakir, I.; Patole, S.P.; Yoo, J.B.; Yang, S.J.; Kang, D.J. Facile synthesis of single crystalline vanadium pentoxide nanowires and their photocatalytic behavior. Mater. Lett. 2010, 64, 2458-2461. [CrossRef]

221. Liu, B.; Li, X.; Zhao, Q.; Liu, J.; Liu, S.; Wang, S.; Tade, M.O. Insight into the Mechanism of Photocatalytic Degradation of Gaseous o-dichlorobenzene over Flower-Type V2O5 Hollow Spheres. J. Mater. Chem. A 2015, 3, 15163-15170. [CrossRef]

222. Liu, H.; Gao, Y.; Zhou, J.; Liu, X.; Chen, Z.; Cao, C.; Luo, H.; Kanehira, M. Growth of oriented vanadium pentaoxide nanostructures on transparent conducting substrates and their applications in photocatalysis. J. Solid State Chem. 2014, 214, 79-85. [CrossRef]

223. Jayaraj, S.K.; Sadishkumar, V.; Arun, T.; Thangadurai, P. Enhanced photocatalytic activity of V2O5 nanorods for the photodegradation of organic dyes: A detailed understanding of the mechanism and their antibacterial activity. Mater. Sci. Semicon. Proc. 2018, 85, 122-133. [CrossRef]

224. Sajid, M.M.; Shad, N.A.; Javed, Y.; Khan, S.B.; Zhang, Z.; Amin, N.; Zhai, H. Preparation and characterization of Vanadium pentoxide (V2O5) for photocatalytic degradation of monoazo and diazo dyes. Surfaces Interfaces 2020, 19, 100502. [CrossRef]

225. Aslam, M.; Ismail, I.M.I.; Salah, N.; Chandrasekaran, S.; Qamar, M.T.; Hameed, A. Evaluation of Sunlight Induced Structural Changes and Their Effect on the Photocatalytic Activity of V2O5 for the Degradation of Phenols. J. Hazard. Mater. 2015, 286, 127-135. [CrossRef]

226. Sahraeian, N.; Esmaeilzadeh, F.; Mowla, D. Hydrothermal synthesis of V2O5 nanospheres as catalyst for hydrogen sulfide removal from sour water. Ceram. Int. 2021, 47, 923-934. [CrossRef]

227. Monfort, O.; Roch, T.; Satrapinskyy, L.; Gregor, M.; Plecenik, T.; Plecenik, A.; Plesch, G. Reduction of V2O5 thin films deposited by aqueous sol-gel method toVO2(B) and investigation of its photocatalytic activity. Appl. Surf. Sci. 2014, 322, 21-27. [CrossRef]

228. Monfort, O.; Roch, T.; Gregor, M.; Satrapinskyy, L.; Plecenik, T.; Plecenik, A.; Plesch, G. Formation of vanadium oxide thin films prepared from aqueous sol-gel system. Key Eng. Mater. 2014, 605, 79-82. [CrossRef]

229. Saini, M.; Dehiya, B.S.; Umar, A. VO2(M)@CeO2 core-shell nanospheres for thermochromic smart Windows and photocatalytic applications. Ceram. Int. 2020, 46, 986-995. [CrossRef]

230. Chen, Z.; Cao, C.; Chen, S.; Luo, H.; Gao, Y. Crystallised mesoporous TiO2(A)-VO2(M/R) nanocomposite films with self-cleaning and excellent thermochromic properties. Mater. Chem. A 2014, 2, 11874. [CrossRef]

231. Li, W.; Ji, S.; Sun, G.; Ma, Y.; Guo, H.; Jin, P. Novel VO2(M)-ZnO heterostructured dandelions with combined thermochromic and photocatalytic properties for application in smart coatings. New J. Chem. 2016, 40, 2592-2600. [CrossRef]

232. Tao, X.; Hang, Q.; Wu, T.; Liao, F. Quasi-Hexagonal VO2/Ag3VO4 Microcrystals for Photo-Catalytic Degradation of Rhodamine B. Asian J. Chem. 2014, 26, 8291-8294. [CrossRef]

233. Li, Y.; Ji, S.; Gao, Y.; Luo, H.; Kanehira, M. Core-shell VO2@TiO2 nanorods that combine thermochromic and photocatalytic properties for application as energy-saving smart coatings. Sci. Rep. 2013, 3, 1370. [CrossRef]

234. Moshfegh, A.Z.; Ignatiev, A. Photo-Enhanced Catalytic Decomposition Of Isopropanol On V205. Catal. Lett. 1990, 4, 113-122. [CrossRef] 
235. Jiang, B.; Peng, X.; Qu, Y.; Wang, H.; Tian, C.; Pan, Q.; Li, M.; Zhou, W.; Fu, H. A New Combustion Route to Synthesize Mixed Valence Vanadium Oxide Heterojunction Composites as Visible-Light-Driven Photocatalysts. ChemCatChem 2014, 6, $2553-2559$. [CrossRef]

236. Zavahir, S.; Xiao, Q.; Sarina, S.; Zhao, J.; Bottle, S.; Wellard, M.; Jia, J.; Jing, L.; Huang, Y.; Blinco, J.P.; et al. Selective Oxidation of Aliphatic Alcohols using Molecular Oxygen at Ambient Temperature: Mixed-Valence Vanadium Oxide Photocatalysts. ACS Catal. 2016, 6, 3580-3588. [CrossRef]

237. Arunadevi, R.; Kavitha, B.; Rajarajan, M.; Suganthi, A. Synthesis of Ce/Mo-V4O9 nanoparticles with superior visible light photocatalytic activity for Rhodamine-B degradation. J. Environ. Chem. Eng. 2018, 6, 3349-3357. [CrossRef]

238. Malathi, A.; Madhavan, J.; Ashokkumar, M.; Arunachalam, P. A review on BiVO4 photocatalyst: Activity enhancement methods for solar photocatalytic applications. Appl. Catal. A 2018, 555, 47-74.

239. Samsudin, M.F.R.; Sufian, S.; Hameed, B.H. Epigrammatic progress and perspective on the photocatalytic properties of BiVO4based photocatalyst in photocatalytic water treatment technology: A review. J. Mol. Liq. 2018, 268, 438-459. [CrossRef]

240. de la Martinez Cruz, A.; Perez, U.M.G. Photocatalytic properties of BiVO4 prepared by the co-precipitation method:Degradation of rhodamine B and possible reaction mechanisms under visible Irradiation. Mater. Res. Bull. 2010, 45, 135-141. [CrossRef]

241. Li, F.; Kang, Y.; Chen, M.; Liu, G.; Lv, W.; Yao, K.; Chen, P.; Huang, H. Photocatalytic degradation and removal mechanism of ibuprofen via monoclinic BiVO4 under simulated solar light. Chemosphere 2016, 150, 139-144. [CrossRef] [PubMed]

242. Shi, W.; Yan, Y.; Yan, X. Microwave-assisted synthesis of nano-scale BiVO4 photocatalysts and their excellent visible-light-driven photocatalytic activity for the degradation of ciprofloxacin. Chem. Eng. J. 2013, 215-216, 740-746. [CrossRef]

243. Kohtani, S.; Koshiko, M.; Kudo, A.; Tokumura, K.; Ishigaki, Y.; Toriba, A.; Hayakawa, K.; Nakagaki, R. Photodegradation of 4-alkylphenols using BiVO4 photocatalyst under irradiation with visible light from a solar simulator. Appl. Catal. B 2003, 46, 573-586. [CrossRef]

244. Huang, C.-M.; Pan, G.-T.; Peng, P.-Y.; Yang, T.C.K. In situ DRIFT study of photocatalytic degradation of gaseous isopropanol over BiVO4 under indoor illumination. J. Mol. Catal. A Chem. 2010, 327, 38-44. [CrossRef]

245. Wang, L.; Liu, J.; Song, W.; Wang, H.; Li, Y.; Liu, J.; Zhao, Z.; Tan, J.; Duan, Z.; Deng, J. Experimental and DFT insights of BiVO4 as an effective photocatalytic catalyst for N2O decomposition. Chem. Eng. J. 2019, 366, 504-513. [CrossRef]

246. Xie, B.; Zhang, H.; Cai, P.; Qiu, R.; Xiong, Y. Simultaneous photocatalytic reduction of Cr(VI) and oxidation of phenol over monoclinic BiVO4 under visible light irradiation. Chemosphere 2006, 63, 956-963. [CrossRef]

247. Jiang, L.; Chen, D.; Qin, L.; Liang, J.; Sun, X.; Huang, Y. Enhanced photocatalytic activity of hydrogenated BiVO4 with rich surface-oxygen-vacancies for remarkable degradation of tetracycline hydrochloride. J. Alloys Compd. 2019, 783, 10-18. [CrossRef]

248. Saison, T.; Chemin, N.; Chaneac, C.; Durupthy, O.; Mariey, L.; Mauge, F.; Brezova, V.; Jolivet, J.-P. New Insights Into BiVO4 Properties as Visible Light Photocatalyst. J. Phys. Chem. C 2015, 119, 12967-12977. [CrossRef]

249. Monfort, O.; Roch, T.; Gregor, M.; Satrapinskyy, L.; Raptis, D.; Lianos, P.; Plesch, G. Photooxidative properties of various $\mathrm{BiVO} / \mathrm{TiO} 2$ layered composite films and study of their photocatalytic mechanism in pollutant degradation. J. Environ. Chem. Eng. 2017, 5, 5143-5149. [CrossRef]

250. Li, J.; Lu, P.; Deng, W.; Zeng, Z.; Lin, L.; Zhao, G. Facile synthesis of sheet-like BiVO4/Bi4V2O11 composite for enhanced photocatalytic properties. Mater. Chem. Phys. 2020, 254, 123489. [CrossRef]

251. Pu, Y.; Liu, T.; Huang, Y.; Chen, C.; Kim, S.I.; Seo, H.J. Optical properties and visible-light-driven photocatalytic activity of Bi8V2O17 nanoparticles. J. Nanopart. Res. 2015, 17, 202. [CrossRef]

252. Ghiyasiya-Arani, M.; Salavati-Niasari, M.; Masjedi-Arani, M.; Mazloom, F. An easy sonochemical route for synthesis, characterization and photocatalytic performance of nanosized FeVO4 in the presence of aminoacids as green capping agents. J. Mater. Sci. Mater. Electron. 2018, 29, 474-485. [CrossRef]

253. Liu, Z.; Lu, Q.; Wei, M.; Guo, E. $\mathrm{FeVO}_{4}$ nanobelts: Controllable synthesis by electrospinning and visible-light photocatalytic properties. J. Sol-Gel Sci. Technol. 2017, 82, 67-74. [CrossRef]

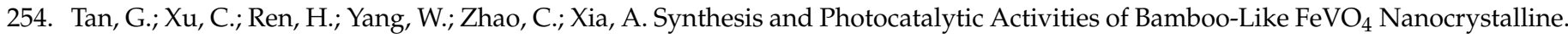
J. Nano Res. 2017, 46, 123-134. [CrossRef]

255. Zhang, J.; Zhao, W.; Li, Z.; Lu, G.; Zhu, M. Visible-light-assisted peroxymonosulfate activation over Fe(II)/V(IV) selfdoped FeVO4 nanobelts with enhanced sulfamethoxazole degradation: Performance and mechanism. Chem. Eng. J. 2021, $403,126384$. [CrossRef]

256. Rahimpour, R.; Chaibakhsh, N.; Zanjanchi, M.A.; Moradi-Shoeili, Z. Fabrication of ZnO/FeVO4 heterojunction nanocomposite with high catalytic activity in photo-Fenton-like process. J. Alloys Compd. 2020, 817, 152702. [CrossRef]

257. Eshaq, G.H.; Wang, S.; Sun, H.; Sillanpaa, M. Superior performance of FeVO4@CeO2 uniform core-shell nanostructures in heterogeneous Fenton-sonophotocatalytic degradation of 4-nitrophenol. J. Hazard. Mater. 2020, 382, 121059. [CrossRef] [PubMed]

258. Sajid, M.M.; Khan, S.B.; Shad, N.A.; Amin, N.; Zhang, Z. Visible light assisted photocatalytic degradation of crystal violet dye and electrochemical detection of ascorbic acid using a BiVO4/FeVO4 heterojunction composite. RSC Adv. 2018, 8, 23489. [CrossRef]

259. Wang, Q.; Liu, Z.; Lu, Q.; Guo, E.; Wei, M. Fabrication of Direct Z-scheme a-Fe2O3/FeVO4 Nanobelts with Enhanced Photoelectrochemical Performance. ChemistrySelect 2018, 3, 809-815. [CrossRef]

260. Marikkani, S.; Vinoth Kumar, J.; Muthuraj, V. Design of novel solar-light driven sponge-like Fe2V4O13 photocatalyst: A unique platform for the photoreduction of carcinogenic hexavalent chromium. Sol. Energy 2019, 188, 849-856. [CrossRef] 
261. Gowthami, K.; Krishnakumar, B.; Thirunarayanan, G.; Swaminathan, M.; Muthuvel, I. Novel Fe2V4O13/ZnO nano-heterojunction: Effective decomposition of methyl orange under solar light irradiation. Mater. Today-Proc. 2020, 29, 1199-1203. [CrossRef]

262. Tahir, M. Hierarchical 3D VO2/ZnV2O4 microspheres as an excellent visible light photocatalyst for CO2 reduction to solar fuels. Appl. Surf. Sci. 2019, 467-468, 1170-1180. [CrossRef]

263. Wang, R.; Cao, L. Facile synthesis of a novel visible-light-driven AgVO3/BiVO4 heterojunction photocatalyst and mechanism insight. J. Alloys Compd. 2017, 722, 445-451. [CrossRef]

264. Cui, X.; Liu, Z.; Li, G.; Zhang, M.; Song, Y.; Wang, J. Self-generating CeVO4 as conductive channel within CeO2/CeVO4/V2O5 to induce Z-scheme charge-transfer driven photocatalytic degradation coupled with hydrogen production. Int. J. Hydrogen Energy 2019, 44, 23921-23935. [CrossRef]

265. Hu, Y.; Fan, J.; Pu, C.; Li, H.; Liu, E.; Hu, X. Facile synthesis of double cone-shaped Ag4V2O7/BiVO4 nanocomposites with enhanced visible light photocatalytic activity for environmental purification. J. Photochem. Photobiol. A 2017, 337, 172-183. [CrossRef]

266. Wang, P.; Yang, H.; Wang, D.; Chen, A.; Dai, W.L.; Zhao, X.; Yang, J.; Wang, X. Activation of Kagome lattice-structured $\mathrm{Cu} 3 \mathrm{~V} 2 \mathrm{O} 7(\mathrm{OH}) 2 \cdot 2 \mathrm{H} 2 \mathrm{O}$ volborthite via hydrothermal crystallization for boosting visible light-driven water oxidation. Phys. Chem. Chem. Phys. 2018, 20, 24561-24569. [CrossRef]

267. Min, W.; Qiong, L. Synthesis and Photocatalytic Property of Cu3V2O8 Prepared by Liquid Phase Precipitation. Adv. Mater. Res. 2011, 236-238, 1675-1678.

268. Kalal, S.; Pandey, A.; Ameta, R.; Punjabi, P.B. Heterogeneous photo-Fenton-like catalysts Cu2V2O7 and Cr2V4O13 for an efficient removal of azo dye in water. Cogent Chem. 2016, 2, 1143344. [CrossRef] 